\title{
Fractal characteristics of pore networks and sealing capacity of Ordovician carbonate cap rocks: a case study based on outcrop analogs from the Tarim Basin, China
}

Jun $\mathrm{Wu}$ a, b, c, d, Tailiang Fan a, b, c*, Enrique Gomez-Rivas d, Anna Travé d, Zhiqian Gao a, b, c, Shanshan Wang e, Xiaolong Sun d

*E-mail address of the corresponding author: jhy17519@126.com (T. Fan)

a, School of Energy Resources, China University of Geosciences (Beijing), Beijing 100083, China;

b, Key Laboratory of Marine Reservoir Evolution and Hydrocarbon Enrichment Mechanism, Ministry of Education, Beijing 100083, China

c, Key Laboratory of Strategy Evaluation for Shale Gas, Ministry of Land and Resource, Beijing 100083, China

d, Department of Mineralogy, Petrology and Applied Geology, Faculty of Earth Sciences, University of Barcelona, Barcelona 08028, Spain

e, Beijing Municipal Commission of Planning and Natural Resources Yanqing Branch, Beijing 102100, China

This article is accepted for publication in the American Association of Petroleum Geologists (AAPG) Bulletin. DOI: 10.1306/03172019022. This is an author's version of the manuscript. To download the final copy-edited version please visit:

http://archives.datapages.com/data/browse/aapg-bulletin/ 
Fractal characteristics of pore networks and sealing capacity of Ordovician carbonate cap rocks: a case study based on outcrop analogs from the Tarim Basin, China

Jun Wu a, b, c, d, Tailiang Fan a, b, c*, Enrique Gomez-Rivas d, Anna Travé d, Zhiqian Gao ${ }^{\text {a, b, c }}$, Shanshan Wang ${ }^{\mathrm{e}}$, Xiaolong Sun ${ }^{\mathrm{d}}$

*E-mail address of the corresponding author: jhy17519@126.com (T. Fan)

a, School of Energy Resources, China University of Geosciences (Beijing), Beijing 100083, China;

b, Key Laboratory of Marine Reservoir Evolution and Hydrocarbon Enrichment Mechanism, Ministry of Education, Beijing 100083, China

c, Key Laboratory of Strategy Evaluation for Shale Gas, Ministry of Land and Resource, Beijing 100083, China

d, Department of Mineralogy, Petrology and Applied Geology, Faculty of Earth Sciences, University of Barcelona, Barcelona 08028, Spain

e, Beijing Municipal Commission of Planning and Natural Resources Yanqing Branch, Beijing 102100, China

\section{Acknowledgments}

This study was supported by the Major National Science-Technology Projects of China (2017ZX05005-002-003 and 2017ZX05009-002), Fundamental Research Funds for the Central Universities (2652018238), Strategic Priority Research Program of the Chinese Academy of Sciences (XDA14010201-02), National Natural Science Foundation of China (41802155, 51574208 and U19B6003), DGICYT Spanish Project CGL2015-66335-C2-1-R, PGC2018-093903-B-C22, and the Grup Consolidat de Recerca "Geologia Sedimentària" (2017-SGR-824). Jun Wu is grateful to the China Scholarship Council (201806400037) for supporting his study as a joint Ph. D. candidate at the University of Barcelona. Enrique Gomez-Rivas acknowledges funding 
by the AGAUR-Agència de Gestió d'Ajuts Universitaris i de Recerca of the Generalitat de Catalunya ("Beatriu de Pinós” fellowship 2017SGR-824), and the Spanish Ministry of Science, Innovation and Universities ("Ramón y Cajal” fellowship RYC2018026335-I). We are grateful to Editor-in-Chief Prof. Robert Merrill, Associate editor Prof. Barry Jay Katz and two anonymous reviewers for their thoughtful suggestions and critical comments that significantly improved the manuscript.

Abstract: Understanding and predicting the main controls on the sealing capacity of carbonate cap rocks is of great significance for ultra-deep carbonate reservoir exploration and production. This study focuses on revealing the pore networks and sealing capacity of the Ordovician carbonate cap rocks in the Tarim Basin, by analyzing samples from outcrop analogs using optical and scanning electron microscopy and a combination of mercury intrusion capillary pressure and nitrogen gas adsorption. Three classes of cap rocks are defined here according to their pore throat structure, fractal dimension and sealing capacity. These carbonate cap rocks are dominated by limestones and dolomitic limestones. Four pore types are identified: microfracture, intragranular pore, intercrystalline pore and intracrystalline pore. Six pore structure types show multiscale variability from macropores to micropores. The pore structures present multiple fractal behaviors, with fractal dimensions showing an increasing trend as the pore diameter decreases. The cover coefficient, a parameter that allows characterization of the cap rock sealing performance, shows an increasing trend along with increasing the fractal dimension of pore structure. The average cover coefficients of six pore 
structure types not only show good correlations (either exponential or linear) with certain fractal dimensions, but they also demonstrate a strong positive correlation with the average fractal dimension. These results suggest that the sealing capacity of the studied rocks increases with increasing fractal dimension. The sealing performance of cap rocks significantly decreases with increasing the amount of macropores. This work provides a relevant case study for further understanding of pore structures and sealing capacity of carbonate cap rocks.

Keywords: Carbonate cap rocks; Pore throat system; Sealing performance; Fractal dimension; Outcrop analog; Tarim Basin

\section{Introduction}

In recent decades, carbonate reservoirs have attracted increasing attention owing to the abundant oil and gas reserves they store worldwide (Garing et al., 2014; Gundogar et al., 2016; Burberry and Peppers, 2017; Volatili et al., 2019). The Tarim Basin in Northwest China is the largest sedimentary basin in the country with an area of $56 \times 10^{4} \mathrm{~km}^{2}\left(21.6 \times 10^{4} \mathrm{mi}^{2}\right)$ (Fig. 1A, B) (Lü, et al., 2017; Pang et al., 2018). This complex basin has become one of the key petroleum exploration and production locations due to the abundant hydrocarbon reserves stored within the Ordovician carbonate strata (Kang, 2005). For example, there are major hydrocarbon breakthroughs in ultra-deep carbonate reservoirs (at depths ranging from 6,000 to 8,000 m [19,685 to $26,247 \mathrm{ft}]$ ) from the Tahe oilfield in the Tabei Uplift. This field has an 
annual production of $730 \times 10^{4}$ tons $(53.509 \mathrm{mbl})$ of crude oil and $15 \times 10^{8} \mathrm{~m}^{3}(52.972$ bcf) of natural gas (Lü et al., 2014).

Pervasively distributed carbonate cap rocks acting as effective sealing layers play a significant role in the preservation of hydrocarbons within carbonate reservoir strata (Lü et al., 2014; Zhang et al., 2015; Rahmani et al., 2018). Accordingly, these cap rocks have received increasing attention, especially the carbonates of the Ordovician Yingshan Formation, because they are considered one of the key sealing rocks in the Tarim Basin (Jin, 2014; Lü et al., 2017; Wu et al., 2019a).

Despite recent studies focusing on the identification and characterization of carbonate cap rocks that have been carried out in the Tazhong uplift (Lü, et al., 2017) and the Tahe oilfield (Wu et al., 2018a, b, 2019a) of the Tarim Basin, only a few researchers have focused on analyzing the pore structures of these cap rocks due to their heterogeneity and complex diagenetic history.

The morphology and connectivity of pore networks in such rocks are key factors that determine their sealing potential (Norbisrath et al., 2015; Lohr and Hackley, 2018). Several methods can be utilized to characterize the heterogeneous pore structure of carbonate rocks, including their pore geometry, connectivity and size distribution. These techniques include optical microscopy, scanning electron microscopy (SEM), field emission scanning electron microscopy (FE-SEM), mercury intrusion capillary pressure (MICP), nitrogen gas adsorption $\left(\mathrm{N}_{2} \mathrm{GA}\right)$, nano X-ray computed tomography 
facility (CT), nuclear magnetic resonance (NMR), and digital image analysis (Rezaee et al., 2012; Anovitz et al., 2013; Clarkson et al., 2013; Norbisrath et al., 2015; Gundogar et al., 2016; Cao et al., 2018; Njiekak et al., 2018; Xiao et al., 2018; Zhao et al., 2018; El Sharawy and Gaafar, 2019; Górniak, 2019). The combined use of multiple pore structure characterization methods (such as optical microscope, SEM, and the combination of MICP and $\mathrm{N}_{2} \mathrm{GA}$ tests) can reveal the wide range of pore sizes and pore size distributions (PSDs) from the nanometer to the micrometer scale (Ross and Bustin, 2009; Schmitt et al., 2013; Cao et al., 2015; Gao et al., 2019), their full aperture and the overall pore throat structure of tight carbonate cap rocks (Wu et al., 2019a). The capillary leakage limits the capacity for retention of natural hydrocarbon accumulations (Vavra et al., 1992; Ingram et al., 1997; Wilkinson et al., 2014). The sealing capacity of carbonate cap rocks is controlled by the capillary pressure (McPhee et al., 2015; Wu et al., 2018a) and can be estimated by measuring the displacement pressure at $10 \%$ mercury saturation during MICP analysis (El Sharawy and Gaafar, 2019). This technique has recently been adopted by Lohr and Hackley (2018) to evaluate the sealing capacity of marine shales from the Tuscaloosa Group in Mississippi (USA).The fractal geometry theory can be used to study the features of pore networks of sedimentary rocks and to characterize reservoirs (Pfeifer and Avnir, 1983). The fractal dimensions calculated through different models, such as the Brunauer-Emmett-Teller (BET) (Brunauer et al., 1938), the Barret-Joyner-Halenda (BJH) (Joyner et al., 1951) and the Frenkel-Halsey-Hill (FHH) models (Avnir and Jaroniec, 1989) quantitatively reflect the 
heterogeneity of rock pore structures. The fractal characteristics of carbonate rocks have historically been less studied than those of tight sandstone and shale reservoirs (Clarkson et al., 2013; Cao et al., 2015; Zhang et al., 2018; El Sharawy and Gaafar, 2019). This is partly because carbonate rocks undergo complex diagenesis (He et al., 2016; Adelinet et al., 2019), resulting in heterogeneous pore connectivity, and therefore pore structures that are challenging to characterize quantitatively (Krohn, 1988; Lesniak and Such, 2006; Gundogar et al., 2016; Wu et al., 2019a).

Despite the huge economic importance of carbonate cap rocks, there are very few systematic studies relating pore structures to sealing capacity (e.g., Kaldi and Atkinson, 1997; Górniak, 2019). Furthermore, the complex relations between pore networks and fractal dimensions are poorly understood (Anovitz et al., 2013). The present study contributes to filling this knowledge gap by systematically characterizing the pore structures of the Ordovician Yingshan Fm. carbonate cap rocks in the Tarim Basin, as well as characterizing the fractal dimensions of the rocks, and using that information to evaluate their sealing capacity.

Previous attempts to systematically characterize pore size distributions and qualitatively investigate the relationships between a series of parameters and sealing capacity of subsurface carbonate cap rocks of the Tahe oilfield have been carried out using samples from a core from a burial depth of >5,500 m (18,045 ft) (Wu et al., 2019a). However, statistical calculations of the dominant lithological types of carbonate cap 
rocks in the Tahe oilfield are likely to be inaccurate due to the limited volume that the core represents. Thus, a systematic characterization of the spatial distribution of these cap rocks cannot be fully achieved because of their deep burial. To overcome this limitation, four outcrop sections with well-exposed carbonate cap rocks of the Ordovician Yingshan Fm. in the Keping and Bachu counties, along the cliff of the Keping uplift in the Tarim Basin have been chosen in this study (Fig. 1C) (Zhu and Ma, 1991). These outcrops expose continuous carbonate successions that can contribute to estimates of the relative importance of lithological types, and at the same time allow a full description of lateral and vertical variability. In order to establish a link between outcrops and wells by the same authors (Wu et al., 2019), the terms used to categorize the carbonate rocks studied at outcrops are also same to those in the Tahe oilfield. These outcrops are analogs to the subsurface Ordovician Yingshan Fm. carbonate reservoir fracture-vug-cavity system, because they present the same rock fabric, were deposited in the same settings, present a very similar diagenetic history (Kang, 1989), and were affected by the same tectonic events resulting in a similar deformation history (Wang et al., 2019; Zhou et al., 2019).

The aims of this study are to: (1) analyze the pore structures of the Yingshan Fm. carbonate cap rocks and their fractal dimensions, (2) unravel the links between fractal variations and rock sealing capacity, and (3) classify the carbonate cap rocks based on their pore structures and sealing capacity. This study provides useful insights into the sealing properties of ultra-deep carbonate cap rocks and can also be relevant for the 
exploration and production of deep carbonate reservoirs in other basins worldwide.

\section{Geological setting}

The Keping uplift is located in the northwestern region of the Tarim Basin (Fig. 1B, C), with an area of $18 \times 10^{4} \mathrm{~km}^{2}\left(6.95 \times 10^{4} \mathrm{mi}^{2}\right)$ (Zhou et al., 2019). The studied outcrops in the Keping uplift experienced deformation during multiple tectonic phases, including the late Caledonian and the early Hercynian orogenies (Pang et al., 2018). The strata in the Keping uplift comprise Paleozoic and Cenozoic sedimentary rocks (Chen et al., 1999). The Paleozoic successions are composed of Cambrian and Ordovician carbonate rocks (Kang, 1989).

The Lower-Middle Ordovician carbonates in this basin are divided into the Lower

Ordovician Penglaiba (80-600 $\mathrm{m}$ [ 262-1,969 ft] in thickness), Lower-Middle Ordovician Yingshan (200-800 m [ 656-2,625 ft] in thickness), and Middle Ordovician Yijianfang (50-200 m [ 164-656 ft] in thickness) formations (Fig. 2) (Dong et al., 2013). The Penglaiba Fm. is characterized by fine crystalline and medium crystalline dolomites that correspond to a carbonate platform ramp in which there was evaporation (Wang et al., 2018). In addition, the Yingshan carbonate formation in this study is about 250-400 $\mathrm{m}(\sim 820-1,312 \mathrm{ft})$ thick at the outcrop sections and can be further subdivided into two parts according to lithological differences. The lower part primarily comprises lime-rich dolomite and peloidal-bearing dolomitic limestone, and has been interpreted as resulting from sedimentation in a restricted carbonate platform (lagoon and tidal flat) 
(Ji et al., 2013). The upper part is composed of intraclastic grainstone, mudstone and packstone, and was deposited in open platform conditions (intraplatform shoal and intershoal sea) (Wu et al., 2018b; Wang et al., 2019). The dense intervals of the Yinghshan Fm. act as local cap rocks for karst reservoirs with fracture-vug-cavity systems (He et al., 2016). The Yijianfang Fm. is composed of bioclastic grainstone, framestone, and oolitic grainstone. This association presents reef and shoal complexes along the carbonate platform margin (Wang et al., 2019). This variation of the depositional environment was probably caused by relative sea-level fluctuation (Chen et al., 1999; Gao et al., 2016).

The burial history for the studied Yingshan Fm. rocks in carbonate successions directly entered the progressive burial stage after deposition, within a short period of time (Fig. 3). The maximum burial depth reached 4,000 meters (13,123 ft) (Du et al., 2017). Most importantly, this succession underwent significant uplift during the late Hercynian orogeny during the Late Permian, resulting in the whole strata exposed to the surface (Kang, 1989, 2005). Subsequently, the Yingshan carbonate formation was extensively altered during four diagenetic stages: penecontemporaneous, shallowintermediate burial, intermediate-deep burial and epigenetic diagenesis (Fig. 3) (Dong et al., 2013). Six main diagenetic processes affected these rocks, including micritization, cementation, dolomitization, dissolution, and mechanical and chemical compaction (Du et al., 2016, 2017). The timing of each diagenetic process can be seen in Fig. 3. 


\section{Samples and methods}

The Yingshan Fm. carbonate cap rocks are composed of limestone and dolomitic limestone, and have been studied at four outcrop sections on the NW margin of the Tarim Basin: at the Dabantage, Yangjikan, Kepingshuinichang and Penglaiba outcrops (Fig. 1C).

Detailed investigations and descriptions of carbonate cap rocks of the Ordovician Yingshan Fm. were carefully carried out at four outcrops (Figs. 1C and 4). The classification of carbonate rocks in this study was based on the scheme propose by Dunham (1962). Because the Ordovician Yingshan Fm. carbonate rocks are exposed to the surface and thus they are susceptible to weathering and erosion. Two steps were taken during sample collection: (i) removal of weathered carbonate layers at the outcrop surface to expose fresh rock surface; and (ii) the rocks were then drilled to a depth of 40 50 cm (1.31 1.64 ft) using a Shaw single backpack drill rig, to obtain intact cylindrical rock samples. Coring was carried out to minimize damage as much as possible. The samples were measured using multiple analytical techniques, including thin-section optical and electron microscope petrography, a combination of MICP and $\mathrm{N}_{2} \mathrm{GA}$ analysis, porosity and permeability tests, and fractal dimension calculation.

\subsection{Optical and electronic microscope petrography}

To study the petrographic properties of the Ordovician Yingshan Fm. carbonate cap rocks of this study, 263 samples from outcrops were selected for thin section 
preparation. Three criteria for the sample selection were used: (1) sampling was carried out in the upper and lower parts of the Yingshan Fm.; (2) the sampling locations were chosen to gather samples from strata with varying thicknesses (including thin-bedded, medium-bedded, thick-bedded and massive rocks); (3) almost the same number of samples were collected from each of the four outcrops, of which 66 samples were from the Penglaiba, Kepingshuinichang and Dabantage outcrops and 65 samples from the Yangjikan outcrop. Thin sections of the samples were studied under a standard polarized microscope at the China University of Geosciences (Beijing). 126 of these sections were half-stained with Alizarin Red S to differentiate calcite and dolomite, and 108 of them were impregnated with epoxy resin dyed with methylene blue to highlight the pore systems and their distributions. The dolomite content was quantitatively determined from more than ten photomicrographs from each thin section through measuring volumetric percentages with image analysis software.

Scanning electron microscopy (SEM) was used to characterize the size of pore space and its location and cement morphology in the cap rock intervals. Fractured surfaces of seven samples coated with gold were examined using a FEI Quanta FEG450 SEM with a working current set at an accelerating voltage of $20 \mathrm{kV}$ at the experimental research center of unconventional technology research institute of China National Offshore Oil Corporation (CNOOC). 


\subsection{Combination of MICP and $\mathrm{N}_{2}$ GA analyses}

A total of 19 cylindrical plugs (Fig. 4, Table 1) with $25 \mathrm{~mm}$ diameter and 38-46 mm length were selected to investigate their pore structures, using a combination of MICP and $\mathrm{N}_{2} \mathrm{GA}$ tests following the Chinese Energy Industry Standards of NB/T 14008-2015 at the Experimental Research Center of the Wuxi Research Institute of Petroleum Geology, SINOPEC.

\subsubsection{Pore size distributions obtained from the mercury intrusion capillary pressure (MICP) tests}

An AUTOPORE IV9520 Micropore Structure Analyzer was utilized to perform the mercury intrusion capillary pressure (MICP) tests following the Chinese standards of GB/T 21650.1-2008. All cylindrical plugs were dried in a vacuum oven at $105^{\circ} \mathrm{C}$ $\left[221^{\circ} \mathrm{F}, \sim 378 \mathrm{~K}\right]$ for 24 hours. Subsequently, each plug was placed in the permeameter, then the sealed permeameter was inserted into the low-pressure port of the device and the air was evacuated by injecting mercury. Next, the mercury-intruded permeameter was removed from the low-pressure port and weighted. After that, the permeameter was placed in the high-pressure port and was loaded with mercury under a stepwise applied pressure (Hao et al., 2017; Guo et al., 2020).

The pore volume of each rock sample $\left(V_{p}\right)$ can be calculated with:

$$
V_{\mathrm{p}}=\frac{M_{H g} \times \phi}{\rho}
$$

where $V_{p}$ is the pore volume of the rock sample(in mL), $\phi$ is the porosity (in \%), $M_{H g}$ 
is the rock sample mass (in $\mathrm{g}$ ), $\rho$ is the rock density (in $\mathrm{g} / \mathrm{cm}^{3}$ ).

To calculate mercury saturation, the total number of test points $(n)$ and the increments of mercury saturation at the first test data point $\left(\Delta S_{\mathrm{Hg}}\right)_{l}$ can be expressed as:

$$
\left(\Delta S_{H \mathrm{~g}}\right)_{1}=\frac{V_{H g 1}-V_{b 1}}{V_{p}} \times 100 \%
$$

where $V_{H g l}$ is the intrusion volume of mercury at the first point (in $\mathrm{mL}$ ) and $V_{b 1}$ is the intrusion volume of mercury in the blank test (in $\mathrm{mL}$ ).

Similarly, the increments of mercury saturation at other test points $\left(\left(\Delta S_{H g}\right)_{i}\right.$, in \%) can be calculated:

$$
\left(\Delta S_{H \mathrm{~g}}\right)_{i}=\frac{\left[V_{H g i}-V_{H g(i-1)}\right]-\left[V_{b i}-V_{b(i-1)}\right]}{V_{p}} \times 100 \%
$$

where $i$ is the serial number of test points in the range of $1-n, V_{H g i}$ and $V_{H g(i-1)}$ are the cumulative intrusion volume of mercury corresponding to each test pressure (in $\mathrm{mL}$ ), $V_{b i}$ and $V_{b(i-1)}$ are the cumulative intrusion volume of mercury at each test point in the blank tests (in mL), $V_{H g i}-V_{H g(i-1)}$ is the intrusion volume of mercury caused by the pressure increase from $P_{i-1}$ to $P_{i}$ (in $\mathrm{mL}$ ) and $V_{b i}-V_{b(i-1)}$ is the intrusion volume of mercury caused by the pressure increase from $P_{i-1}$ to $P_{i}$ in the blank tests (in mL). In addition, $\left(\Delta S_{H g}\right)_{i}=0$ if $\left[V_{H g i}-V_{H g(i-1)}\right] \leq V_{b i}-V_{b(i-1)}$.

The cumulative intrusion volume of mercury corresponding to each test point $\left(S_{H g}\right)_{i}$ can be calculated using: 


$$
\left(S_{H \mathrm{~g}}\right)_{i}=\sum_{1}^{\mathrm{i}}\left(\Delta S_{H \mathrm{~g}}\right)_{i}
$$

Therefore, the pore space not occupied by mercury $\left(\phi_{\mathrm{i}}\right)$ can be expressed as:

$$
\phi_{i}=\phi \times\left[1-\left(S_{H \mathrm{~g}}\right)_{i}\right]
$$

\subsubsection{Pore size distributions obtained from the nitrogen gas adsorption $\left(\mathrm{N}_{2} \mathrm{GA}\right)$ tests}

Nitrogen gas adsorption $\left(\mathrm{N}_{2} \mathrm{GA}\right)$ tests were conducted using a JWBK-22 Surface Area Analyzer to determine the full-aperture and pore size distributions of the study rocks following the Chinese standard of GB/T 21650.2-2008. About 0.5 grams powder ( $<100$ mesh) from each sample was heated to degas and remove adsorbed moisture at $150^{\circ} \mathrm{C}\left[302^{\circ} \mathrm{F}, \sim 423 \mathrm{~K}\right]$ for at least two hours. $\mathrm{N}_{2}$ adsorption volumes at $-195.85^{\circ} \mathrm{C}[-$ $\left.320.5^{\circ} \mathrm{F}, 77.3 \mathrm{~K}\right]$ liquid nitrogen condition were obtained under a wide range of relative pressures $\left(P / P_{o}\right)$ ranging from 0.001 to 0.990 . In general, one milliliter of nitrogen gas can be condensed into $1.547 \times 10^{-3}$ milliliters of liquid nitrogen under standard conditions (Gregg et al., 1967). Hence, the total pore volume was converted from the maximum $\mathrm{N}_{2}$ adsorption. The volume of pore size in the range of 2-200 $\mathrm{nm}$ was calculated using the BJH model (Joyner et al., 1951).

The total number of test points using the $\mathrm{N}_{2} \mathrm{GA}$ method is $n^{\prime}+1$. The pore radii and their corresponding adsorption volumes are $r_{0}, r_{1}, r_{2}, \ldots r_{n}$, and $V_{0}, V_{l}, V_{2}, \ldots V_{n}$.

The increments of saturation from the first test point to the second one $\left(\Delta S_{N_{2}}\right)_{0}$ : 


$$
\left(\Delta S_{N_{2}}\right)_{0}=\frac{\left[V_{0}-V_{1}\right] \times \rho}{M_{\mathrm{a}} \times \phi_{n}} \times 100 \%
$$

where $V_{0}$ is the adsorption volume at the first test point (in $\mathrm{mL}$ ), $V_{l}$ is the total adsorption volume at the second test point and is also the first point connecting with the MICP data (in $\mathrm{mL}$ ), $\rho$ is the apparent rock sample density (in $\mathrm{g} / \mathrm{cm}^{3}$ ) and $M_{a}$ is the rock mass (in g).

Thus, the increments of adsorption saturation at each test point $\left(\left(\Delta S_{N_{2}}\right)_{\mathrm{j}}\right.$, in \%) can be calculated:

$$
\left(\Delta S_{N_{2}}\right)_{j}=\frac{V_{j}-V_{j+1}}{V_{1}} \times \frac{\phi_{n}}{\phi} \times 100 \%
$$

where $j$ is the serial number of test points in the range of $1-n, V_{j^{-}} V_{j+1}$ is pore volume with pore radii ranging from $r_{j}$ to $r_{j+1}$ (in $\mathrm{mL}$ ).

The cumulative saturation corresponding to every test point $\left(\left(S_{N_{2}}\right)_{\mathrm{j}}\right.$, in \%) can be obtained using:

$$
\left(S_{N_{2}}\right)_{\mathrm{j}}=\sum_{1}^{j}\left(\Delta S_{N_{2}}\right)_{j}
$$

Hence, the total pore volume corresponding to pore sizes lower than $2 \mathrm{~nm}\left(V_{n}\right.$, in $\mathrm{mL}$ ) is the adsorption volume at the last test point of the $\mathrm{N}_{2} \mathrm{GA}$ method. The saturation corresponding to pores less than $2 \mathrm{~nm}$ in size, namely $\left(\left(\Delta S_{N_{2}}\right)_{\mathrm{n}^{\prime}}\right.$, in \%), can be calculated using: 


$$
\left(\Delta S_{N_{2}}\right)_{\mathrm{n}^{\prime}}=\frac{V_{n^{\prime}}}{V_{1}} \times \frac{\phi_{n}}{\phi} \times 100 \%
$$

\subsubsection{Linking the results of nercury intrusion capillary pressure and nitrogen gas adsorption analyses}

The connection between the results of the MICP and $\mathrm{N}_{2} \mathrm{GA}$ analyses can be divided into three steps:

Step (1): Converting the measured laboratory capillary curves into the capillary pressure under the gas-water phase condition and the corresponding capillary radii.

The pore throat sizes were quantified from the pressure versus intrusion volume data according to the Washburn equation (Washburn, 1921):

$$
P_{c}=\frac{2 \sigma \cos \theta}{r_{\mathrm{c}}}
$$

where $P_{c}$ is the capillary pressure (in MPa), $\sigma$ is the interfacial tension (in $\mathrm{N} / \mathrm{m}$ ), $\theta$ is the wetting angle (in ${ }^{\circ}$ ) and $r_{c}$ is the pore radius that is intruded by mercury (in $\mu \mathrm{m}$ ).

The interfacial tensions of mercury and water can be expressed by $\sigma_{H_{g}}=0.48 \mathrm{~N} / \mathrm{m}$ and $\sigma_{w}=72 \times 10^{-3} \mathrm{~N} / \mathrm{m}$. The wetting angles of mercury and water are $\theta_{\mathrm{Hg}}=140^{\circ}$ and $\theta_{w}=140^{\circ}$ under experimental standard condition. Thus, after substitution, the intrusion mercury pressure values $\left(P_{c(H g)}\right)$ can be directly converted to the corresponding pore radii: 


$$
P_{c(H g)}=\frac{0.735}{r_{\mathrm{c}}}
$$

Meanwhile, the capillary pressure of water in rock samples under gas-water twophase conditions $\left(P_{c(g / w)}\right)$ is inversely proportional to the pore radii:

$$
P_{c(g / w)}=\frac{0.14}{r_{\mathrm{c}}}
$$

By combing Eqs. (11) and (12), both the capillary pressures of water in rock samples under gas-water two-phase conditions $\left[P_{c(g / w)}\right]_{i}$ and their corresponding cumulative saturations $\left(\left(S_{\mathrm{Hg}}\right)_{i}\right)$ at each test point can be obtained from the conversion of the measured laboratory capillary pressure:

$$
P_{c(H g)}=P_{c(\mathrm{~g} / w)} \times 5.25
$$

Step (2): Converting the pore radii obtained from the $\mathrm{N}_{2} \mathrm{GA}$ tests to capillary pressures under gas-water phase condition.

According to Eq. (11), the pore radii $\left(r_{j}\right)$ are converted to capillary pressures for a gas-water two-phase condition $\left[P_{c(g / w)}\right] j$. Their corresponding cumulative saturations are the sum of the cumulative saturations of the last test point of the MICP measurement and the cumulative saturations of each test point of the $\mathrm{N}_{2} \mathrm{GA}$ measurement, namely $\left(S_{H \mathrm{~g}}\right)_{\mathrm{n}}+\sum_{1}^{j}\left(\Delta S_{N_{2}}\right)_{j}$

Step (3): Linking test datum of the MICP and $\mathrm{N}_{2} \mathrm{GA}$ analyses 
As mentioned before, although MICP tests can theoretically quantify porosity defined by pores with radii ranging from 6 to $10,000 \mathrm{~nm}$ (Wang and Yu, 2017), it is convenient to also measure large-scale PSDs because this procedure may create new microcracks under high-pressure conditions during mercury intrusion. The $\mathrm{N}_{2} \mathrm{GA}$ technique is mainly used to characterize the distribution of pore sizes with pore radii in the range of $1-10 \mathrm{~nm}$. On the basis of conversion in the first two steps, taking the logarithm of the capillary pressure under the gas-water phase condition as the ordinate and the cumulative saturation as the abscissa, a full-pore capillary pressure curve is obtained from the combination of MICP and $\mathrm{N}_{2} \mathrm{GA}$ analyses (Cheng et al., 2006).

Accordingly, nine parameters comprising the measured porosity, permeability, breakthrough pressure $\left(P_{b}\right)$, breakthrough radius $\left(R_{b}\right)$, median pressure $\left(P_{m}\right)$, median radius $\left(R_{m}\right)$, height of gas column $(H G C)$, cover coefficient $(C C)$ and specific surface area $(S S A)$ can be obtained to quantitatively characterize the pore structure and sealing capacity of cap rocks (Cheng et al., 2006). The critical accumulation height of oil and/or gas is defined as the height of the cap rock gas column (HGC) (Berg, 1975; Wilkinson et al., 2014; Shu et al., 2017; Lohr and Hackley, 2018). The HGC trapped in a reservoir is potentially controlled by the breakthrough pressure $\left(P_{b}\right)$ of cap rocks (Ingram et al., 1997). The sealing capacity of cap rocks for each hydrocarbon field is expressed by the cover coefficient $(C C)$ in a specific trap (Cheng et al., 2006). Accordingly, two important parameters $(H G C$ and $C C)$ can be calculated using the following equations (14) and (15). The ratio of the surface in contact with fluid and the total volume can be 
expressed by the specific surface area (SSA) (Zambrano et al., 2018).

$$
\begin{aligned}
& H G C=\frac{P_{\mathrm{b}}}{\left(\rho_{\text {water }}-\rho_{\text {hydrocarbon }}\right) g} \\
& C C=\frac{H G C}{Z} \times 100 \%
\end{aligned}
$$

where $P_{b}$ is the breakthrough pressure (in $\mathrm{MPa}$ ), $\rho_{\text {water }}$ and $\rho_{\text {hydrocarbon }}$ are the density of water and hydrocarbon (in $\mathrm{g} / \mathrm{cm}^{3}$ ), respectively, $g$ is the acceleration of gravity $\left(9.8 \mathrm{~m} / \mathrm{s}^{2}\right), C C$ is the cover coefficient (in $\left.\%\right)$ and $Z$ is the closure of the structure (in $\mathrm{m}$ ).

\subsection{Porosity and permeability tests}

Porosity and permeability measurements of 19 cap rock samples (with $25 \mathrm{~mm}$ $[\sim 0.08 \mathrm{ft}]$ diameter and $40 \mathrm{~mm}[\sim 0.13 \mathrm{ft}]$ length) were carried out at the Experimental Research Center of the Wuxi Research Institute of Petroleum Geology, SINOPEC. Porosities and permeabilities were analyzed using a QK-98 Helium Gas Porosimeter (YQ2-98-01) and a GDS-90F Helium Gas Permeameter (YQ2-12-01) following Chinese standard industry methods (GB/T 29172-2012) (Li et al., 2015). Through the difference between the measured skeletal rock density and bulk density, the He-porosity was obtained for each sample using the helium expansion method (Cao et al., 2018). The detailed description of the experimental setup can be found in Wang and Yu (2017)., Permeability was tested under a constant pressure gradient using a bubble flowmeter to allow helium pass through the core sample until the permeability value obtained was stable. Subsequently, permeability was calculated using Darcy's law. 


\subsection{Fractal dimension calculation}

The fractal theory is widely used to characterize the irregularity and roughness of the pore space in sedimentary rocks (Krohn, 1988). Many fractal models have been utilized to obtain the fractal dimension of the rock's pore structure (e.g., Brunauer et al., 1938; Joyner et al., 1951; Avnir and Jaroniec, 1989). The computed values of fractal dimension based on these models differ from each other. Their relationship with the rock heterogeneity is always similar in a way that the greater the fractal dimension, the stronger the heterogeneity of the rock's pore structure (Li, 2010; Li et al., 2017; Zhang et al., 2017; Song et al., 2018; Xiao et al., 2018; Zhang et al., 2018; Sharawy and Gaafar, 2019). This is because these models are derived theoretically and interrelated on the basis of fractal modeling of porous media (Li, 2004; Li et al., 2010; Song et al., 2018). Accordingly, here the He-Hua (1998) model was adopted to calculate the fractal dimension of carbonate rocks. There are two main reasons that support the choice of this model over the others:

(1) The carbonate cap rocks of the Lower-Middle Ordovician Yingshan Fm. are typically characterized by highly heterogeneous pore structures due to the influence of depositional setting variations, diagenetic overprints and the effects of tectonic events (Garing et al., 2014; Gundogar et al., 2016; Lü et al., 2017; Wu et al., 2018b; Zhang et al., 2018). The He-Hua model utilized here to calculate the fractal dimension of the rock's pore structures has been widely used to quantitatively characterize pore structures in tight sandstones, shales and also carbonate rocks (e.g., Hollis et al., 2010; 
Rezaee et al., 2012; Clarkson et al., 2013; Cao et al., 2015; Brunauer and Emmett, 2017;

Hao et al., 2017; Li et al., 2017; Zhang et al., 2017; Zhang et al., 2018; Guo et al., 2020).

Moreover, the cap rocks analyzed here present very low porosity and permeability, making this method appropriate (Lü et al., 2017; Wu et al., 2018a; Zhou et al., 2019). Plus, previous analyses of cap rocks in the Tahe oilfield proved the validity of the HeHua model for these rock types (Wu et al., 2019a).

(2) Previously published studies showed that the He-Hua model can comprehensively reflect the rock's pore structure over a wide range of scales and also allows the evaluation of the influence of the remaining pores that are not intruded by mercury, as well as those isolated or enclosed (Zhang et al., 2017; Guo et al., 2020). This not only helps to achieve an accurate description of the pore structures with a fullaperture, but also contributes to the most appropriate evaluation of the carbonate cap rocks sealing capacity (Jin, 2014). Quantitatively assessing the pore structures of carbonate cap rocks, including pore irregularities and their complex connectivity, has become one of the key tasks for the cap rock classification (Lü et al., 2017).

Subsequently, the derivation process of the He-Hua model in this paper is as follows: The number of pores with a radius larger than $r$ is first counted $N(>r)$. According to the fractal geometry theory, $N(>r)$ will exhibit a good relationship with the pore radius $(r)$ if the pore size distribution presents a fractal structure (Zhang et al., 2017; Wu et al., 2019b): 


$$
N(>r)=\int_{r}^{r_{\max }} f(r) d r=a r^{-D}
$$

where $r_{\max }$ and $f(r)$ are the maximum pore radius and the distribution density of pore radius, respectively; $a$ and $D$ are a proportionality coefficient associated with the pore shapes and the fractal dimension of the pores, respectively (Hao et al., 2017).

The distribution density of pore radius $f(r)$ can be expressed by the derivative of the pore radius (r), Eq. (17) can be computed from Eq. (16).

$$
f(r)=\frac{d N(>r)}{d r}=-D_{a r}^{-D-1}
$$

The volume of pores with radius less than $r, V(<r)$ can be calculated by integrating $r$, as expressed in Eq. (18):

$$
V(<r)=\int_{r_{\min }}^{r} f(r) \beta r^{3} d r=-\frac{D \beta a}{3-D}\left(r^{3-D}-r_{\min }^{3-D}\right)
$$

where $\beta$ is a constant related to the geometric shape of the pore and $r_{\min }$ is the minimum pore radius in the cap rocks.

Consequently, the total pore volume $(V)$ of the sample can be obtained:

$$
V=-\frac{D \beta a}{3-D}\left(r_{\max }^{3-D}-r_{\min }^{3-D}\right)
$$

Combined with Eqs. (18) and (19), the cumulative volume fraction $S(<r)$ of pores with a radius less than $r$ in terms of the total pore volume can be transformed as follows:

$$
S(<r)=\frac{V(<r)}{V}=\frac{r^{3-D}-r_{\min }^{3-D}}{r_{\max }^{3-D}-r_{\min }^{3-D}}
$$

Considering $r_{\text {min }}<<r_{\text {max }}, r$, Eq. (20) can be re-arranged as: 


$$
S(<r)=\left(\frac{r}{r_{\max }}\right)^{3-D}
$$

According to the relationship between capillary pressure $\left(P_{c}\right)$ and rock pore radius (Berg, 1975; Zhang et al., 2017), and assuming that the pore size does not influence the wetting capillary pressure (Mcphee et al., 2015), the value $r_{\max }$ corresponds to the minimum capillary pressure $\left(P_{\min }\right)$ :

$$
\begin{aligned}
& P_{c}=\frac{2 \sigma \cos \theta}{r} \\
& P_{\min }=\frac{2 \sigma \cos \theta}{r_{\max }}
\end{aligned}
$$

where $\sigma$ is the interfacial tension, $N / m$ and $\theta$ is the wetting angle, ${ }^{\circ}$.

Therefore, by combing Eqs. (21), (22) and (23) the cumulative volume percentage $S(<r)$ with pore radius less than $r$ can be expressed as:

$$
S(<r)=\left(\frac{P_{\min }}{P_{c}}\right)^{3-D}
$$

Taking the logarithm of both sides in Eq. (24), Eq. (25) can be written as:

$$
\lg S(<r)=(D-3) \lg P_{c}-(D-3) \lg P_{\min }
$$

where $S(<r)$ is the wetting phase saturation corresponding to $P_{c}$. The wetting phase in this paper is air and the non-wetting phase is mercury.

Due to the non-wetting properties of mercury in carbonates, it cannot penetrate the pores until an external pressure is applied (Mcphee et al., 2015; Gao et al., 2019). The 
pores with larger sizes are more likely to be filled with mercury. The cumulative mercury volume intruded into pores at a certain pressure can be recorded as $V_{H g}$, which is equal to the pore volume with pore radius larger than $r$ (Gao et al., 2019).

$$
V_{H \mathrm{~g}}=V(>r)=V-V(<r)
$$

In addition, the mercury saturation $\left(S_{H g}\right)$ defined as the ratio of cumulative mercury volume and the total volume can be obtained:

$$
S_{H g}=\frac{V_{H g}}{V}
$$

According to the method adopted by Zhu et al. (2018) and Wu et al. (2019b), the cumulative volume percentage with a pore radius less than $r$ can be expressed as:

$$
S(<r)=1-S_{H g}
$$

The following formula can be derived by combing Eqs. (25) and (28):

$$
\lg \left(1-S_{H g}\right)=(D-3) \lg P_{c}-(D-3) \lg P_{\text {min }}
$$

The derivation of Eq. (29) is consistent with the conclusion drawn by Yang et al. (2015), who proposed another way for getting the Brooks-Corey type capillary pressure model. Consequently, a linear trend in the cross-plot between $\lg \left(1-S_{H g}\right)$ and $\lg P_{c}$ can be found when the pore-throat features match the fractal theory (Li et al., 2017). The slope of the straight line $(B)$ in the log-log plot can be obtained and the fractal dimension of pore structures in carbonate cap rocks will be calculated using the Eq. (30) as follows: 


$$
D=3+B
$$

According to Eq. (29), the double-logarithm coordination $\left(\lg \left(1-S_{H g}\right)-\lg P_{c}\right)$ shows overall linearity when the structures from large to small pore throats are almost similar. This means that their fractal dimensions are very close and can be classified as an integral (i.e., single) fractal. Otherwise, the plot of $\lg \left(1-S_{H g}\right)$ versus $\lg P_{c}$ shows a curved trend and has various inflection points, which can be divided into several segments to calculate the corresponding fractal dimension of distinct pore throats (Hao et al., 2017; Zhang et al., 2017; Song et al., 2018). According to the method reported in several publications (Li et al., 2017; Zhang et al., 2017; Wu et al., 2019a), the multi-fractal dimension characterizing the whole pore-throat sizes in combination with the weighted average porosity was used to calculate the total fractal dimension $\left(D_{\text {total }}\right)$.

$$
D_{\text {total }}=\sum_{i=1}^{n} \varphi_{i} D_{i}
$$

where $\phi_{i}$ and $D_{i}$ are the porosity and fractal dimension of the corresponding pore-throat size.

\section{Results}

\subsection{Petrography}

Two main lithological types of the Ordovician Yingshan Fm. carbonate cap rocks in the Tarim Basin are recognized according to the field and petrographic observations: limestones and dolomitic limestones. 


\subsubsection{Limestones}

The limestones in this study are represented by mudstone and well-cemented peloidal grainstone.

(1) Mudstone: the Dabantage and Penglaiba outcrops contain mudstones mainly composed of grey massive micrite intercalated with intraclastic micrite (Figs. 5A, 6B, 7A, B), while the Yangjikan and Kepingshuinichang outcrops expose mudstones characterized by dark grey medium-bedded micrite with a few layers containing some bioclasts. Generally, mudstones indicate a quiet hydrodynamic condition during deposition. Thin sections reveal that this type of cap rock is quite tight and is primarily composed of fine calcite crystals $(<0.01 \mathrm{~mm}$ in diameter $)$, distorted bioclasts and rare microfractures (Fig. 7A). Tightly packed mudstone separates the peloidal grainstone into two zones (Fig. 5E). In addition, according to the stylolite classification proposed by Koehn et al. (2016), various types of bedding-parallel stylolites (rectangular layer, seismogram pinning and simple wave-like types) are present in the micrite matrix or at lithological transitional interfaces between peloidal grainstones and mudstones. Bedding-parallel stylolites cut column-shaped calcite strips (Fig. 5D). Blocky calcite crystals and/or euhedral dolomite crystals appear in the vicinity of stylolites (Figs. 5G, 6D), indicating intensive cementation (Fig. 5G).

(2) Well-cemented peloidal grainstone: the Dabantage, Penglaiba and Kepingshuinichang outcrops have light grey medium-to thick-bedded dense peloidal grainstones alternating with thin-bedded mudstones. However, the Yangjikan outcrop 
has dark grey and thick-bedded peloidal grainstones that exhibit no dissolution features. Thin sections reveal that intraclasts in this lithology have a wide variation, ranging from 0.18 to $2.4 \mathrm{~mm}$ in size (Fig. 7C, D, F, 8A, C). The amount of cement ranges between 9.4\% and $47.4 \%$. Elongate or bladed calcite crystals around intraclasts mostly occur as first generation calcite cements (Fig. 7C). Three generations of calcite cements include elongate blocky, drusy and blocky cements along microfractures, and another two generations of calcite cements, namely isopachous and blocky cements formed around micrite envelops of intraclasts (Fig. 8A). Drusy and/or blocky cements occlude the pore space between intraclasts with various geometries and sizes (Fig. 7D, F). These peloidal grainstones experienced intense compaction due to the overburden of overlying strata during burial (Dong et al., 2013). The intraclasts appear tightly packed, and there are some diffuse stylolites of the sharp peak and simple wave-like types distributed within the crystal mosaic. Broken bioclastic fragments are rarely present and appear surrounded by drusy calcite crystals (Figs. 6C, 7B, 8C).

\subsubsection{Dolomitic limestones}

The dolomitic limestone cap rocks of this study are mainly characterized by light grey medium- to thick-bedded and grey thin- to medium-bedded rocks that appear alternated with bioclastic limestones at the four outcrops (Fig. 6A, C). The dolomitic limestones are principally composed of scattered subhedral to anhedral dolomite rhomb crystals (Fig. 8B), varying from 18.6 to $210 \mu \mathrm{m}$ in size. These crystals float locally in the peloidal grainstone, and sometimes display crystals that appear clustered along 
stylolites (Fig. 5H). Fine- to medium-crystalline dolomite crystals account for around $10 \%-52 \%$ of the total volume of dolomitic limestones. Dolomitic crystals with intermediate size $(100-250 \mu \mathrm{m})$ were commonly subjected to intense recrystallization and mechanical compaction (Fig. 8D) (Ji et al., 2013). Accordingly, these crystals do not retain the rhomb shapes, and show an anhedral and/or subhedral crystal appearance (Fig. 6C).

\subsection{Pore types}

Thin section optical petrography and SEM analysis indicate that primary intergranular pores formed during deposition were rarely preserved as a result of complex diagenetic alteration that started just after deposition and continued through the burial stage (Dong et al., 2013; Wang et al., 2019). Secondary pores are mainly microfractures, and intragranular, intercrystalline and intracrystalline pores, accounting for the vast majority of porosity of these carbonate cap rocks.

\subsubsection{Microfractures}

Microfractures are abundant in the mudstones and well-cemented peloidal grainstones of this study, and can be observed in the outcrops and thin section photomicrographs, displaying different shapes and apertures (Figs. 6C, E, 7A, 8A, 9B, $\mathrm{D}, \mathrm{F})$. Their widths and lengths are highly variable ranging from $0.03 \mu \mathrm{m}$ to $0.23 \mathrm{~mm}$ and from $0.12 \mu \mathrm{m}$ to $8.6 \mathrm{~cm}$, respectively (Figs. 5B, 6C, 10B). Microfractures formed in these highly fractured intervals during different tectonic phases (Wang et al., 2019), 
and appear widely distributed but with a fracture density greater than 45 fractures per meter (Fig. 10C). However, most microfractures are partially or even completely filled with coarse calcite crystals in tight zones, forming veins (Figs. 5B, H, 6C, 9D, F). Residual microfractures are always short in length and have a small aperture (Fig. 9B, D). Pervasively recrystallized calcite crystals fill microfractures, and dolomite crystals are locally distributed at stylolite peaks (Fig. 6F). Additionally, completely-filled microfractures are present within the algal-bearing zone (Fig. 6E).

\subsubsection{Intragranular pores}

Intragranular pores observed in this study are characterized by irregular and sharpedged pore structures (Fig. 10E). Irregular pores appear pervasively occluded by calcite crystals with minor pyrite, illite and/or pyrobitumen. Some intragranular pores are partly filled with blocky calcite cements (Fig. 10D). Calcite cements are commonly present in vuggy and fracture porosity (Fig. 9B). Two to three different generations of calcite cements (marine, meteoric and burial) can be recognized (Zhang et al., 2018).

Additionally, SEM analysis shows that there are abundant calcite crystals with various geometries (that vary from 20 to $300 \mu \mathrm{m}$ in size) filling intragranular pores and microfractures (Fig. 10B). Minor amounts of illite are found locally also filling intragranular pores. Intragranular pores are rarely well preserved due to continued mechanical and chemical compaction. The residual pore space is partially filled by late quartz or calcite crystals from the margin to the center. In rare cases, illite is the least 
common fracture- and intragranular pore-filling product in the carbonate cap rock (Fig. $10 \mathrm{H})$.

\subsubsection{Intercrystalline pores}

Intercrystalline pores observed in this study are generally occluded by coarse calcite crystals (Fig. 5H). Initial elongate blocky calcite cements occlude a major volume of the pore space. Alternatively, some intercrystalline pores were partially or completely filled with anhedral calcite and/or dolomite crystals (Figs. 5C, 9A, C), and also by other infills (e.g., pyrobitumen, pyrite and clay minerals) (Fig. 6C, D, H). Furthermore, blocky calcite crystals filling microfractures appear partially dissolved, thereby forming intercrystalline pores (Fig. 9E).

\subsubsection{Intracrystalline pores}

Intracrystalline pores in the cap rocks are small in number, and show angular to subangular shapes with sizes ranging from $0.43 \mu \mathrm{m}$ to $0.96 \mathrm{~mm}$ (Fig. 9B). In rare cases, intracrystalline pores appear not connected and scattered in the peloidal grainstone and mudstone (Figs. 9F, 10A, D, F). Both pyrite and clay minerals plug intracrystalline pores in highly-fractured intervals (Fig. 5F). In addition, some goethite within intracrystalline pores is distributed along or perpendicular to microfractures and presents different shapes (e.g., beam-shaped and lumpy) (Fig. 10E).

\subsection{Types of pore structures}

The pore size distributions (PSDs) of carbonate cap rocks derived from the 
combination of MICP and $\mathrm{N}_{2} \mathrm{GA}$ data are plotted in Figs. 11, 12 and 13. Six types of pore throat structures in the carbonate cap rocks are identified based on the cross-plot morphology of capillary vs. mercury saturation, median pressure and dominant pore throat diameters. The detailed descriptions can be seen in Table 2 .

(1) The dominant PSDs for the type A pore structure are larger than 2,500 nm, and account for $58.41 \%$ of the total pore volume. The pore throat volume with diameters of 25-50 nm, 100-250 nm, 250-500 nm, 500-1,000 nm represents less than 13\% (Fig. 11A, C, E).

(2) The pore throat diameters of the type B pore structure are distributed in a wide size range from 100 to $8,000 \mathrm{~nm}$. $32.56 \%$ of the pore volume corresponds to pore throat diameters greater than $2,500 \mathrm{~nm}$, followed by $18.38 \%$ of the total volume with pore diameters in the range of 100-250 nm (Fig. 11B, D, F).

(3) The volume proportion of different pore throat distributions in the type C pore structure significantly increases from $1.18 \%$ to $41.51 \%$, with increasing pore throat diameter (Fig. 12A, C, E).

(4) Proportionately, the pore throats with diameters greater than $2,500 \mathrm{~nm}$ in the type D pore structure are dominant, and account for $51.7 \%$ of the total pore volume (Fig. 12B, D, F).

(5) For the type E pore structure, the pore throat volume with pore diameters greater than 2,500 $\mathrm{nm}$ and in the range of $500-1,000 \mathrm{~nm}$ make up $39.51 \%$ and $18.12 \%$ 
of the total pore volume, respectively (Fig. 13A, C, E).

(6) The highest peak of the unimodal PSD in the type F pore structure skews towards smaller pore sizes compared to the other five types. There is $45.78 \%$ of the total pore volume that corresponds to a PSD in the range of $2-5 \mathrm{~nm}$, followed by $21.53 \%$ with pore throats greater than 2,500 $\mathrm{nm}$ in diameter (Fig. 13B, D, F).

\subsection{Porosity and permeability}

The studied cap rocks of the Yingshan Fm. in the Tarim basin have ultra-low porosity and permeability. The porosity within the carbonate cap rocks has a narrow range between $0.22 \%$ and $1.27 \%$, with an average of $0.55 \%$. The permeability of these rocks is in the range of $0.00428 \times 10^{-3} \mu \mathrm{m}^{2}-0.036 \times 10^{-3} \mu \mathrm{m}^{2}$ with an average of $0.011 \times 10^{-}$ ${ }^{3} \mu \mathrm{m}^{2}$. The cross-plot of both parameters shows that there is a poor relationship between porosity and permeability, with a very low correlation coefficient for the 19 carbonate cap rocks analyzed (Fig. 14). For instance, sample S-7 presents the largest permeability of $0.036 \times 10^{-3} \mu \mathrm{m}^{2}$ but has a porosity of $0.67 \%$. However, this is significantly lower than that of sample S-14 (1.27\%), which has a lower permeability of $0.00858 \times 10^{-3} \mu \mathrm{m}^{2}$ (Table 1).

Average porosity and permeability for the different lithological types of the 19 carbonate cap rocks studied here show a narrow range, varying from $0.45 \%$ to $0.69 \%$ and from $0.008 \times 10^{-3} \mu \mathrm{m}^{2}$ to $0.026 \times 10^{-3} \mu \mathrm{m}^{2}$, respectively (Table 1 ). The porosities of peloidal grainstone samples vary from $0.22 \%$ to $0.91 \%$, with an average of $0.45 \%$, and 
are much lower than those of the other two lithological types (Fig. 14B). Mudstone cap rocks display higher average porosities $(0.69 \%)$. Similar to porosity, the average permeability of peloidal grainstones also yields low values $\left(0.007 \times 10^{-3} \mu \mathrm{m}^{2}\right)$, ranging from $0.004 \times 10^{-3} \mu \mathrm{m}^{2}$ to $0.013 \times 10^{-3} \mu \mathrm{m}^{2}$. However, the mudstone cap rocks have higher average porosities, while their average permeabilities $\left(0.0095 \times 10^{-3} \mu \mathrm{m}^{2}\right)$ are significantly lower than those of dolomitic limestones $\left(0.026 \times 10^{-3} \mu \mathrm{m}^{2}\right)$. Although porosity has a positive relationship with permeability in dolomitic limestone $\left(\mathrm{R}^{2}=0.978\right.$; Fig. 14B), it cannot truly reflect their relationship due to the limited number of rock samples of this type available for this study. There is no evident correlation between porosity and permeability in mudstones and well-cemented peloidal grainstones (Fig. 14B). The results of this study are consistent with those from subsurface mudstones and well-cemented peloidal grainstones of the same formation by Wu et al. (2018a, 2019a).

\subsection{Fractal dimension characteristics}

Based on the cross-plots of $\lg \left(P_{c}\right)$ and $\lg \left(1-S_{H g}\right)$ of carbonate cap rock samples at the Tarim Basin outcrops, the fractal characteristics of pore structures can be derived from the combination of MICP and $\mathrm{N}_{2} \mathrm{GA}$ analyses (Fig. 15). According to various logarithmic capillary pressure inflection points for the six pore structure types (Zhu et al., 2018), the pore structures of Tarim Basin carbonate cap rocks with various pore size ranges have different fractal characteristics (Yang et al., 2016).

As mentioned in Section 4.4, and following the classification scheme defined in a 
previous study (Wu et al., 2019b), the pore size range of carbonate cap rocks can be divided into four groups (Table 3). The first group corresponds to the pore size range between 4,422 and $12,720 \mathrm{~nm}$, while the second, third and fourth groups correspond to 2,770 to $5,525 \mathrm{~nm}, 180$ to $3145 \mathrm{~nm}$, and 2 to $325 \mathrm{~nm}$, respectively. The detailed pore size ranges of all the cap rock samples in this study are listed in Table 3. In addition, the fractal dimensions (D1, D2, D3 and D4) of each of these four groups of pore size ranges can be obtained.

In terms of the type $\mathrm{D}$ pore structure of cap rocks in this study, and taking sample S-25 as an example, the relation of $\lg \left(1-S_{H g}\right)$ and $\lg P_{c}$ shows an overall linear trend, which indicates that the fractal dimensions of D1, D2, D3 and D4 (from large pores to small ones) are very close and can be described by an integral (i.e., single) fractal (Yang et al., 2016; Wu et al., 2019b). This implies that all the fractal dimensions from D1 to D4 are equal to the integral fractal dimension. Therefore, the method proposed by $\mathrm{Wu}$ et al., (2019b) can be referred and used when comparing fractal dimensions within a certain pore size range. Otherwise, the plots of $\lg \left(1-S_{H g}\right)$ versus $\lg P_{c}$ for the other five types of pore structures show a curved trend with various inflection points (Hao et al., 2017). They can be divided into several segments to calculate the corresponding fractal dimension of distinct pore throats (Li et al., 2017). In summary, the fractal dimensions (D) can be divided into one-segment (type D), two-segment (types A, B, C and F) and three-segment (type E) patterns. Each segment is associated with different pore throat diameter distributions (Zhu et al., 2018). This suggests that the pore fractal 
characteristics of carbonate cap rock samples from the Ordovician Yingshan Fm. show multiple fractal structures with various pore size distributions (Song et al., 2018).

The values of fractal dimensions from D1 to D4 that correspond to different pore diameters (from macropores to micropores) for the cap rock samples were calculated using Eqs. (29) and (30) and the results are listed in Fig. 16 and Table 3. The correlation coefficients of the double logarithmic cross plot between $\lg \left(P_{c}\right)$ and $\lg \left(1-S_{H_{g}}\right)$ are greater than 0.94 . This implies that carbonate cap rocks within a certain range of pore size distributions from the Tarim Basin present a fractal behavior (Lesniak and Such, 2006). However, some fractal dimension values are lower than 2.0 and therefore they do not conform to the fractal theory for rock heterogeneity (Pfeifer and Avnir, 1983; Zhu et al., 2018). According to Nooruddin et al. (2014) and He et al. (2016), this result may be due to detection errors of experimental instruments during micropore measuring. Therefore, these meaningless fractal dimension values were excluded in this study (Zhu et al., 2018; Wu et al., 2019a).

D1, D2, D3 and D4 of all cap rock samples are in the range of 2.210-2.905, 2.4892.692, 2.281-2.923, and 2.055-2.749, respectively (Fig. 16, Table 3). Although each pore structure type has various fractal dimensions, their fractal behaviors can be compared among these six types because each fractal dimension corresponding to almost the same pore size range was defined to characterize the heterogeneity of pore structure in this studied cap rocks, as proposed by Hao et al. (2017) and Zhu et al. (2018). 
The fractal dimensions from D1 to D4 for the six pore throat types show an increasing trend as the pore throat diameter decreases. This result suggests that small pores of the cap rocks present more complex and rougher surfaces with higher fractal dimension values than large pores with lower fractal dimension values (Krohn, 1988; Yang et al., 2016; Zhu et al., 2018).

Consequently, the slope of the straight line $(B)$ in the log-log plot can be read and the fractal dimension of pore structures in the study cap rocks can be calculated using Eq. (30). The total fractal dimensions of types A, B and F pore structure can be calculated using Eq. (32) to reveal the multi-fractal dimension characterizing the whole pore-throat sizes in combination with the weighted average porosity ( $\mathrm{Li}$ et al., 2017; Wu et al., 2019b). Meanwhile, by combing with Eqs. (33), (34) and (35), the total fractal dimensions corresponding to the types C, D and E pore structure were also calculated in Table 3.

$$
\begin{aligned}
& D_{\text {total }}=\frac{\phi_{1} \times D_{1}+\phi_{3} \times D_{3}}{\phi_{1}+\phi_{3}} \\
& D_{\text {total }}=\frac{\phi_{1} \times D_{1}+\phi_{2} \times D_{2}}{\phi_{1}+\phi_{2}} \\
& D_{\text {total }}=\frac{\phi_{1} \times D_{1}+\phi_{2} \times D_{2}+\phi_{3} \times D_{3}+\phi_{4} \times D_{4}}{\phi_{1}+\phi_{2}+\phi_{3}+\phi_{4}} \\
& D_{\text {total }}=\frac{\phi_{1} \times D_{1}+\phi_{3} \times D_{3}+\phi_{4} \times D_{4}}{\phi_{1}+\phi_{3}+\phi_{4}}
\end{aligned}
$$

The results show that the values of total fractal dimensions of all rock samples are in the range of 2.250 to 2.919 . In terms of average values of the total fractal dimension 
for the six pore structure types (from type A to F), they present the relationship: $D_{\text {avg. }}($ type $\mathrm{F})>D_{\text {avg. }}$ (type $\left.B\right)>D_{\text {avg. }}$ (type $\left.C\right)>D_{\text {avg. }}($ type $D)>D_{\text {avg. }}($ type $E)>D_{\text {avg. }}$ (type $\left.A\right)$.

The type $\mathrm{F}$ pore structure has the greatest heterogeneity, and type $\mathrm{A}$ is the most homogeneous one.

\subsection{Sealing capacity characteristics}

Table 1 shows the three parameters (e.g., $H G C, C C$ and $S S A$ ) that characterize the sealing capacity of 19 carbonate cap rocks. The height of gas column $(H G C)$ is between 1.95 and $2.85 \mathrm{~m}$, with an average of $2.29 \mathrm{~m}$. The cover coefficient $(C C)$ refers to the sealing capacity of carbonate cap rock to natural gas in specific traps (Cheng et al., 2006). The $C C$ varies from $3.90 \%$ and $5.71 \%$, with an average of $4.57 \%$. The specific surface area (SSA) is in a range of $2.21-3.98 \mathrm{~m}^{2} / \mathrm{g}$, with an average of $2.95 \mathrm{~m}^{2} / \mathrm{g}$.

\section{Discussion}

\subsection{Relationship between fractal dimension and sealing capacity}

As mentioned previously, better sealing capacity of carbonate cap rocks is revealed by a higher $\mathrm{CC}$, while a poorer sealing capacity is represented by a low $\mathrm{CC}$ value (Cheng et al., 2006).

\subsubsection{Relationships between different fractal dimensions and cover coefficients}

Fig. 17 shows the relationship between the fractal dimension and the rock's sealing capacity. D2 has a poor positive correlation with the cover coefficient $\left(\mathrm{R}^{2}=0.24\right)$, while D4 shows no apparent correlation with this parameter $\left(\mathrm{R}^{2}=0.01\right)$. However, linear 
relationships between cover coefficients and D1 and D3 arise, with $\mathrm{R}^{2}=0.79$ and 0.76 , respectively (Fig. 17A, C). The cover coefficients of carbonate cap rocks show an increasing trend along with increasing fractal dimensions (e.g., D1 and D3). This suggests that, although D2 and D4 have little effect on the rock's sealing capacity, the fractal dimensions D1 and D3 have a significant impact on the sealing performance of the corresponding carbonate cap rocks (Fig. 17B, D). In addition, there is also a close relationship between the cover coefficient and $\mathrm{D}_{\text {total }}$ with a relatively higher correlation coefficient of $\mathrm{R}^{2}=0.77$ (Fig. 17E). This is probably disturbed by D2 and D4 together with extremely irregular pore structures, an observation supported by optical microscopy and SEM analyses (Figs. 9, 10). Pyrobitumen, pyrite and clay minerals occlude the pore throats and alter the pore morphology, resulting in poorly interconnected pore systems (Figs. 5, 6 and 10) (Zhang et al., 2018). These pore-filling materials play a significant role in reducing the percolation properties of the rock (Ross and Bustin, 2009; Xiao et al., 2018), enhance the pore system heterogeneity and weaken the impact of D2 and D4 on the $\mathrm{D}_{\text {total. }}$.

Furthermore, the average cover coefficients in the six PSD types are strongly positively correlated with the average fractal dimension $\left(\mathrm{D}_{\text {avg. }}\right)\left(\mathrm{R}^{2}=0.88\right)($ Fig. 17F). The close relationship between cover coefficients and certain fractal dimensions (D1, $\mathrm{D} 3, \mathrm{D}_{\text {total }}$, and $\mathrm{D}_{\text {avg. }}$ ) reveals the significance of the fractal dimension in controlling the sealing capacity of the Tarim Basin carbonate cap rocks. This can be attributed to the fact that a higher fractal dimension suggests that the pore structures of these rocks are 
characterized by highly heterogeneous pore networks and rough pore surfaces (Burberry and Peppers, 2017; Zhu et al., 2018). Accordingly, the sealing capacity of a carbonate cap rock increases with increasing the fractal dimension.

\subsubsection{Relationships of average D1, D3 and average cover coefficients}

The average cover coefficients of the six pore structures show good exponential relationships with the average D1, with a correlation coefficient of 0.83 (Fig. 18A). Additionally, they also present a good linear correlation with the average D3, with $\mathrm{R}^{2}=0.88$ (Fig. 18B). The relationships of average D1, D3 and average cover coefficient can be expressed as follows:

$$
\begin{aligned}
& C C_{\text {avg. }}=1.1978 e^{0.534 A v g . D 1} \\
& C C_{\text {avg. }}=2.4185 A v g . D 3-1.5874
\end{aligned}
$$

Eqs. (36) and (37) imply that not only the increase in average D1 but also the increase in average D3 result in a significant increase of average cover coefficients. Accordingly, Fig. 19 characterizes the three-dimensional relationships of average D1, average D3 and average cover coefficients of six carbonate cap rock pore structures. In terms of the average cover coefficient of these types, they present the relationship:

$$
\left.\left.\left.\left.\left.\left.C C_{\text {avg. }} \text { (type } F\right)>C C_{\text {avg. }} \text { (type } C\right)>C C_{\text {avg. }} \text { (type } B\right)>C C_{\text {avg. }} \text { (type } E\right)>C C_{\text {avg. }} \text { (type } D\right)>C C_{\text {avg. }} \text { (type } A\right)
$$

- Therefore, an integrated empirical formula can be established to reflect the relationship between these three parameters for the study rocks: 


$$
C C_{\text {avg. }}=0.5989 e^{0.534 A v g . D 1}+1.20925 A v g . D 3-0.7937
$$

The calculated cover coefficients can be obtained from Eq. (38), and the results are shown in Fig. 18C. The statistical analysis shows that there are good positive correlations between the cover coefficients resulting from the lab tests and the calculated values, with a correlation coefficient larger than 0.92 . This suggests that the empirical formula is reliable in this case for calculating the average cover coefficient of Tarim Basin carbonate cap rocks.

\subsection{Relationships between pore size proportion and sealing capacity}

Various types of pores with wide ranges of pore radii can be observed in the Yingshan Fm. cap rocks (Figs. 20). Carbonate cap rocks always have heterogeneous pore structures with large PSD variations (Wu et al., 2019a; Zhou et al., 2019). The poor relationship between porosity and permeability for all the carbonate cap rock analyzed samples (Fig. 14) reveals that the impact of porosity on permeability is quite limited for tight carbonate cap rocks (Gao et al., 2019). Another important controlling factor of permeability that cannot be ignored is the effect of the pore structure (e.g., pore radius), as proposed by Rezaee et al. (2012) and Lai et al. (2018).

The studied carbonate cap rocks present strong heterogeneity and complex relationship between porosity and permeability (Garing et al., 2014). The rather complex carbonate cap rock pore structures are probably a consequence of the abundant presence of nanometer- to micrometer-sized pores and throats (Chalmers et al., 2012; 
Cao et al., 2015). This results from the influence of the sedimentary environments in which the sediments forming these rocks were deposited together with the complex diagenetic alterations they underwent (Ross and Bustin, 2009; Anovitz et al., 2013; Lai and Wang, 2015; Liu et al., 2018; Rahmani et al., 2018).

The proportion of different pore sizes of the total pore volume reveals the heterogeneity of the pore throat structure (Sharawy and Gaafar, 2019), while the heterogeneity of these carbonate cap rocks can be reflected by their fractal dimensions (Volatili et al., 2019). The cross-plots of transitional pore (10-100 nm), mesopore (100$1,000 \mathrm{~nm})$, macropore proportion $(>1,000 \mathrm{~nm}$ and $>2,500 \mathrm{~nm})$ and average cover coefficient of the six pore structure types are summarized in Fig. 20.

From the regression analysis, the results show that the average cover coefficients have a very weak negative correlation with the transitional pore proportion $\left(\mathrm{R}^{2}=0.21\right)$ (Fig. 20A), and almost no correlation with the proportion corresponding to mesopores $\left(\mathrm{R}^{2}=0.18\right)($ Fig. 20B). However, there is a very good negative logarithmic relationship between the average cover coefficients and macropore $(>1,000 \mathrm{~nm})$ proportion (Fig. 20C). Furthermore, the average of cover coefficients is strongly negatively correlated with the macropore proportion, with pore sizes larger than 2,500 $\mathrm{nm}$ and a correlation coefficient $\left(\mathrm{R}^{2}\right)$ of 0.91 in this case (Fig. 20D). This indicates that the cover coefficient utilized to indicate the sealing performance of carbonate cap rocks is significantly controlled by the amount of macropores. An increasing proportion of macropores 
contributes to the decreasing sealing capacity of the carbonate cap rocks (Wu et al., 2019a). When the macopores and microfractures are connected by small pore throats and occupy the major part of the total pore volume, the flow of fluids along the pore space becomes easier (Wilkinson et al., 2014). Although this is obviously beneficial to improving the rock's reservoir quality (Lai et al., 2018), the reduction of the resistance force to migration is not appropriate for the rock's capacity for sealing the oil and gas in the underlying reservoirs (Lohr and Hackley, 2018; Wu et al., 2018b; Zhu et al., 2018).

\subsection{Classification and evaluation of the rock's sealing capacity}

The scattered distributions of fractal dimensions reveal the complexity and heterogeneity of the pore structure (Lesniak and Such, 2005). The capillary resistance force determines the sealing capacity of carbonate cap rocks (Berg, 1975; Kaldi and Atkinson, 1997; Wu et al., 2018a). According to the petrology, pore structures, their fractal dimensions and estimated sealing capacity, the studied carbonate cap rock samples are divided into three classes: I, II, and III (Fig. 22).

(1) Class I carbonate cap rocks are mainly dominated by well-cemented peloidal grainstones, include the types $\mathrm{C}$ and $\mathrm{F}$ pore structures, and present the best sealing capacity. Some residual dissolved intragranular pores can be detected due to the relatively low-image resolution of thin sections (Njiekak et al., 2018), while the SEM analysis reveals that there are quite minor amounts of pores connected by effective 
microfractures due to the multiple generations of calcite cements (Fig. 10F). Very few partially residual intercrystalline pores and microfractures could potentially act as effective fluid flow pathway. Meanwhile, fluids within isolated intragranular pores and dead-end intracrystalline pores are considered immovable due to the precipitation of calcite cement (Fig. 10A) (Zambrano et al., 2018). The reduction of the pore space can be attributed to the complex cementation combined with compaction (Figs. 6G, 8A, C) (Anovitz et al., 2013; Wu et al., 2018b). The breakthrough pressures and median pressures are larger than those of Classes II and III. Fractal dimensions D1, D2, and D3 of this class are larger than 2.55, implying that the pore structures in Class I samples are complex and heterogeneous and result in poor pore connectivity (Gundogar et al., 2016; He et al., 2016; Zhu et al., 2018). In addition, the cover coefficient and sealing gas column height are the largest among the three classes proposed. The abundance of trimodal PSDs indicates that the heterogeneity of the pore throat system has a significant impact on the fractal dimension (Gundogar et al., 2016; Burberry and Peppers, 2017), as well as on the sealing capacity of cap rocks. Furthermore, this also indirectly provides qualitative evidence that the increase in the proportion of small but effectively connected pores and narrow strip-shaped throats does not only make a significant contribution to the enhancement of the pore structure heterogeneity and capillary force (Cai et al., 2019; Lai et al., 2019), but also favors the increase of the rock's sealing performance.

(2) Class II carbonate cap rocks are primarily composed of mudstones and 
dolomitic limestones, cover the types B and E pore structures, and present a moderate sealing capacity. Some intragranular pores are rarely preserved because they have undergone extreme mechanical and chemical compaction (Fig. 10D, E) (Hollis et al., 2010; Dong et al., 2013). However, some intercrystalline pores induced by dissolution with local calcite cement fills can be observed in thin sections and through SEM analysis (Fig. 9A). The coexistence of almost completely filled intracrystalline and residual intragranular pores is characterized by bimodal PSDs obtained from the combination of MICP and $\mathrm{N}_{2} \mathrm{GA}$ analyses (Figs. 12B, 15B). The fractal dimensions of this class display a wide range from 2.392 to 2.655 , implying that both types $\mathrm{B}$ and $\mathrm{E}$ pore structures have relatively strong intrinsic heterogeneity. Although the tortuous intragranular pores are rarely developed, the occurrence of large body pores but only interconnected by extremely narrow throats results in a moderate capillary force (Wilkinson et al., 2014). Hence, the Class II carbonate cap rocks also present moderate cover coefficient and sealing gas column height values.

(3) Class III carbonate cap rocks are predominately composed of well-cemented peloidal grainstones and mudstones, contain pore structures of the types $\mathrm{A}$ and $\mathrm{D}$, and present a poor sealing capacity. The pore systems of this class are typically characterized by abundant microfractures and intercrystalline pores (Figs. 6C, E, 7A, 8A, 9B, D, F), and pores with large radii are always connected by smooth throats. Part of these completely filled microfractures have been subjected to surface-derived meteoric water leaching when the whole strata were uplifted (Dong et al., 2013). Vugs 
formed as a consequence of dissolution during epigenetic diagenesis. Microfractures within highly-compacted zones are discontinuous and partially closed due to mechanical compaction during the burial stage. However, SEM analysis reveals that some of them were partially reopened during the exposure stage to form effective channels that get connected with intergranular pores (Fig. 10C). The fractal dimension values of this class are the lowest $(<2.50)$ of the three classes, and present almost equal values for the type A (2.232 and 2.299) pore structure. For the type D pore structure, the cross-plot of $\lg (P c)$ versus $\lg \left(1-S_{H g}\right)$ can be fitted by a single straight line, and can be calculated with the same fractal dimension value (2.499). The type D pore structure also shows the rareness of small and poorly connected pores. In addition, the cover coefficient and the height of the gas column are much lower than those estimated for the first two classes. Lai et al. (2019) described how microfractures determine the capillary force. Although Class III samples have similar pore characteristics, the sealing capacity determined by the capillary force becomes extremely poor if these microfractures and wide strip-shaped throats can act as effective fluid migration and leakage pathways (Ross and Bustin, 2009; Xiao et al., 2018). Additionally, stylolites provide pathways for fluid flow and hydrocarbon charging (Du et al., 2017). This finding is supported by Zhu et al. (2018), who proposed that smooth pore surfaces with small fractal dimensions are not beneficial for hydrocarbon preservation.

\section{Conclusions}

(1) Two main lithological types carbonate cap rocks of the Ordovician Yingshan 
Fm. (Tarim Basin) can be defined by analyzing outcrop analogs. These include limestones and dolomitic limestones. Their pore types are dominated by microfractures and intragranular pores, followed by inter- and intracrystalline pores. Pore structures present a wide range and are divided into six types from A to F. There is no apparent correlation between porosity and permeability for these carbonate cap rocks.

(2) The carbonate cap rocks with a certain range $(50-5,000 \mathrm{~nm})$ of pore size distributions present multiple pore size distribution fractal behaviors. The values of the fractal dimensions from D1 to D4, corresponding to different pore diameters (from macropores to micropores), present an increasing trend as the pore throat diameters decrease. The average total fractal dimension of the type A pore structure is the highest among the six pore structure types defined in this study.

(3) The close relationships between the cover coefficients and fractal dimensions (D1, D3, $\mathrm{D}_{\text {total }}$, and $\mathrm{D}_{\text {avg. }}$ ) reveal the significance of the pore structure fractal dimension in controlling the rock's sealing capacity. The sealing capacity of carbonate cap rock increases with increasing the fractal dimension. A higher fractal dimension of a carbonate cap rock suggests that its pore structure is controlled by highly heterogeneous pore networks.

(4) An integrated empirical formula has been established to reflect the relationships of average D1, average D3 and the average cover coefficient. The cover coefficient, which indicates the sealing performance of carbonate cap rocks, is 
significantly controlled by the amount of macropores. The increasing proportion of macropores results in a decrease of the rock's sealing capacity.

(5) Three classes of carbonate cap rocks are defined according to the pore throat structures, fractal dimensions and their sealing capacities. Class I rocks presents the best sealing performance because of the presence of small but effectively connected pore and narrow strip-shaped throats, which make a significant contribution to the roughness and enhancement of the pore structure heterogeneity.

\section{References}

Adelinet, M., J.-F. Barthélémy, E. Bemer, and Y. Hamon, 2019, Effective medium modeling of diagenesis impact on the petroacoustic properties of carbonate rocks: GEOPHYSICS, v. 84, no. 4, p. WA43-WA57, doi:10.1190/geo2018-0559.1.

Anovitz, L. M., D. R. Cole, G. Rother, L. F. Allard, A. J. Jackson, and K. C. Littrell, 2013, Diagenetic changes in macro- to nano-scale porosity in the St. Peter Sandstone: An (ultra) small angle neutron scattering and backscattered electron imaging analysis: Geochimica et Cosmochimica Acta, v. 102, p. 280-305, doi:10.1016/j.gca.2012.07.035.

Avnir, D., and M. Jaroniec, 1989, An isotherm equation for adsorption on fractal surfaces of heterogeneous porous materials: Langmuir, v. 5, no. 6, p. 1431-1433, doi:10.1021/la00090a032.

Berg, R. R., 1975, Capillary pressures in stratigraphic traps: AAPG Bulletin, v. 59, no. 6, p. 939956.

Brunauer, S., P. H. Emmett, and E. Teller, 1938, Adsorption of Gases in Multimolecular Layers: Journal of the American Chemical Society, v. 60, no. 2, p. 309-319, doi:10.1021/ja01269a023.

Burberry, C. M., and M. H. Peppers, 2017, Fracture characterization in tight carbonates: An example from the Ozark Plateau, Arkansas: AAPG Bulletin, v. 101, no. 10, p. 1675-1696, doi:10.1306/01251715242.

Cai, J., Z. Zhang, W. Wei, D. Guo, S. Li, and P. Zhao, 2019, The critical factors for permeabilityformation factor relation in reservoir rocks: Pore-throat ratio, tortuosity and connectivity: Energy, v. 188, p. 116051, doi:10.1016/j.energy.2019.116051.

Cao, T., M. Deng, Z. Song, H. Luo, and A. S. Hursthouse, 2018, Characteristics and controlling 
factors of pore structure of the Permian shale in southern Anhui province, East China: Journal of Natural Gas Science and Engineering, v. 60, p. 228-245, doi:10.1016/j.jngse.2018.10.018.

Cao, T., Z. Song, S. Wang, X. Cao, Y. Li, and J. Xia, 2015, Characterizing the pore structure in the Silurian and Permian shales of the Sichuan Basin, China: Marine and Petroleum Geology, v. 61, p. 140-150, doi:10.1016/j.marpetgeo.2014.12.007.

Chalmers, G. R. L., D. J. K. Ross, and R. M. Bustin, 2012, Geological controls on matrix permeability of Devonian Gas Shales in the Horn River and Liard basins, northeastern British Columbia, Canada: International Journal of Coal Geology, v. 103, p. 120-131, doi:10.1016/j.coal.2012.05.006.

Chen, G., J. Shi, L. Xue, Q. Wang, and L. Xiao, 1999, Sequence stratigraphy of the Paleozoic in West Tarim Basin: Acta Sedimentoloica Sinica, v. 17, no. 4, p. 560-565.

Cheng, Q., H. Chen, M. Fan, Q. Wang, W. Chen, 2006, Determination of the total pore texture of caprock: Petroleum Geology and Experiment, v. 28, no. 6, p. 604-608.

Clarkson, C. R., N. Solano, R. M. Bustin, A. M. M. Bustin, G. R. L. Chalmers, L. He, Y. B. Melnichenko, A. P. Radliński, T. P. Blach, 2013, Pore structure characterization of North American shale gas reservoirs: using USANS/SANS, gas adsorption, and mercury intrusion: Fuel, v. 103, no. 1, p. 606-616, doi: 10.1016/j.fuel.2012.06.119.

Dong, S., D. Chen, H. Qing, X. Zhou, D. Wang, Z. Guo, M. Jiang, and Y. Qian, 2013, Hydrothermal alteration of dolostones in the Lower Ordovician, Tarim Basin, NW China: Multiple constraints from petrology, isotope geochemistry and fluid inclusion microthermometry: Marine and Petroleum Geology, v. 46, p. 270-286, doi:10.1016/j.marpetgeo.2013.06.013.

Du, Y., T. Fan, and Z. Gao, 2016, Geochemical characteristics and their implications to diagenetic environment of Lower-Middle Ordovician carbonate rocks, Tarim Basin, China: A case study of Bachu Dabantage outcrop and Aksu Penglaiba outcrop: Natural Gas Geoscience, v. 27, no. 08, p. 1509-1523.

Du, Y., T. Fan, Z. Gao, H. Han, and Q. Zhang, 2017, Diagenesis and sequence stratigraphic framework of the Lower-Middle Ordovician Yingshan Formation, Tarim Basin: A case study from Tahe area and Keping-Bachu outcrop: Oil \& Gas Geology, v. 38, no. 4, p. 677-692.

El Sharawy, M. S., and G. R. Gaafar, 2019, Pore-Throat size distribution indices and their relationships with the petrophysical properties of conventional and unconventional clastic reservoirs: Marine and Petroleum Geology, v. 99, p. 122-134, doi:10.1016/j.marpetgeo.2018.10.006.

Gao, Z., T. Fan, Q. Ding, and X. Hu, 2016, A third-order unconformity within Lower Ordovician carbonates in the Tarim basin, NW China: Implications for reservoir development: Journal of Petroleum Geology, v. 39, no. 3, p. 287-304, doi:10.1111/jpg.12647.

Gao, Z., X. Yang, C. Hu, L. Wei, Z. Jiang, S. Yang, Y. Fan, Z. Xue, and H. Yu, 2019, Characterizing 
the pore structure of low permeability Eocene Liushagang Formation reservoir rocks from Beibuwan Basin in northern South China Sea: Marine and Petroleum Geology, v. 99, p. $107-$ 121, doi:10.1016/j.marpetgeo.2018.10.005.

Garing, C., L. Luquot, P. A. Pezard, and P. Gouze, 2014, Electrical and flow properties of highly heterogeneous carbonate rocks: AAPG Bulletin, v. 98, no. 1, p. 49-66, doi:10.1306/05221312134.

Górniak, K., 2019, The cap rocks sealing the reservoir in the Węglówka oil field, sub-Silesian unit, Polish outer Carpathians: Petrographical approach: AAPG Bulletin, v. 103, no. 10, p. 23692398, doi:10.1306/01211917085.

Gregg, S. J., K. S. W. Sing, and H. W. Salzberg, 1967, Adsorption Surface Area and Porosity: Journal of The Electrochemical Society, v. 114, no. 11, p. 279C, doi:10.1149/1.2426447.

Gundogar, A. S., C. M. Ross, S. Akin, and A. R. Kovscek, 2016, Multiscale pore structure characterization of middle east carbonates: Journal of Petroleum Science and Engineering, v. 146, p. 570-583, doi:10.1016/j.petrol.2016.07.018.

Guo, R., Q. Xie, X. Qu, M. Chu, S. Li, D. Ma, and X. Ma, 2020, Fractal characteristics of porethroat structure and permeability estimation of tight sandstone reservoirs: A case study of Chang 7 of the Upper Triassic Yanchang Formation in Longdong area, Ordos Basin, China: Journal of Petroleum Science and Engineering, v. 184, p. 106555, doi: 10.1016/j.petrol.2019.106555.

Hao, L., J. Tang, Q. Wang, H. Tao, X. Ma, D. Ma, and H. Ji, 2017, Fractal characteristics of tight sandstone reservoirs: A case from the Upper Triassic Yanchang Formation, Ordos Basin, China: Journal of Petroleum Science and Engineering, v. 158, p. 243-252, doi:10.1016/j.petrol.2017.08.060.

He, C., and M. Hua, 1998, Fractal geometry description of reservoir pore structure: Oil \& Gas Geology, v. 19, no. 1, p. 17-23.

He, J., W. Ding, A. Li, Y. Sun, P. Dai, S. Yin, E. Chen, and Y. Gu, 2016, Quantitative microporosity evaluation using mercury injection and digital image analysis in tight carbonate rocks: A case study from the Ordovician in the Tazhong Palaeouplift, Tarim Basin, NW China: Journal of Natural Gas Science and Engineering, v. 34, p. 627-644, doi:10.1016/j.jngse.2016.07.025.

Hollis, C., V. Vahrenkamp, S. Tull, A. Mookerjee, C. Taberner, and Y. Huang, 2010, Pore system characterisation in heterogeneous carbonates: An alternative approach to widely-used rocktyping methodologies: Marine and Petroleum Geology, v. 27, no. 4, p. 772-793, doi: 10.1016/j.marpetgeo.2009.12.002.

Ingram, G. M., J. L. Urai, and M. A. Naylor, 1997, Sealing processes and top seal assessment, in Norwegian Petroleum Society Special Publications: p. 165-174, doi: 10.1016/S09288937(97)80014-8. 
Ji, C., H. Qing, D. Chen, P. Luo, Z. Jin, and L. Shao, 2013, Characteristics and Dolomitization of Upper Cambrian to Lower Ordovician Dolomite from Outcrop in Keping Uplift, Western Tarim Basin, Northwest China: Acta Geologica Sinica - English Edition, v. 87, no. 4, p. 10051018, doi:10.1111/1755-6724.12106.

Jin, Z., 2014, A study on the distribution of oil and gas reservoirs controlled by source-cap rock assemblage in unmodified foreland region of Tarim Basin: Oil \& Gas Geology, v. 35, no. 6, p. 763-770.

Joyner, L. G., E. P. Barrett, and R. Skold, 1951, The Determination of Pore Volume and Area Distributions in Porous Substances. II. Comparison between Nitrogen Isotherm and Mercury Porosimeter Methods: Journal of the American Chemical Society, v. 73, no. 7, p. 3155-3158, doi: 10.1021/ja01151a046.

Kang, Y., 1989, Dissolution on several petro-geological problems in the Northern Tarim Basin: Geoscience, v. 3, no. 1, p. 111-123.

Kang, Y., 2005, Cases of Discovery and Exploration of Marine Fields in China (Part 4): Tahe Oilfield in Tarim Basin: Marine Origin Petroleum Geology, v. 10, no. 4, p. 31-38.

Kaldi, J. G., and C. D. Atkinson, 1997, Evaluating Seal Potential: Example from the Talang Akar Formation, Offshore Northwest Java, Indonesia: Seals, Traps, and the Petroleum System.

Koehn, D., M. P. Rood, N. Beaudoin, P. Chung, P. D. Bons, and E. Gomez-Rivas, 2016, A new stylolite classification scheme to estimate compaction and local permeability variations: Sedimentary Geology, v. 346, p. 60-71, doi:10.1016/j.sedgeo.2016.10.007.

Krohn, C. E., 1988, Fractal measurements of sandstones, shales, and carbonates: Journal of Geophysical Research, v. 93, no. B4, p. 3297-3305, doi: 10.1029/JB093iB04p03297.

Lai, J., and G. Wang, 2015, Fractal analysis of tight gas sandstones using high-pressure mercury intrusion techniques: Journal of Natural Gas Science and Engineering, v. 24, p. 185-196, doi:10.1016/j.jngse.2015.03.027.

Lai, J. et al., 2018, Investigation of pore structure and petrophysical property in tight sandstones: Marine and Petroleum Geology, v. 91, p. 179-189, doi:10.1016/j.marpetgeo.2017.12.024.

Lai, F., Z. Li, T. Zhang, A. Zhou, and B. Gong, 2019, Characteristics of microscopic pore structure and its influence on spontaneous imbibition of tight gas reservoir in the Ordos Basin, China: Journal of Petroleum Science and Engineering, v. 172, p. 23-31, doi:10.1016/j.petrol.2018.09.020.

Lesniak, G., and P. Such, 2005, Fractal approach, analysis of images and diagenesis in pore space evaluation: Natural Resources Research, v. 14, no. 4, p. 317-324.

Li, K., 2004, Characterization of Rock Heterogeneity Using Fractal Geometry, in SPE International Thermal Operations and Heavy Oil Symposium and Western Regional Meeting: Society of Petroleum Engineers, doi: 10.2118/86975-MS. 
Li, K., 2010, Analytical derivation of Brooks-Corey type capillary pressure models using fractal geometry and evaluation of rock heterogeneity: Journal of Petroleum Science and Engineering, v. 73, no. 1-2, p. 20-26, doi:10.1016/j.petrol.2010.05.002.

Li, P., F. Hao, X. Guo, H. Zou, X. Yu, and G. Wang, 2015, Processes involved in the origin and accumulation of hydrocarbon gases in the Yuanba gas field, Sichuan Basin, southwest China: Marine and Petroleum Geology, v. 59, p. 150-165, doi:10.1016/j.marpetgeo.2014.08.003.

Li, P., M. Zheng, H. Bi, S. Wu, and X. Wang, 2017, Pore throat structure and fractal characteristics of tight oil sandstone: A case study in the Ordos Basin, China: Journal of Petroleum Science and Engineering, v. 149, p. 665-674, doi:10.1016/j.petrol.2016.11.015.

Liu, H., Z. Tian, B. Liu, R. Guo, D. Yang, Y. Deng, Y. Yu, and K. Shi, 2018, Pore types, origins and control on reservoir heterogeneity of carbonate rocks in Middle Cretaceous Mishrif Formation of the West Qurna oilfield, Iraq: Journal of Petroleum Science and Engineering, v. 171, p. 1338-1349, doi:10.1016/j.petrol.2018.08.034.

Lohr, C. D., and P. C. Hackley, 2018, Using mercury injection pressure analyses to estimate sealing capacity of the Tuscaloosa marine shale in Mississippi, USA: Implications for carbon dioxide sequestration: International Journal of Greenhouse Gas Control, v. 78, p. 375-387, doi:10.1016/j.ijggc.2018.09.006.

Lü, H., Y. Ding, F. Geng, 2014, Hydrocarbon accumulation patterns and favorable exploration areas of the Ordovician in Tarim Basin: Oil \& Gas Geology, v. 35, no. 6, p. 798-805.

Lü, X., Y. Wang, H. Yu, and Z. Bai, 2017, Major factors affecting the closure of marine carbonate caprock and their quantitative evaluation: A case study of Ordovician rocks on the northern slope of the Tazhong uplift in the Tarim Basin, western China: Marine and Petroleum Geology, v. 83, p. 231-245, doi:10.1016/j.marpetgeo.2017.03.006.

McPhee, C., J. Reed, and I. Zubizarreta, 2015, Capillary Pressure, in Developments in Petroleum Science: p. 449-517, doi:10.1016/B978-0-444-63533-4.00009-3.

Njiekak, G., D. R. Schmitt, and R. S. Kofman, 2018, Pore systems in carbonate formations, Weyburn field, Saskatchewan, Canada: Micro-tomography, helium porosimetry and mercury intrusion porosimetry characterization: Journal of Petroleum Science and Engineering, v. 171, p. 14961513, doi:10.1016/j.petrol.2018.08.029.

Nooruddin, H. A., M. E. Hossain, H. Al-Yousef, and T. Okasha, 2014, Comparison of permeability models using mercury injection capillary pressure data on carbonate rock samples: Journal of Petroleum Science and Engineering, v. 121, p. 9-22, doi:10.1016/j.petrol.2014.06.032.

Norbisrath, J. H., G. P. Eberli, B. Laurich, G. Desbois, R. J. Weger, and J. L. Urai, 2015, Electrical and fluid flow properties of carbonate microporosity types from multiscale digital image analysis and mercury injection: AAPG Bulletin, v. 99, no. 11, p. 2077-2098, doi:10.1306/07061514205. 
Pang, X., C. Jia, H. Pang, and H. Yang, 2018, Destruction of hydrocarbon reservoirs due to tectonic modifications: Conceptual models and quantitative evaluation on the Tarim Basin, China: Marine and Petroleum Geology, v. 91, p. 401-421, doi:10.1016/j.marpetgeo.2018.01.028.

Pfeifer, P., and D. Avnir, 1983, Chemistry in noninteger dimensions between two and three. I. Fractal theory of heterogeneous surfaces: The Journal of Chemical Physics, v. 79, no. 7, p. 3558-3565, doi:10.1063/1.446210.

Rahmani, O., M. Khoshnoodkia, H. Mohseni, and M. Hajian, 2018, Sequence stratigraphy of the Triassic Period: Case from the Dashtak and Khaneh-Kat formations, the Zagros Basin, Iran: Journal of Petroleum Science and Engineering, v. 167, p. 447-457, doi:10.1016/j.petrol.2018.03.092.

Rezaee, R., A. Saeedi, and B. Clennell, 2012, Tight gas sands permeability estimation from mercury injection capillary pressure and nuclear magnetic resonance data: Journal of Petroleum Science and Engineering, v. 88-89, p. 92-99, doi:10.1016/j.petrol.2011.12.014.

Ross, D. J. K., and R. Marc Bustin, 2009, The importance of shale composition and pore structure upon gas storage potential of shale gas reservoirs: Marine and Petroleum Geology, v. 26, no. 6, p. 916-927, doi:10.1016/j.marpetgeo.2008.06.004.

Schmitt, M., C. P. Fernandes, J. A. B. da Cunha Neto, F. G. Wolf, and V. S. S. dos Santos, 2013, Characterization of pore systems in seal rocks using Nitrogen Gas Adsorption combined with Mercury Injection Capillary Pressure techniques: Marine and Petroleum Geology, v. 39, no, 1, p. 138-149, doi:10.1016/j.marpetgeo.2012.09.001.

Shu, Y., M. Wilkinson, and N. Heinemann, 2017, Using Hydrocarbon Fields of the UK North Sea as Analogues for Effective Pore Throat Radii Prediction in Mudstone Caprocks: Energy Procedia, v. 114, p. 5329-5336, doi:10.1016/j.egypro.2017.03.1656.

Song, Z., G. Liu, W. Yang, H. Zou, M. Sun, and X. Wang, 2018, Multi-fractal distribution analysis for pore structure characterization of tight sandstone-A case study of the Upper Paleozoic tight formations in the Longdong District, Ordos Basin: Marine and Petroleum Geology, v. 92, p. 842-854, doi:10.1016/j.marpetgeo.2017.12.018.

Vavra, C. L., J. G. Kaldi, and R. M. Sneider, 1992, Geological Applications of Capillary Pressure: A Review: AAPG Bulletin, v. 76, no. 6, p. 840 - 850, doi:10.1306/BDFF88F8-1718-11D7$8645000102 \mathrm{C} 1865 \mathrm{D}$.

Volatili, T., M. Zambrano, A. Cilona, B. A. H. Huisman, A. Rustichelli, M. Giorgioni, S. Vittori, and E. Tondi, 2019, From fracture analysis to flow simulations in fractured carbonates: The case study of the Roman Valley Quarry (Majella Mountain, Italy): Marine and Petroleum Geology, v. 100, p. 95-110, doi:10.1016/j.marpetgeo.2018.10.040.

Washburn, E. W., 1921, Note on a Method of Determining the Distribution of Pore Sizes in a Porous Material: Proceedings of the National Academy of Sciences, v. 7, no. 4, p. 115-116, 
doi:10.1073/pnas.7.4.115.

Wang, Q., J. Han, H. Li, Y. Sun, H. He, and S. Ren, 2019, Carbonate sequence architecture, sedimentary evolution and sea level fluctuation of the Middle and Lower Ordovician on outcrops at the northwestern margin of Tarim Basin: Oil \& Gas Geology, v. 40, no. 4, p. 835$850+916$.

Wang, M., and Q. Yu, 2017, Pore structure characterization of Carboniferous shales from the eastern Qaidam Basin, China: Combining helium expansion with low-pressure adsorption and mercury intrusion: Journal of Petroleum Science and Engineering, v. 152, p. 91-103, doi:10.1016/j.petrol.2017.02.007.

Wilkinson, M., Z. Chen, and Y. Shu, 2014, Retention capacity of seals from hydrocarbon field analogues for appraisal of saline aquifers: International Journal of Greenhouse Gas Control, v. 28, p. 126-133, doi:10.1016/j.ijggc.2014.06.027.

$\mathrm{Wu}$, J. et al., 2018a, Identification and characteristic analysis of carbonate cap rock: A case study from the Lower-Middle Ordovician Yingshan Formation in Tahe oilfield, Tarim Basin, China: Journal of Petroleum Science and Engineering, v. 164, p. 362-381, doi:10.1016/j.petrol.2017.12.070.

Wu, J. et al., 2018b, A conceptual model to investigate the impact of diagenesis and residual bitumen on the characteristics of Ordovician carbonate cap rock from Tarim Basin, China: Journal of Petroleum Science and Engineering, v. 168, p. 226-245, doi:10.1016/j.petrol.2018.05.034.

Wu, J., T. Fan, E. Gomez-Rivas, Z. Gao, S. Yao, W. Li, C. Zhang, Q. Sun, Y. Gu, and M. Xiang, 2019, Impact of pore structure and fractal characteristics on the sealing capacity of Ordovician carbonate cap rock in the Tarim Basin, China: Marine and Petroleum Geology, v. 102, p. 557579, doi:10.1016/j.marpetgeo.2019.01.014.

Wu, Y., P. Tahmasebi, C. Lin, M. A. Zahid, C. Dong, A. N. Golab, and L. Ren, 2019, A comprehensive study on geometric, topological and fractal characterizations of pore systems in low-permeability reservoirs based on SEM, MICP, NMR, and X-ray CT experiments: Marine and Petroleum Geology, v. 103, p. 12-28, doi:10.1016/j.marpetgeo.2019.02.003.

Xiao, D., S. Jiang, D. Thul, S. Lu, L. Zhang, and B. Li, 2018, Impacts of clay on pore structure, storage and percolation of tight sandstones from the Songliao Basin, China: Implications for genetic classification of tight sandstone reservoirs: Fuel, v. 211, p. 390-404, doi:10.1016/j.fuel.2017.09.084.

Yang, R., S. He, J. Yi, and Q. Hu, 2016, Nano-scale pore structure and fractal dimension of organicrich Wufeng-Longmaxi shale from Jiaoshiba area, Sichuan Basin: Investigations using FESEM, gas adsorption and helium pycnometry: Marine and Petroleum Geology, v. 70, p. 27-45, doi:10.1016/j.marpetgeo.2015.11.019.

Zambrano, M., E. Tondi, L. Mancini, G. Lanzafame, F. X. Trias, F. Arzilli, M. Materazzi, and S. Torrieri, 2018, Fluid flow simulation and permeability computation in deformed porous carbonate grainstones: Advances in Water Resources, v. 115, p. 95-111, 
doi:10.1016/j.advwatres.2018.02.016.

Zhang, B., B. Yu, G. Zhu, Y. Wang, J. Su, K. Wang, and X. Liu, 2015, Research on hydrocarbon distribution regularity and main accumulation controlling factors of Tazhong northern slope hydrocarbon-rich region: Earth Science Frontiers, v. 22, no. 1, p. 271-280, doi:10.13745/j.esf.2015.01.023.

Zhang, K., X. Pang, Z. Zhao, X. Shao, X. Zhang, W. Li, and K. Wang, 2018, Pore structure and fractal analysis of Lower Carboniferous carbonate reservoirs in the Marsel area, Chu-Sarysu basin: Marine and Petroleum Geology, v. 93, p. 451-467, doi:10.1016/j.marpetgeo.2018.03.027.

Zhang, X., C. Wu, and T. Li, 2017, Comparison analysis of fractal characteristics for tight sandstones using different calculation methods: Journal of Geophysics and Engineering, v. 14, no. 1, p. 120-131, doi: 10.1088/1742-2140/14/1/120.

Zhao, J., Z. Jin, Q. Hu, K. Liu, Z. Jin, Z. Hu, H. Nie, W. Du, C. Yan, and R. Wang, 2018, Mineral composition and seal condition implicated in pore structure development of organic-rich Longmaxi shales, Sichuan Basin, China: Marine and Petroleum Geology, v. 98, p. 507-522, doi:10.1016/j.marpetgeo.2018.09.009.

Zhou, X., X. Lü, H. Quan, W. Qian, X. Mu, K. Chen, Z. Wang, and Z. Bai, 2019, Influence factors and an evaluation method about breakthrough pressure of carbonate rocks: An experimental study on the Ordovician of carbonate rock from the Kalpin area, Tarim Basin, China: Marine and Petroleum Geology, v. 104, p. 313-330, doi:10.1016/j.marpetgeo.2019.03.034.

Zhu, F., W. Hu, J. Cao, F. Sun, Y. Liu, and Z. Sun, 2018, Micro/nanoscale pore structure and fractal characteristics of tight gas sandstone: A case study from the Yuanba area, northeast Sichuan Basin, China: Marine and Petroleum Geology, v. 98, p. 116-132, doi:10.1016/j.marpetgeo.2018.08.013.

Zhu, L., and B. Ma, 1991, The sedimentary environment of Cambrian-Ordovician in the Aksu and Keping Areas of Tarim Basin: Acta Sedimentologica Sinica, v. 9, no. 2, p. 55-62.

\section{Vitae}

JUN WU School of Energy Resources, China University of Geosciences (Beijing), No. 29 Xueyuan Road, Haidian District, Beijing 100083, China; Department of Mineralogy, Petrology and Applied Geology, Faculty of Earth Sciences, University of Barcelona, Barcelona 08028, Spain; zgdzdxbjwj@126.com. Jun Wu is a Ph. D. candidate at the China University of Geosciences (Beijing). He graduated in 2010 with 
a B.S. degree in Petroleum Engineering from the same university. He has spent one year as a joint Ph. D. scholar at the University of Barcelona. His research focuses on carbonate sedimentology and diagenesis, carbonate cap rocks characterization, and sealing capacity evaluation in the Tarim Basin.

TAILIANG FAN School of Energy Resources, China University of Geosciences (Beijing), No. 29 Xueyuan Road, Haidian District, Beijing 100083, China; jhy17519@126.com. Tailiang Fan is a Professor of Petroleum Geology at the China University of Geosciences (Beijing). He received his Ph. D. from this university in 1990. He is currently the leader of the Key Laboratory of Marine Reservoir Evolution and Hydrocarbon Enrichment Mechanism, Ministry of Education, China. He has worked for more than 30 years in petroleum exploration and development in the Tarim Basin. His research interests focus on sequence stratigraphy, sedimentology, and carbonate reservoirs characterization.

ENRIQUE GOMEZ-RIVAS $\sim$ Department of Mineralogy, Petrology and Applied Geology, Faculty of Earth Sciences, University of Barcelona, Barcelona 08028, Spain; e.gomez-rivas@ub.edu. Enrique Gomez-Rivas is currently a research fellow at the University of Barcelona. He graduated with a $\mathrm{PhD}$ in structural geology from the Autonomous University of Barcelona in 2008. After that he worked at the universities of Tübingen (Germany) and Aberdeen (United Kingdom) as researcher and lecturer, respectively. His research interests mainly focus on sedimentary geology, the formation 
of tectonic structures as well as on fluid-rock interactions, integrating field studies with numerical simulations.

ANNA TRAVÉ $\sim$ Department of Mineralogy, Petrology and Applied Geology, Faculty of Earth Sciences, University of Barcelona, Barcelona 08028, Spain; atrave@ub.edu. Anna Trave is a Professor at the University of Barcelona. She graduated with a $\mathrm{PhD}$ in sedimentary geology from this university. Her research interests focus on carbonate reservoirs characterization, carbonate diagenesis and fluid flow and deformation.

ZHIQIAN GAO School of Energy Resources, China University of Geosciences (Beijing), No. 29 Xueyuan Road, Haidian District, Beijing 100083, China; gzq@cugb.edu.cn. Zhiqian Gao is a Professor of Petroleum Geology at the China University of Geosciences (Beijing). He received his Ph.D. in 2007 from this university. His research interests focus on carbonate reservoir geology and sedimentology.

SHANSHAN WANG Beijing Municipal Commission of Planning and Natural Resources Yanqing Branch, No. 6 Xiangyuan Street, Yanqing District, Beijing 102100, China; 18811589738@163.com. Shanshan Wang graduated with a M.S. degree from the China University of Geosciences (Beijing) in 2018. She is mainly interested in the prevention and control of geological hazards, the restoration and control of mine geological environments, and on the management of mineral resources.

XIAOLONG SUN Department of Mineralogy, Petrology and Applied Geology, Faculty of Earth Sciences, University of Barcelona, Barcelona 08028, Spain; 
upc_sxl@126.com. Xiaolong Sun is a Ph. D. candidate at the University of Barcelona. He received his B.S. degree and M.S. degree from the China University of Petroleum (East China) $(2015,2018)$. His research focuses on carbon dioxide sequestration in compressional basins, including studies of sedimentology, diagenesis and mechanical stratigraphy.

\section{Figure captions}

Fig. 1 (A) and (B) Location map of the Tarim Basin, NW China, showing the main tectonic units (uplifts, slopes and depressions); (C) The locations of the Dabantage (DBTG), Yangjikan (YJK), Kepingshuinichang (KPSNC) and Penglaiba (PLB) outcrops in the Keping and Akesu areas are located in the NW Tarim Basin margin, and four studied outcrops are marked with dark blue triangles.

Fig. 2 Sequence stratigraphy and depositional settings of the Lower-Upper Ordovician successions at these outcrop sections in the Keping uplift, northwestern margin of the Tarim Basin (modified from Wang et al., 2019).

Fig. 3 Burial history of the Lower-Middle Ordovician Yingshan Fm. and their corresponding diagenetic stages and diagenetic processes at the studied outcrops in the Keping uplift, Tarim Basin (modified from Dong et al., 2013).

Fig. 4 Sampling positions of 19 studied samples, stratigraphic column and lithologic successions from the Lower Ordovician Penglaiba Fm. to the Middle Ordovician Yijianfang Fm. 
Fig. 5 (A) Field photograph and photomicrographs showing carbonate cap rock composed of medium-bedded to massive limestone at the Penglaiba outcrop. (B) Field photograph showing massive carbonate cap rock cut by fractures formed at multiple stages. Coarse calcite crystals fill them for different distances depending on the fracture set: the first fracture set (F1) presents calcite filling distances of $21-53 \mathrm{~cm}$, the second set $(\mathrm{F} 2)$ has shorter extensions $(10-20 \mathrm{~cm})$ and thin widths $(0.3-1 \mathrm{~cm})$, and the third one (F3) presents the shortest extensions of 3-8 cm without local infills; Karst-related holes were partially-filled by coarse calcite crystals. (C) Dissolution vug completely filled with calcite crystals, and local anhedral dolomite crystals (Dol) within intergranular pores. (D) Column-shaped calcite strips cut by bedding-parallel stylolites with an amplitude of 3-5 $\mu \mathrm{m}$, with residual pyrobitumen present along these pressure-solution seams. (E) Tightly packed micrite crystal zone separating a peloidal grainstone into two zones, almost without porosity. (F) Pyrite and clay minerals nearly completely plugged the intracrystalline pores in highly fractured intervals. (G) Blocky calcite crystals distributed in the vicinity of stylolites, indicating intensive cementation. $(\mathrm{H})$ Photomicrograph of subhedral dolomite crystals scattered along the stylolites, together with residual pyrobitumen, and coarse calcite crystals occluding intercrystalline pores and microfractures.

Fig. 6 (A) Field photograph of thin and thick-bedded dolomitic limestone carbonate cap rock at the Penglaiba outcrop. (B) Field photograph of a low-amplitude stylolite in massive mudstone at the Penglaiba outcrop. (C) Intraclast dolomitic limestone, with 
anhedral dolomite crystals (Dol) scattered in wavy stylolites. Pyrobitumen and bioclast fragments were rarely embedded within sparite, and then fully plugged microfractures with later calcite crystals. (D) Euhedral dolomite crystals distributed along and/or in the vicinity of stylolites in mudstone, which are coated by residual bitumen. (E) Completely-cemented algal-bearing zones (white dot ovals). (F) Microfracture pervasively cemented by calcite crystals. In this case, dolomization is locally found at the peak of stylolites in the host limestone. (G) Euhedral dolomite crystals underwent intensive mechanical compaction, accompanied by column-shaped calcite strips. $(\mathrm{H})$ Vuggy porosity is occluded by blocky calcite crystals, with intercrystalline pores partially filled with pyrobitumen and pyrite.

Fig. 7 Thin-section photomicrographs of carbonate cap rock from the Yingshan Fm. at Yangjikan, Penglaiba and Kepingshuinichang outcrops. (A) Mudstone. Microfracture with a width of $0.15 \mathrm{~mm}$ was completely filled with calcite crystals, S-12; (B) Peloidal grainstone. The deformation of bioclasts occurred during mechanical compaction, $\mathrm{S}-1$; (C) Peloidal grainstone. The intergranular pores were completely filled with two generations of calcite cements: bladed (C1) and drusy (C2) calcite cements, S-5; (D) Peloidal grainstone. Blocky calcite cements with various geometries and sizes occluded the pore space between intraclasts, S-7; (E) Ooidal-peloidal grainstone. Subhedral dolomite crystals are scattered filling the space between intraclasts, S-6; (F) Peloidal grainstone, with two different cementation zones showing the relationship between cement distribution and intraclast size, S-5. (A) from the Yangjikan outcrop, (B) from 
the Penglaiba outcrop, (C), (D), (E) and (F) from the Kepingshuinichang outcrop.

Fig. 8 Thin-section photomicrographs of carbonate cap rocks from the Yingshan Fm. at Dabantage, Kepingshuinichang, and Penglaiba outcrops. (A) Peloidal grainstone, with three generations of calcite cements including elongate blocky $(\mathrm{C} 1)$, drusy $(\mathrm{C} 2)$ and blocky (C3) cements along microfractures, and other two generations of calcite cements: isopachous (C4) and blocky (C5) cements, S-9; (B) Dolomitic limestone, showing anhedral (D1) and euhedral (D2) crystals, S-10; (C) Peloidal grainstone showing the presence of a broken bioclast due to mechanical compaction during burial. The bioclast is surrounded by blocky calcite crystals, S-23; (D) Dolomitic limestone showing intense recrystallized dolomite crystals and intraclasts are highly compacted. (A) and (B) from the Dabantage outcrop, (C) from the Kepingshuinichang outcrop, and (D) from the Penglaiba outcrop.

Fig. 9 Thin-section photomicrographs of pore types of carbonate cap rocks from the Yingshan Fm. in the Tarim Basin outcrops. (A) Intercrystalline pores with triangular shape within blocky calcite cements. (B) A residual microfracture is occluded with calcite cements, and intragranular and intercrystalline pores are present as a result of dissolution. (C) Intercrystalline pores distributed in the vicinity of euhedral dolomite crystals. (D) Pyrobitumen and calcite cements plug a partly-cemented microfracture. (E) Blocky calcite crystals filled partially dissolved microfracture, thereby forming intercrystalline pores. (F) Microfractures and disconnected intracrystalline pores are 
scattered in peloidal grainstone.

Fig. 10 SEM photomicrographs of pore types of the Ordovician Yingshan Fm. carbonate cap rocks. (A) Intracrystalline pores with a diameter ranging from 0.02 to $0.83 \mu \mathrm{m}$. These pores appear almost disconnected. Mudstone, S-2; (B) Microfracture with a width of $0.11-0.21 \mu \mathrm{m}$, and intragranular pores are partly-filled with calcite cements. Mudstone, S-2; (C) Two highly-compacted zones are separated by a discontinuous microfracture, which is partly filled with calcite crystals. Peloidal grainstone, S-9; (D) Intragranular pores and partly-filled intracrystalline pores all have different geometries, and some scatted dolomite crystals (Do.). Mudstone, S-3; (E) Intragranular pores with diameters ranging from 0.14 to $2.13 \mu \mathrm{m}$. The microfracture is thin and short. Goethite fills intercrystalline pores and microfractures. Dolomitic limestone, S-7; (F) Previous dissolved intragranular pores are completely filled with calcite crystals (Cal.) and subhedral dolomite crystals (Do.), as well as isolated intracrystalline pores and microfracture. Dolomitic limestone, S-10; (G) Energydispersive spectrometer (EDS) analysis of goethite in sample (E); (H) Illite fills the intergranular pores. (A), (B), (D) and (H) are from the Penglaiba outcrop and (C), (E), (F) and (G) are from the Dabantage outcrop.

Fig. 11 Cross-plots of capillary vs. mercury saturation curves and the PSDs of pore structure types A and B derived from the combination of MICP and $\mathrm{N}_{2} \mathrm{GA}$ tests.

Fig. 12 Cross-plots of capillary vs. mercury saturation curves and the PSDs of pore 
structure types $\mathrm{C}$ and $\mathrm{D}$ derived from the combination of MICP and $\mathrm{N}_{2} \mathrm{GA}$ tests.

Fig. 13 Cross-plots of capillary vs. mercury saturation curves and the PSDs of pore structure types $\mathrm{E}$ and $\mathrm{F}$ derived from the combination of $\mathrm{MICP}$ and $\mathrm{N}_{2} \mathrm{GA}$ tests.

Fig. 14 Cross-plots of porosity vs. permeability in relation to six pore structure types (A) and three lithological types (B) of carbonate cap rock.

Fig. 15 Fractal analysis resulting from the combination of MICP and $\mathrm{N}_{2} \mathrm{GA}$ through double logarithmic cross-plot between $\lg (P c)$ and $\lg \left(1-S_{H g}\right)$ for carbonate cap rocks.

Fig. 16 (A) Fractal dimensions from D1 to D4 of six pore structure types (from Type A to Type F) for 19 carbonate cap rocks in the Tarim Basin; (B) Average fractal dimensions from D1 to D4 of six pore structure types from the analyzed cap rock samples.

$\underline{\text { Fig. } 17}$ Cover coefficient vs. different fractal dimensions of D1, D2, D3, D4, D total, $\mathrm{D}_{\text {avg. }}$ of the Yingshan Fm. carbonate cap rocks in the Tarim Basin.

Fig. 18 Correlations of the average cover coefficient with average D1 (A), average D3 (B) and calculated cover coefficient (C) of six pore structure types of carbonate cap rocks in the Tarim Basin.

Fig. 19 Three-dimensional visualization representing the relationships of average D1, average D3 and average cover coefficient for six pore structures in the carbonate cap rocks from the Tarim Basin. 
Fig. 20 Pore size distributions and proportion of macropores, mesopores, transitional pores and micropores of six pore structure types of carbonate cap rocks of the Ordovician Yingshan Fm. in the Tarim Basin.

Fig. 21 Relationships between the proportion of pore volume of different pore sizes and the average fractal dimensions of the six pore structures defined for the Tarim Basin Ordovician Yingshan Fm. carbonate cap rocks. (A) Transitional pore (10-100 nm); (B) Mesopore (100-1,000 nm); (C) Macropore (>1,000 nm); (D) Macropore (>2,500 nm) proportions.

Fig. 22 Three classes Ordovician Yingshan Fm. carbonate cap rocks classified according to their pore throat structures, fractal characteristics and sealing performance at four outcrops in the Tarim Basin. 

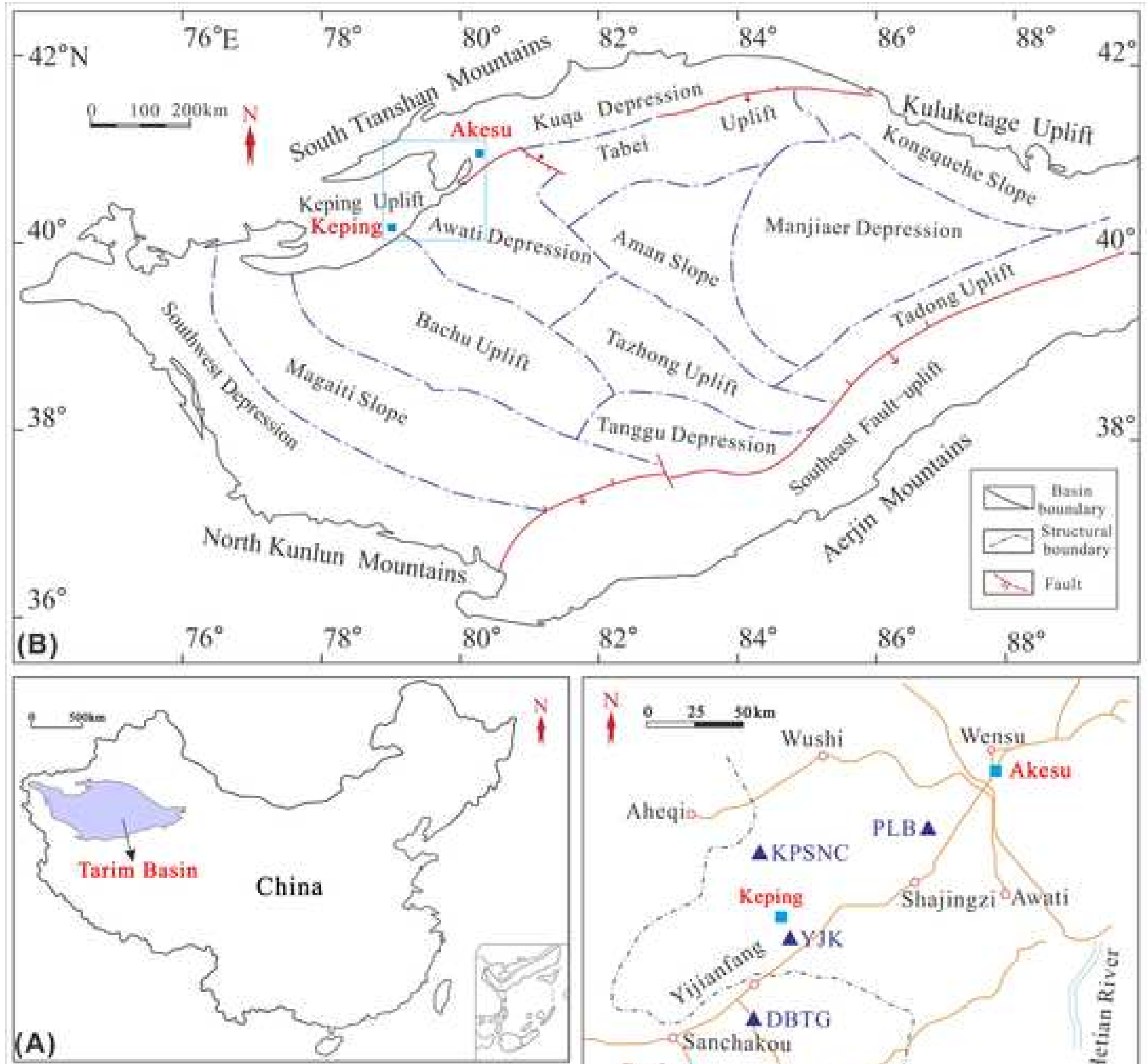

$\square$ Road $\square$ Administative boundary

$\boldsymbol{\Delta}$ Outerop

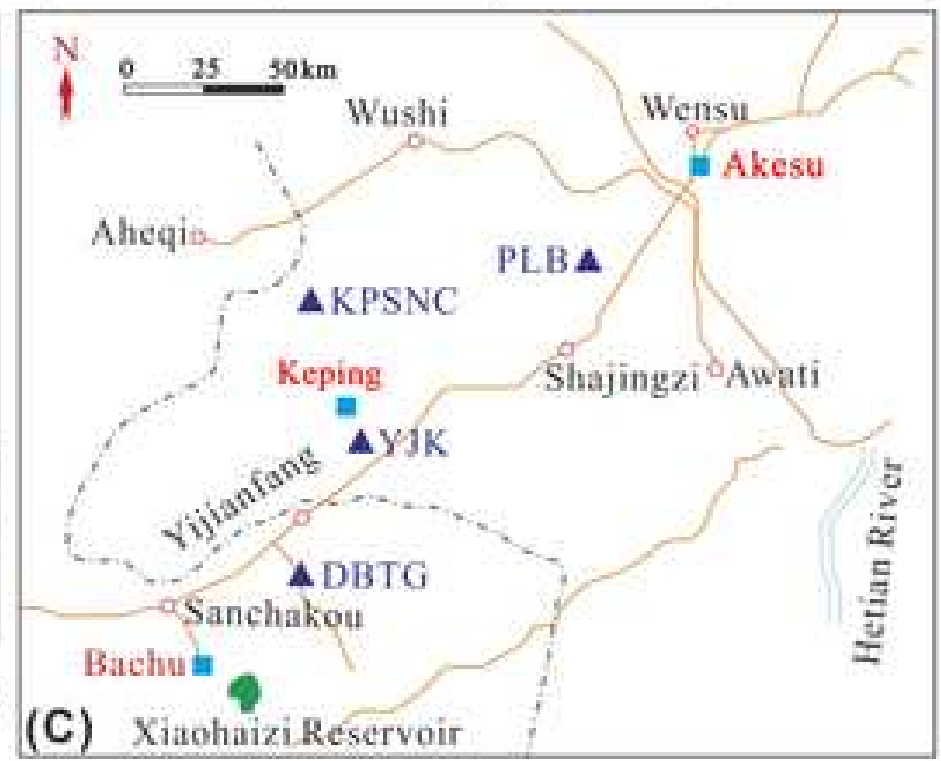




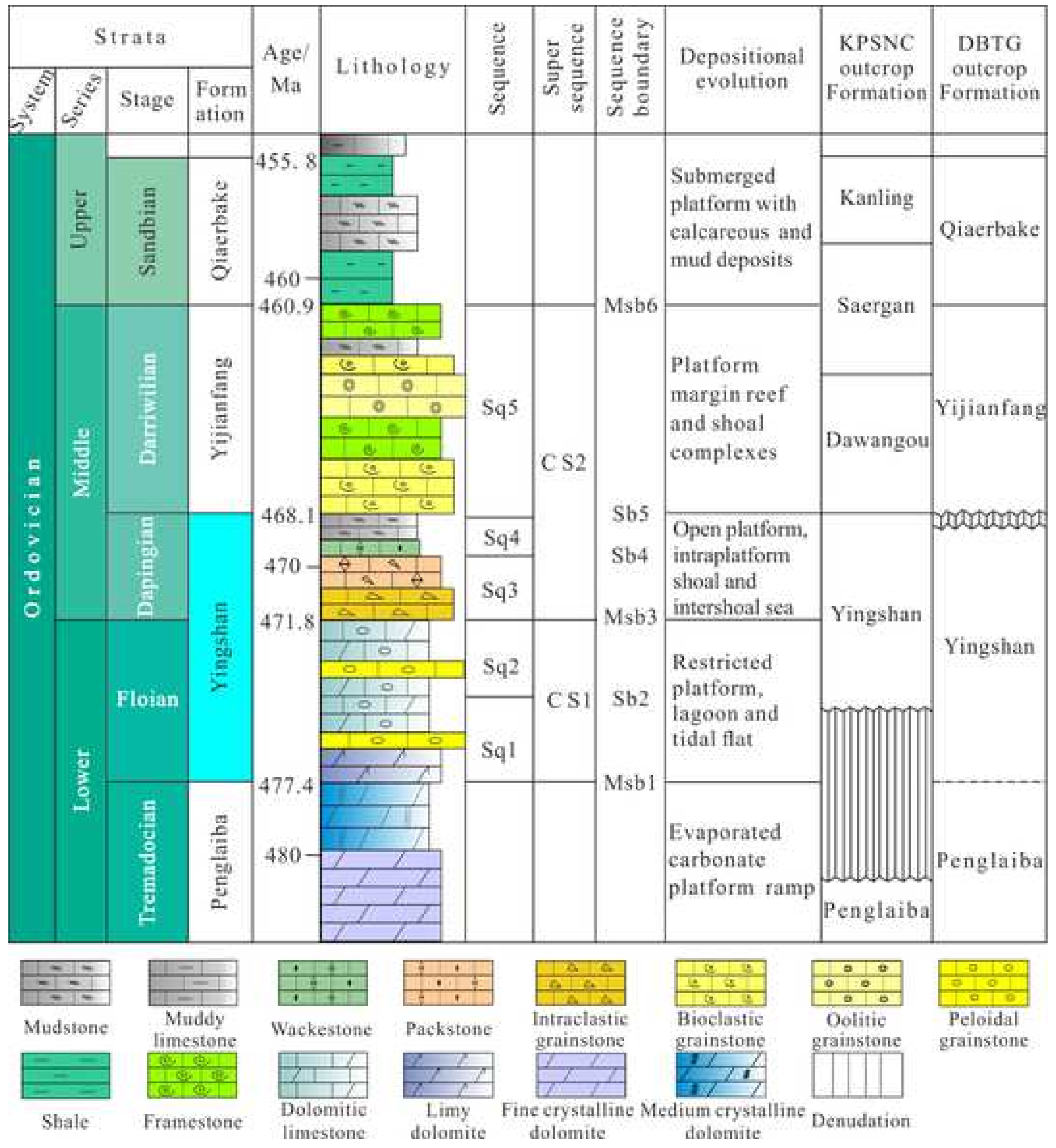




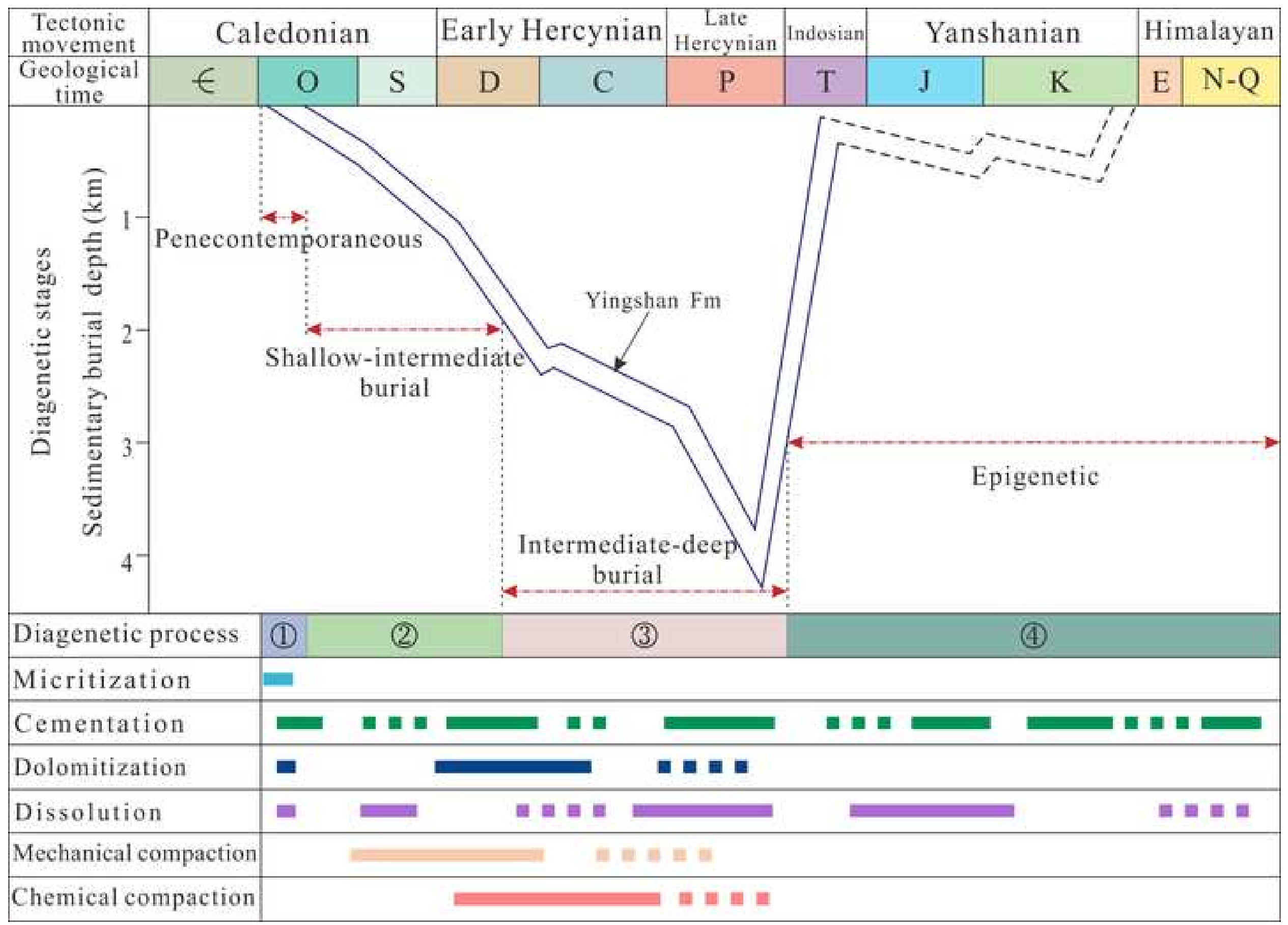




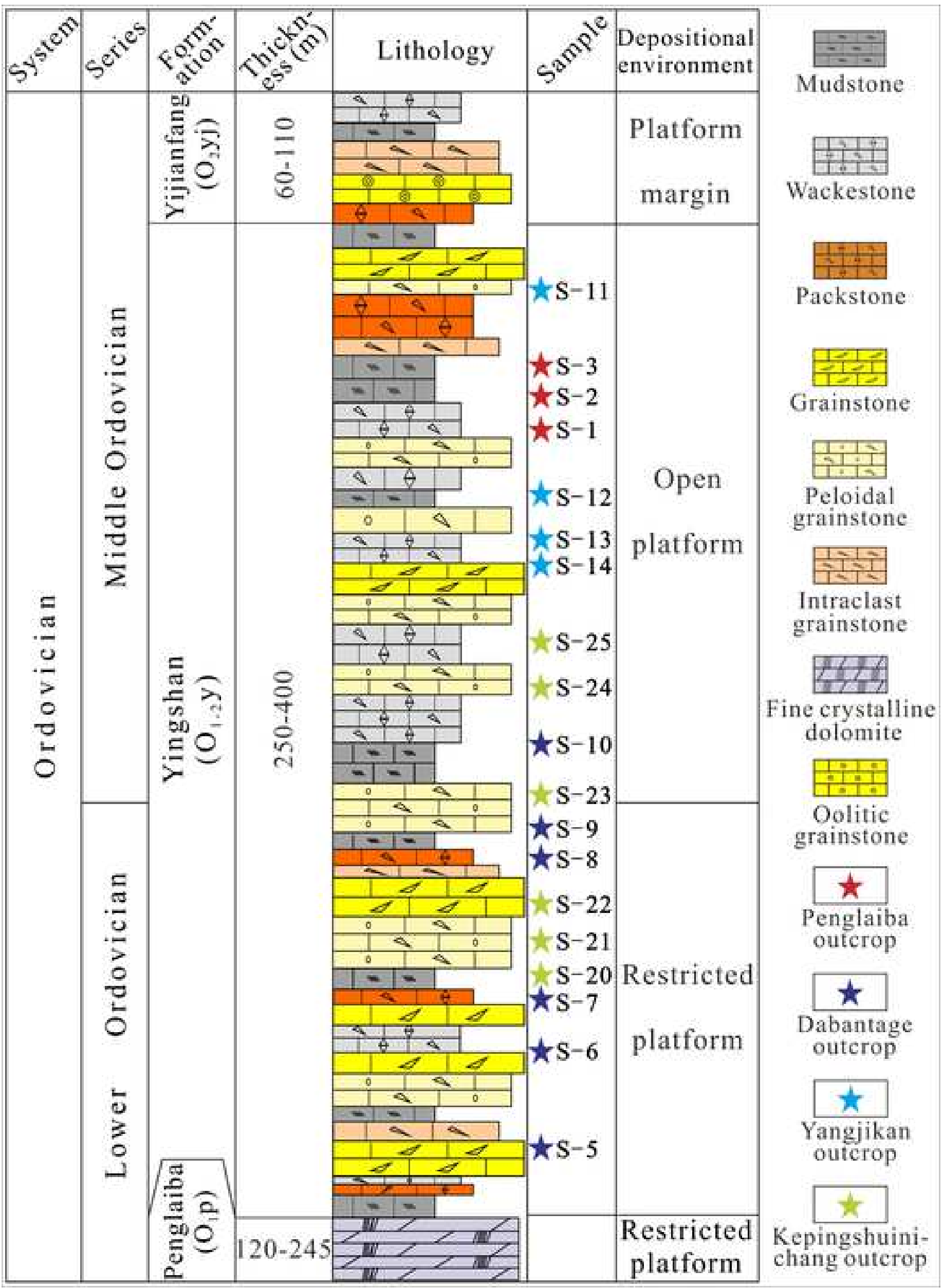



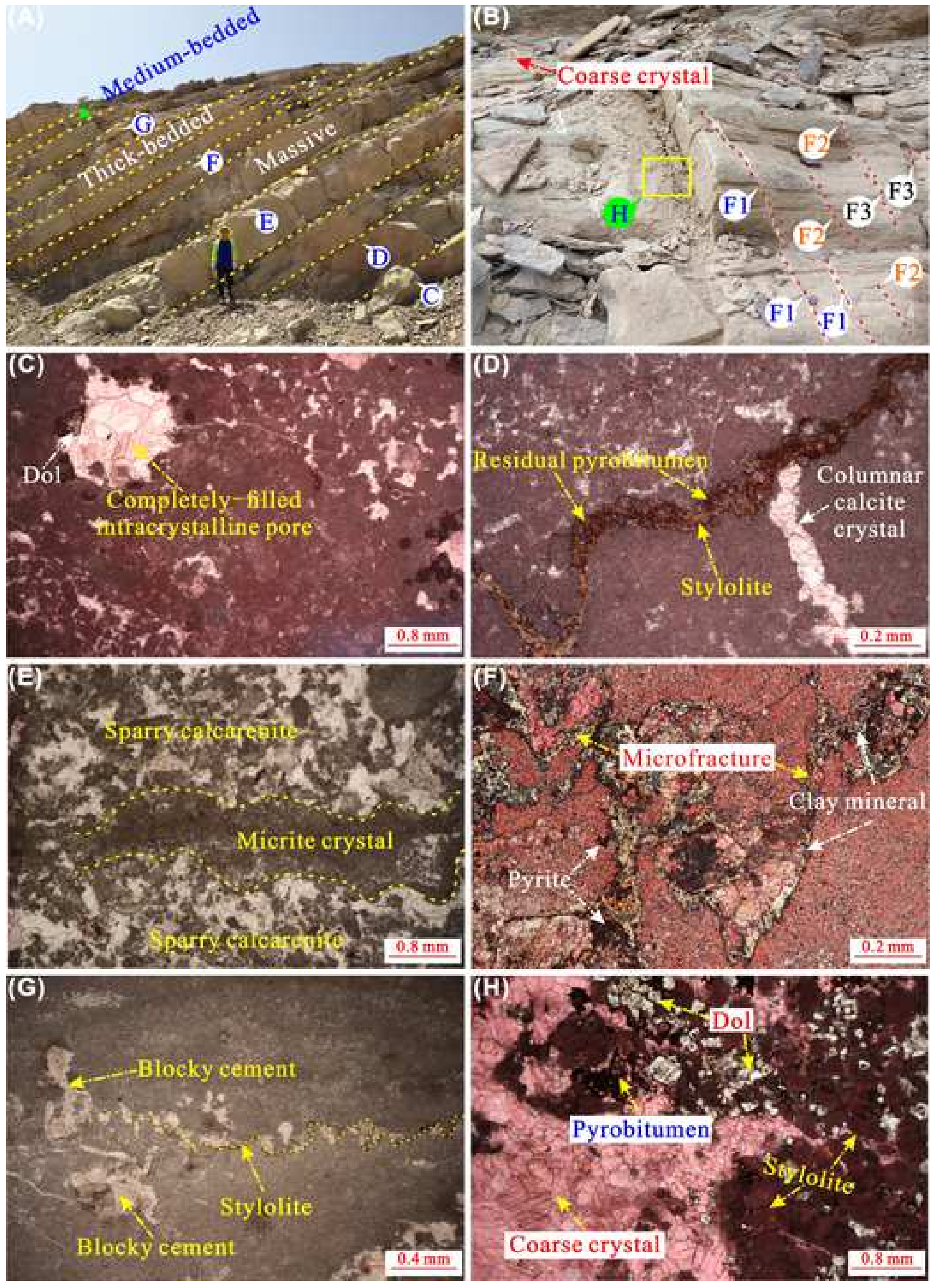

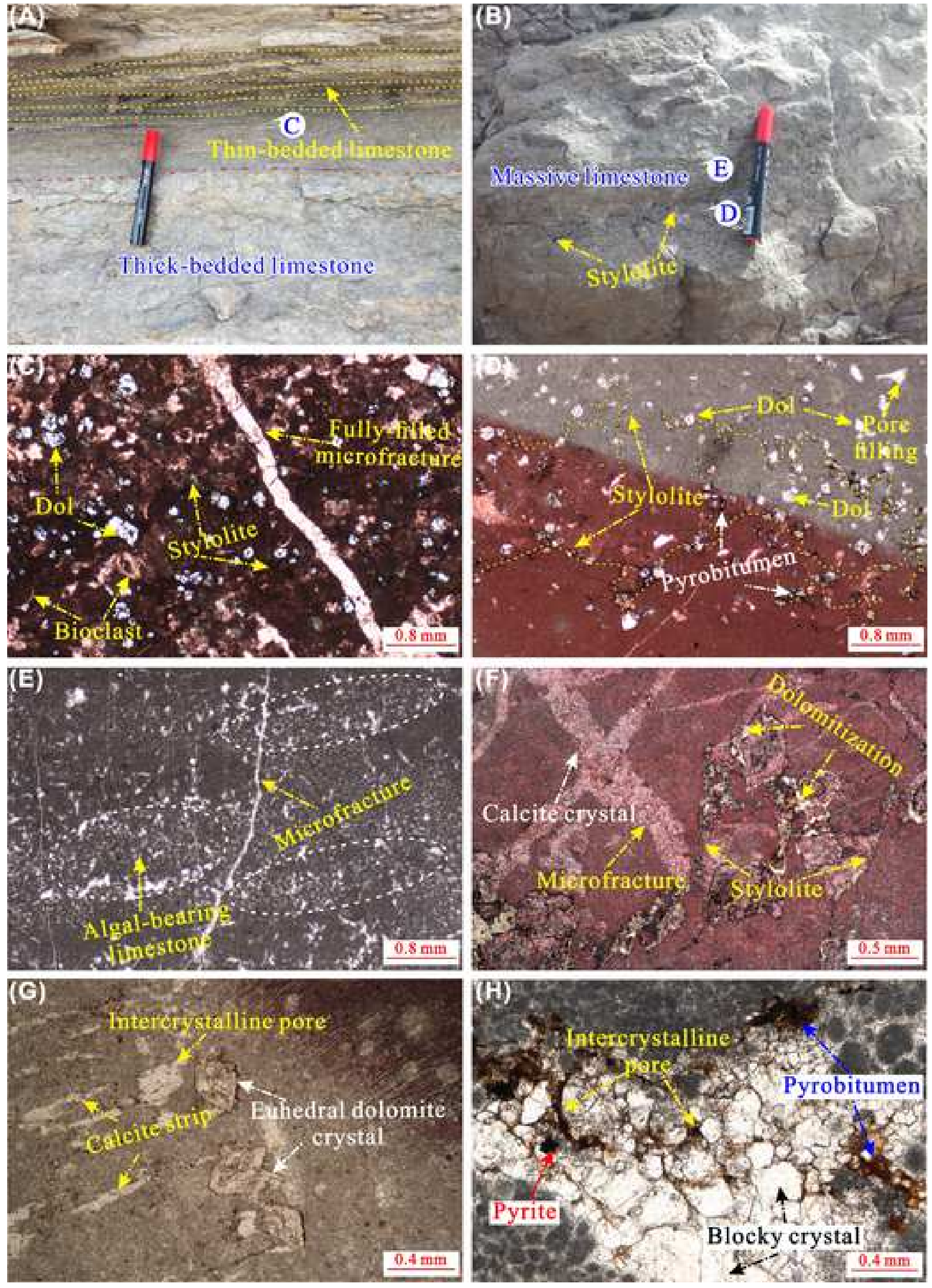

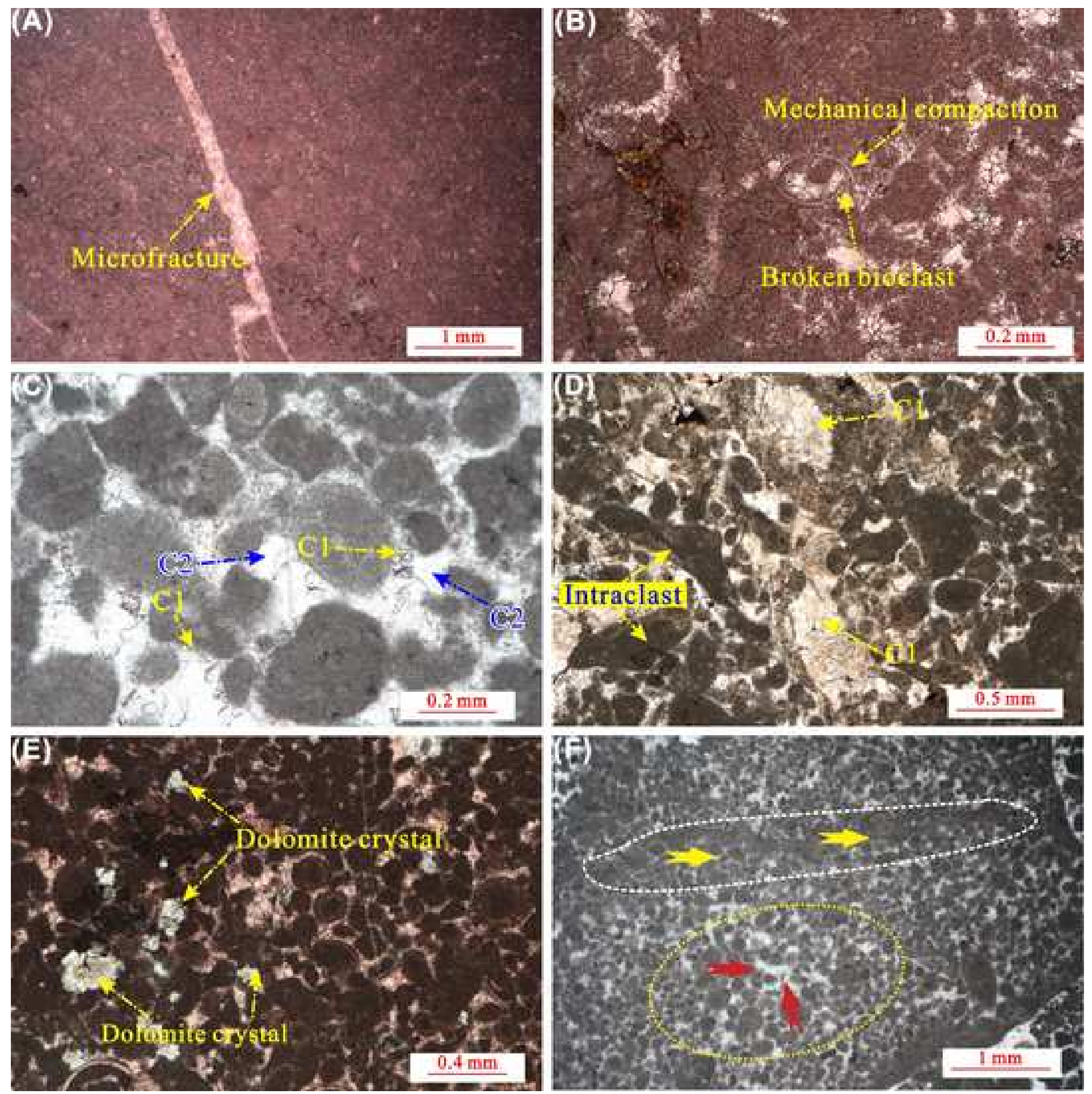

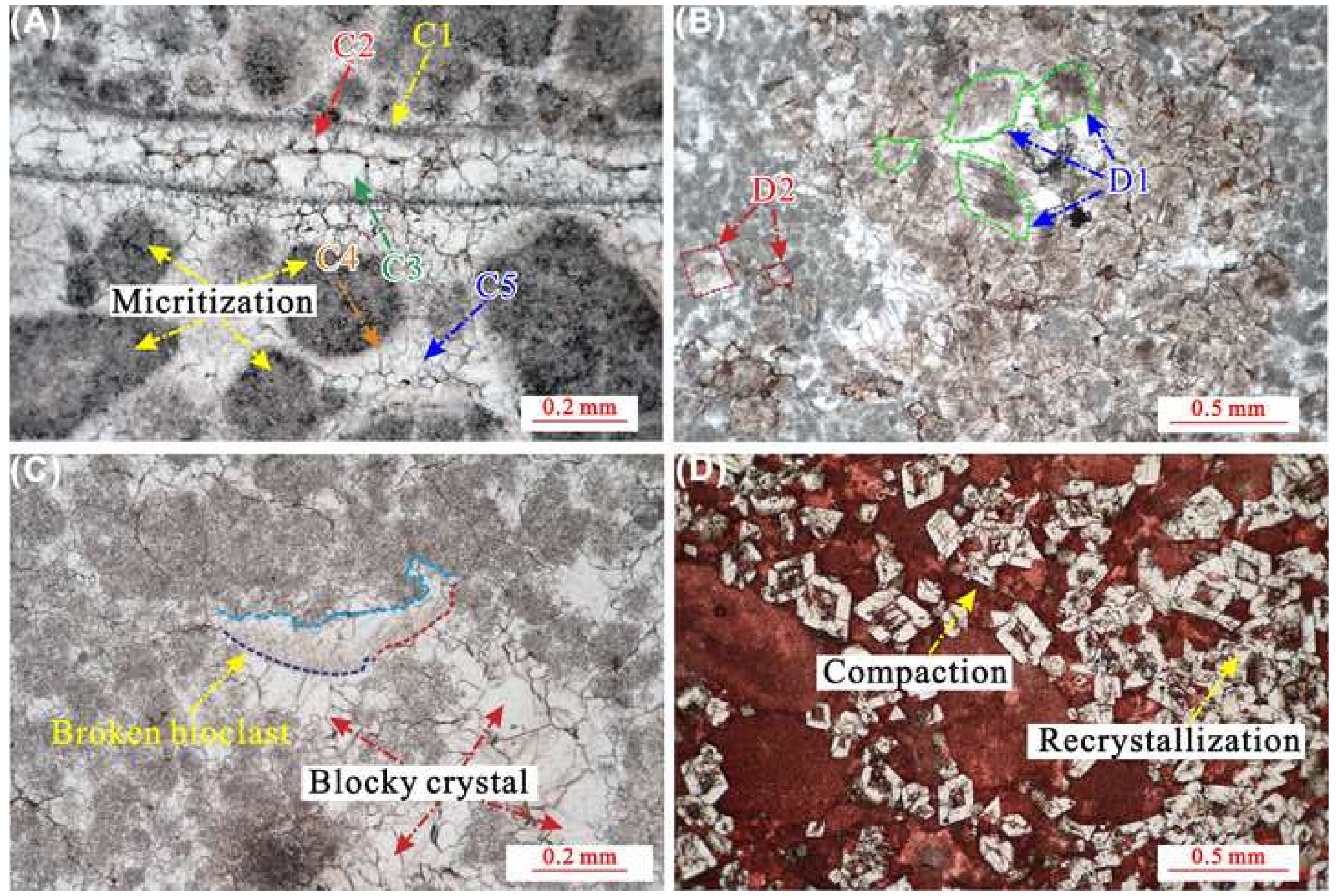

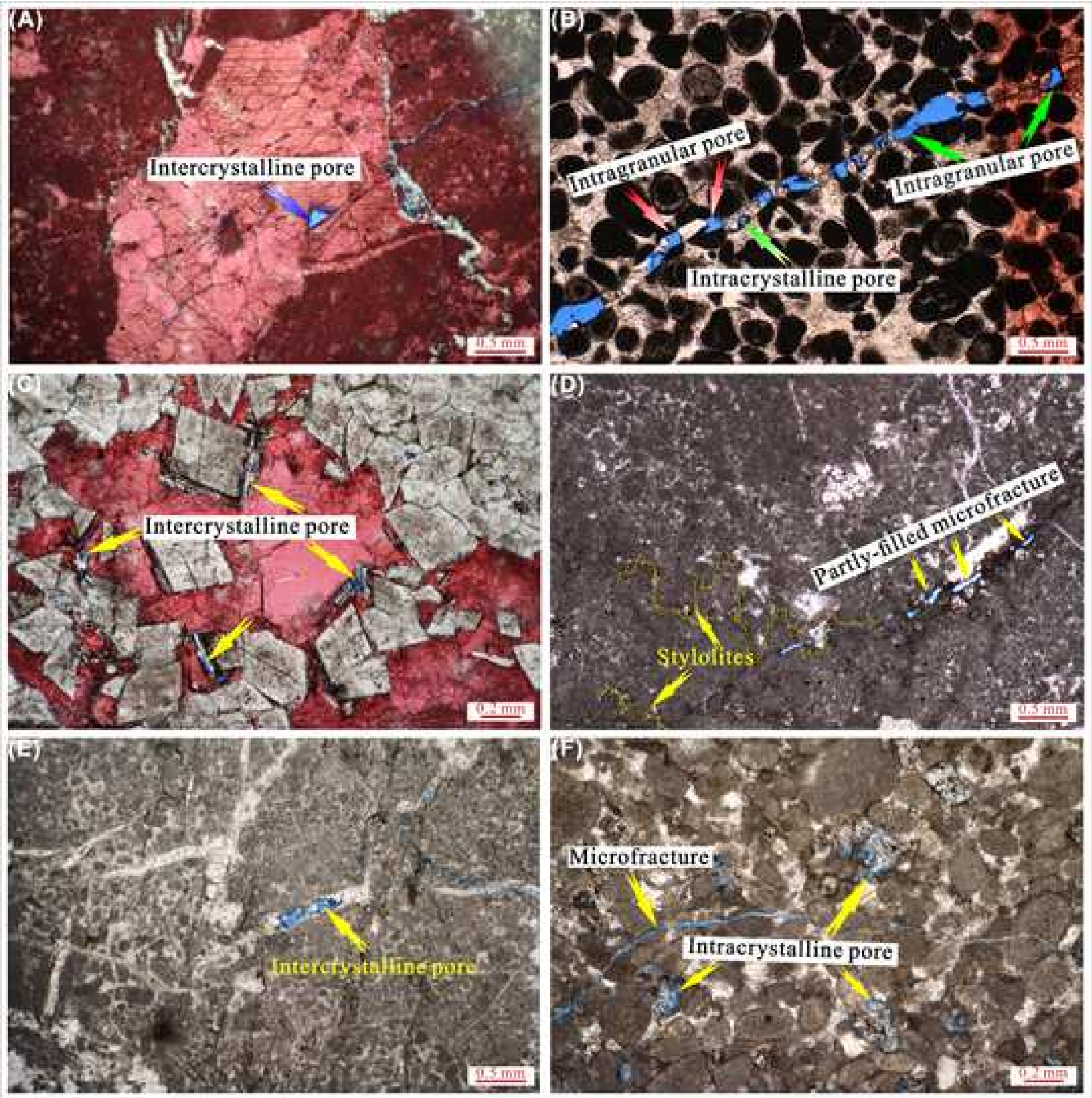

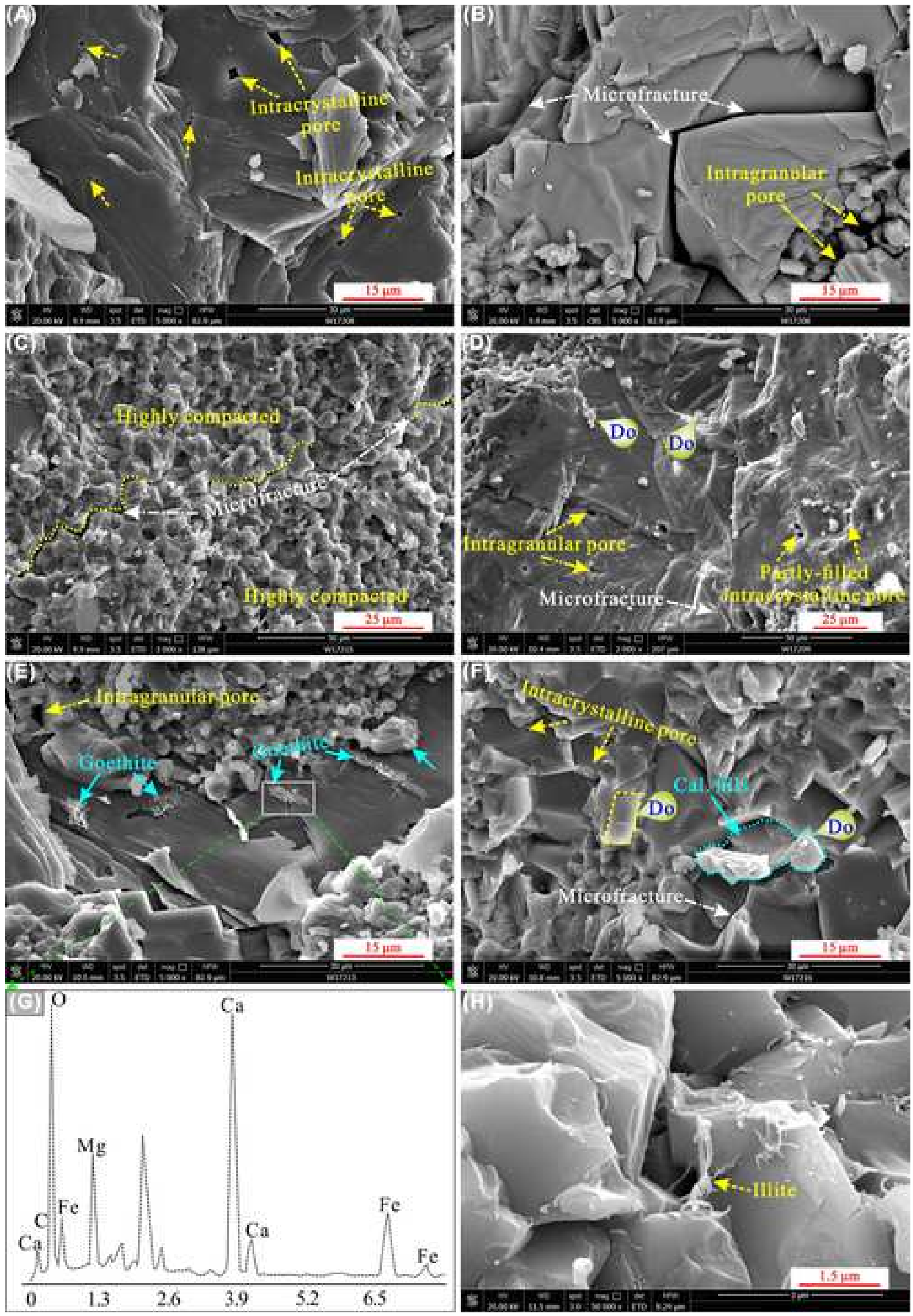

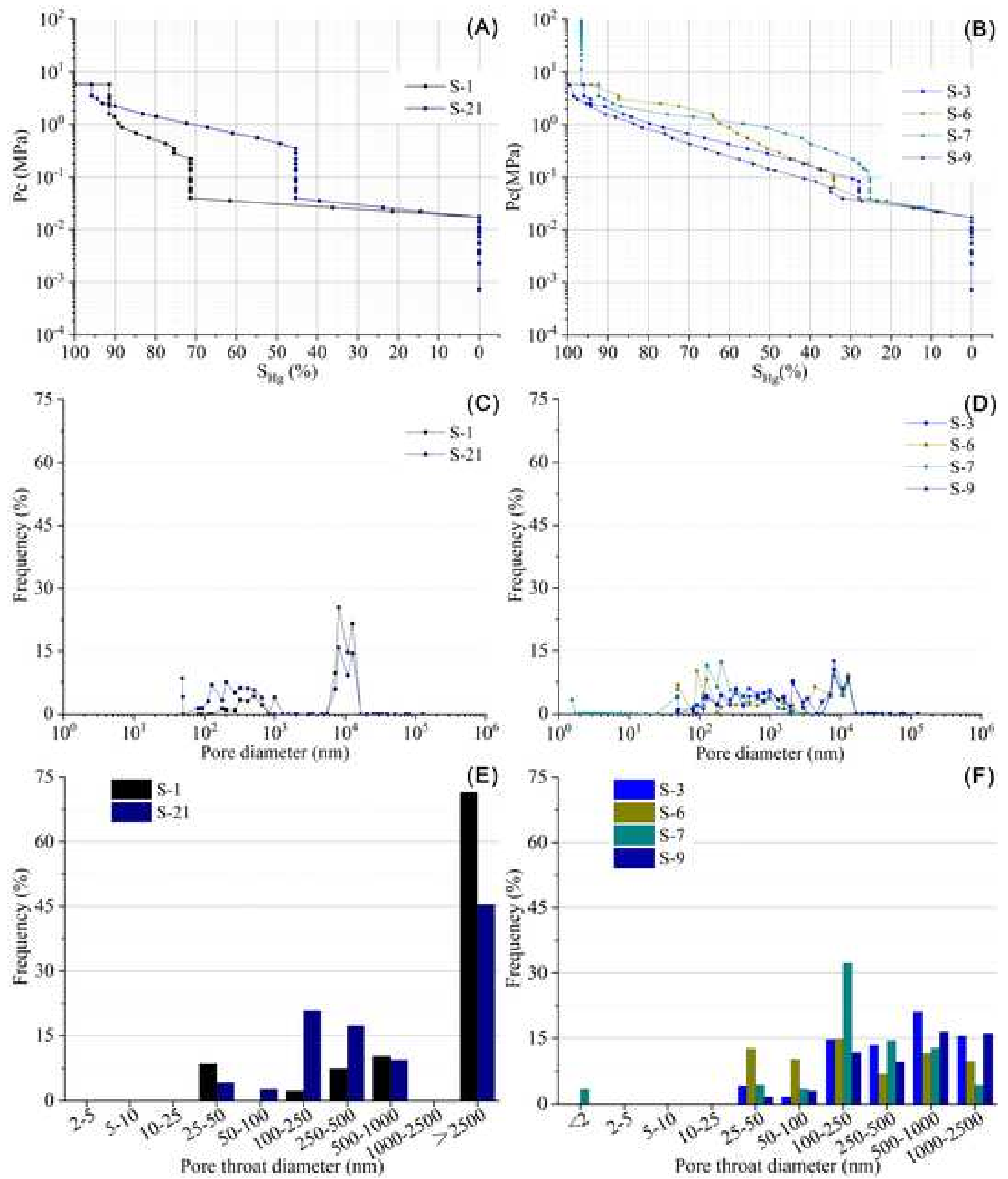

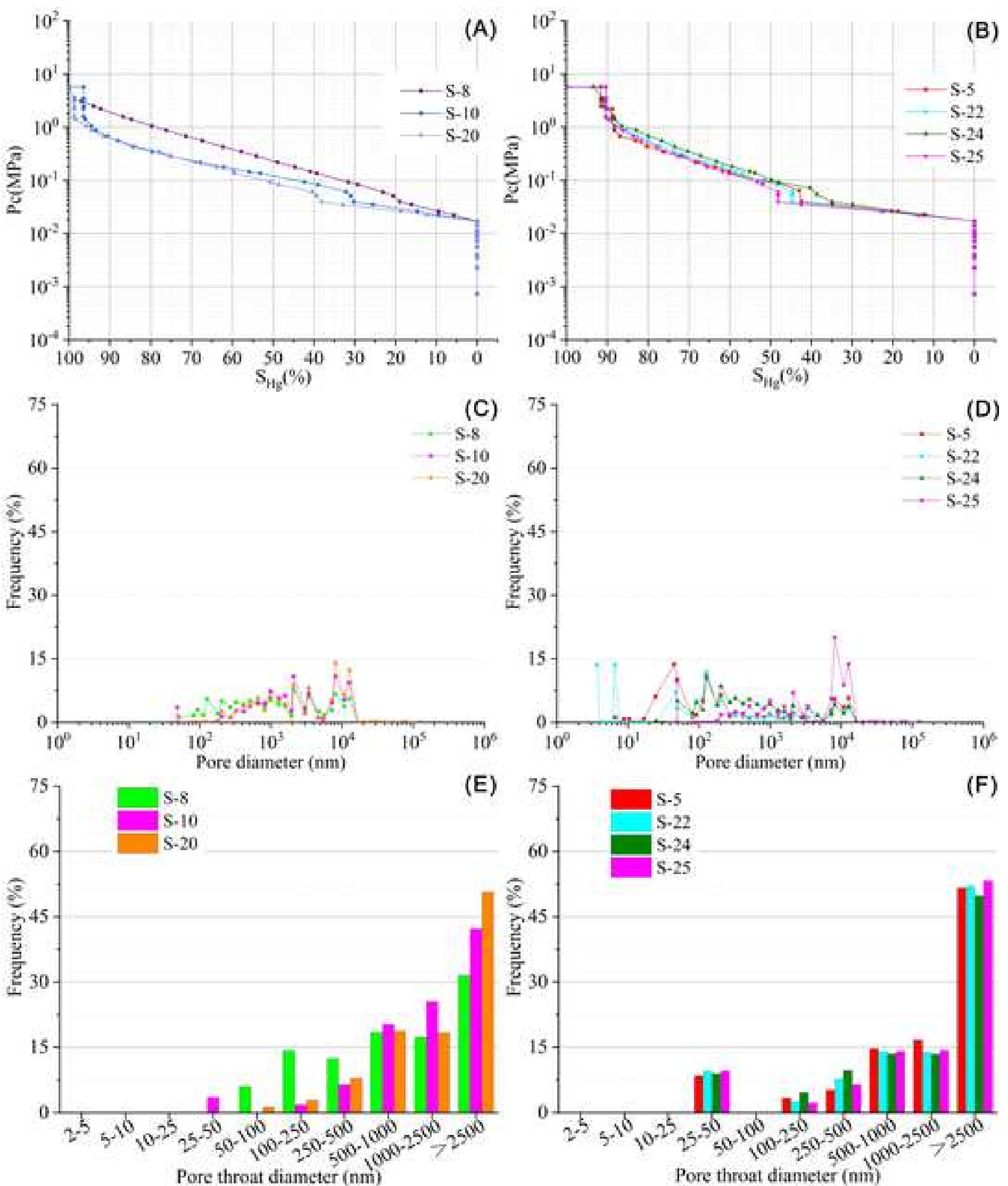

(E)

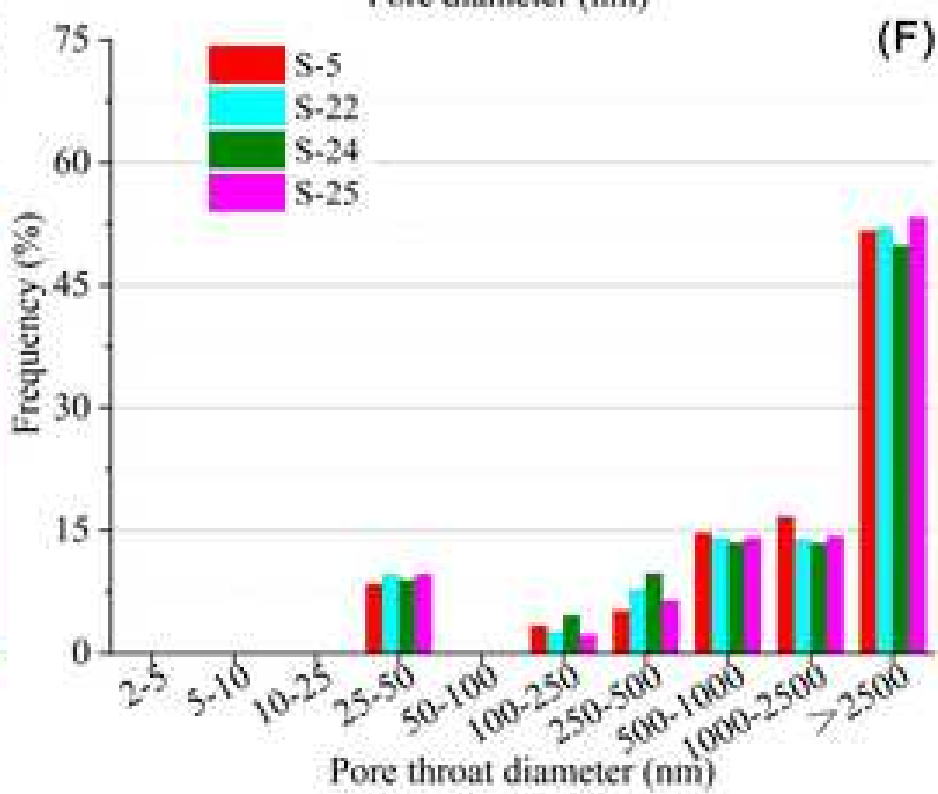

(F)

Pore throat diameter (nm) 

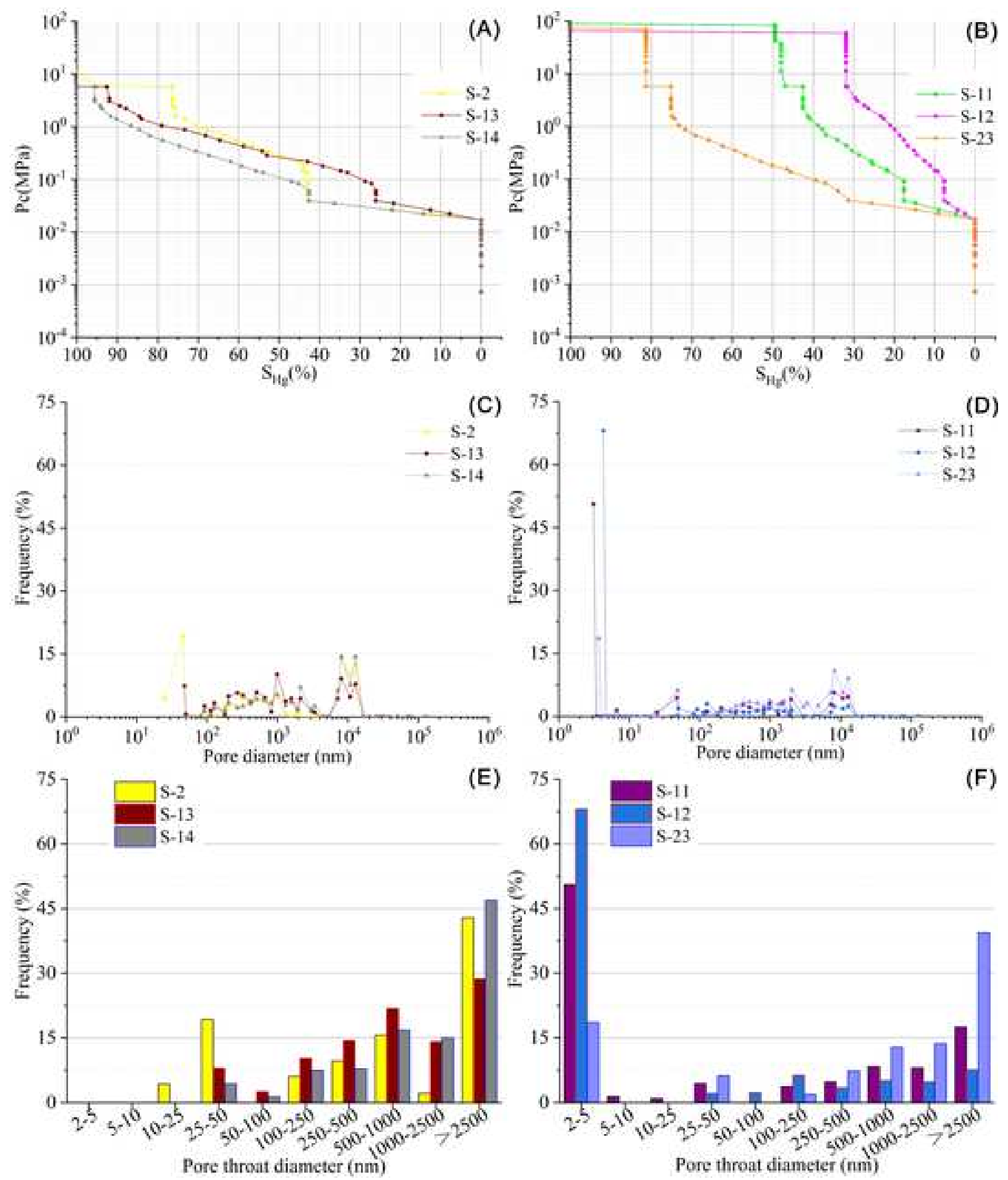

(F)

Pore throat diameter (nm) 

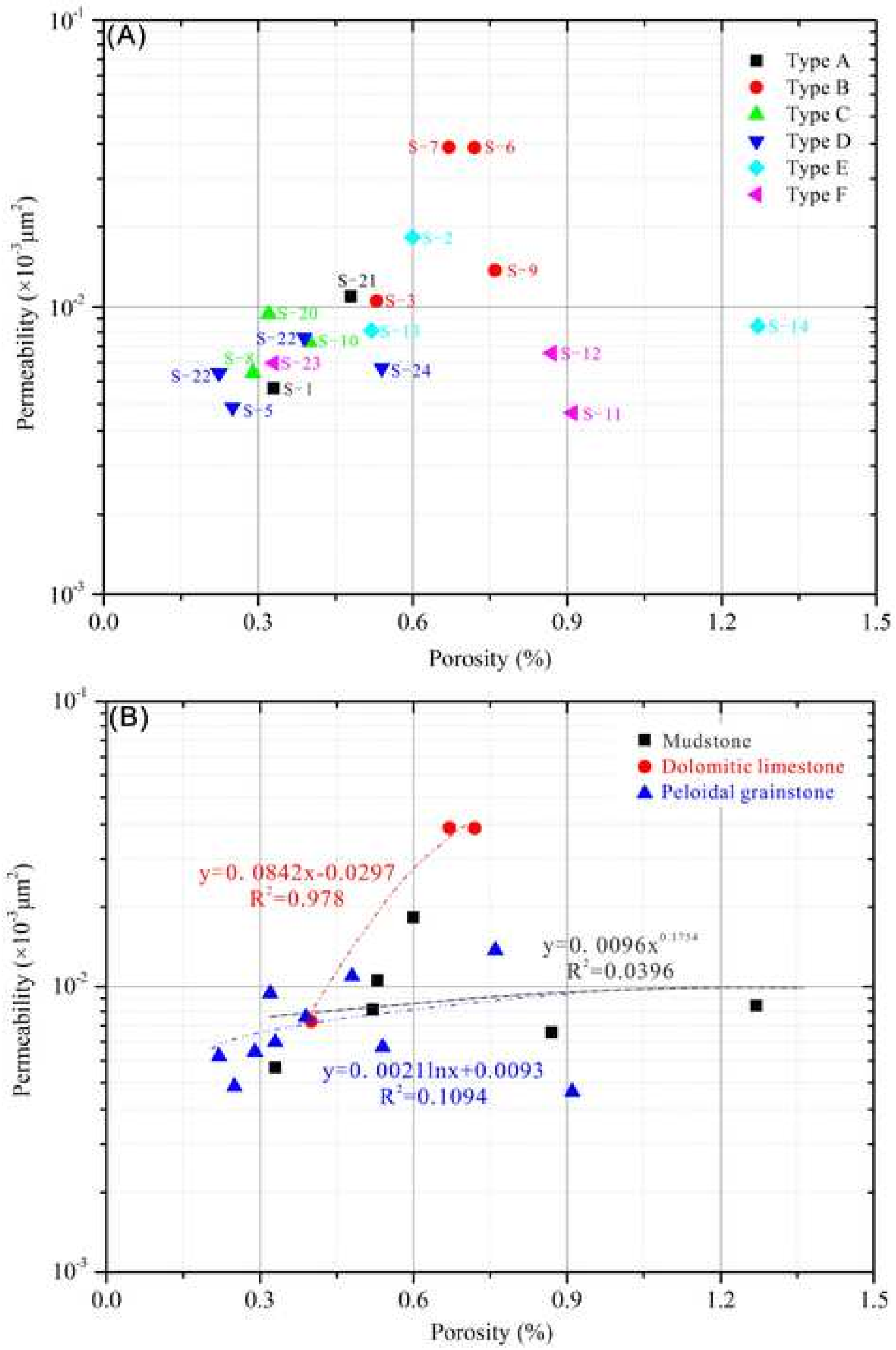

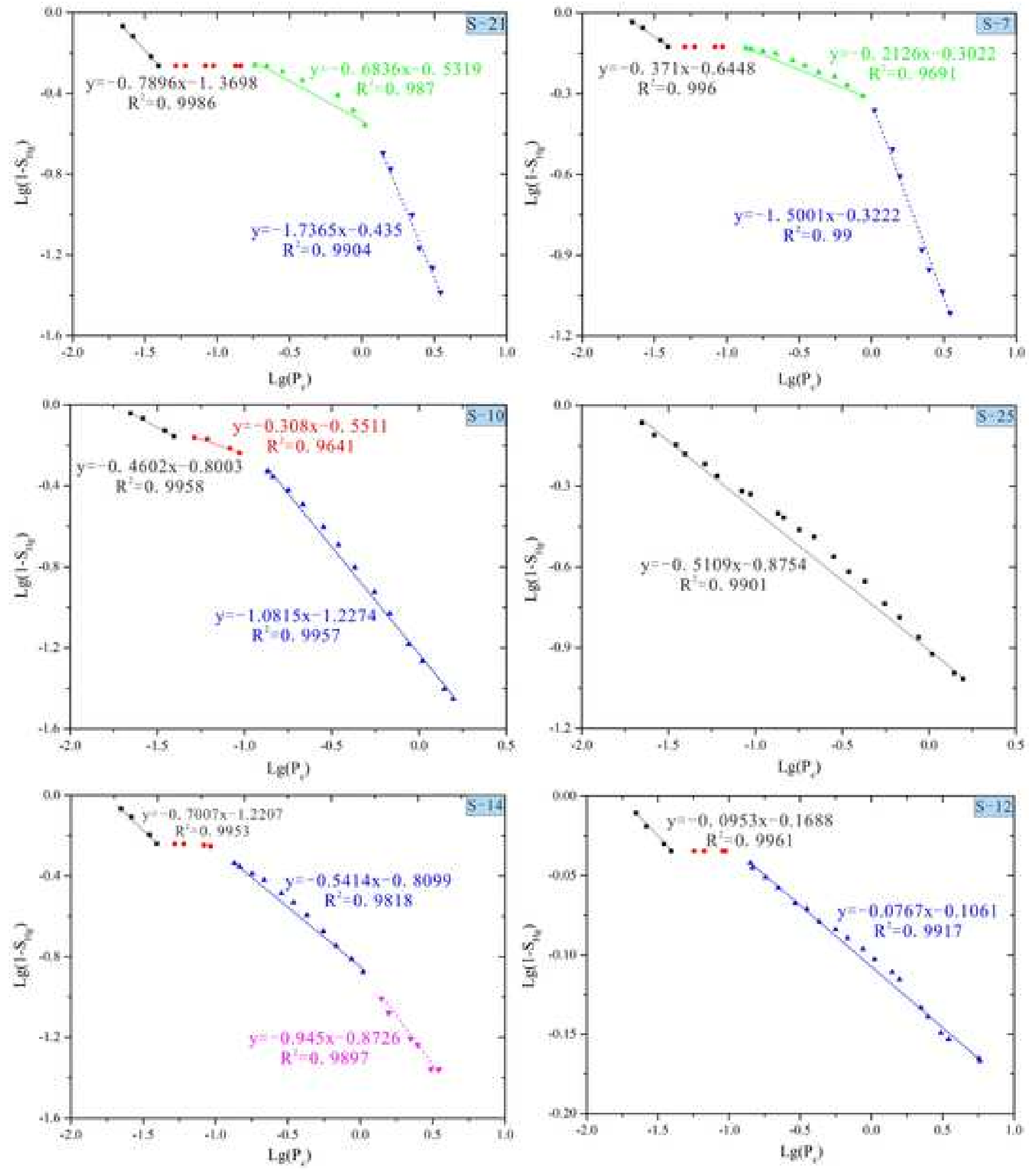

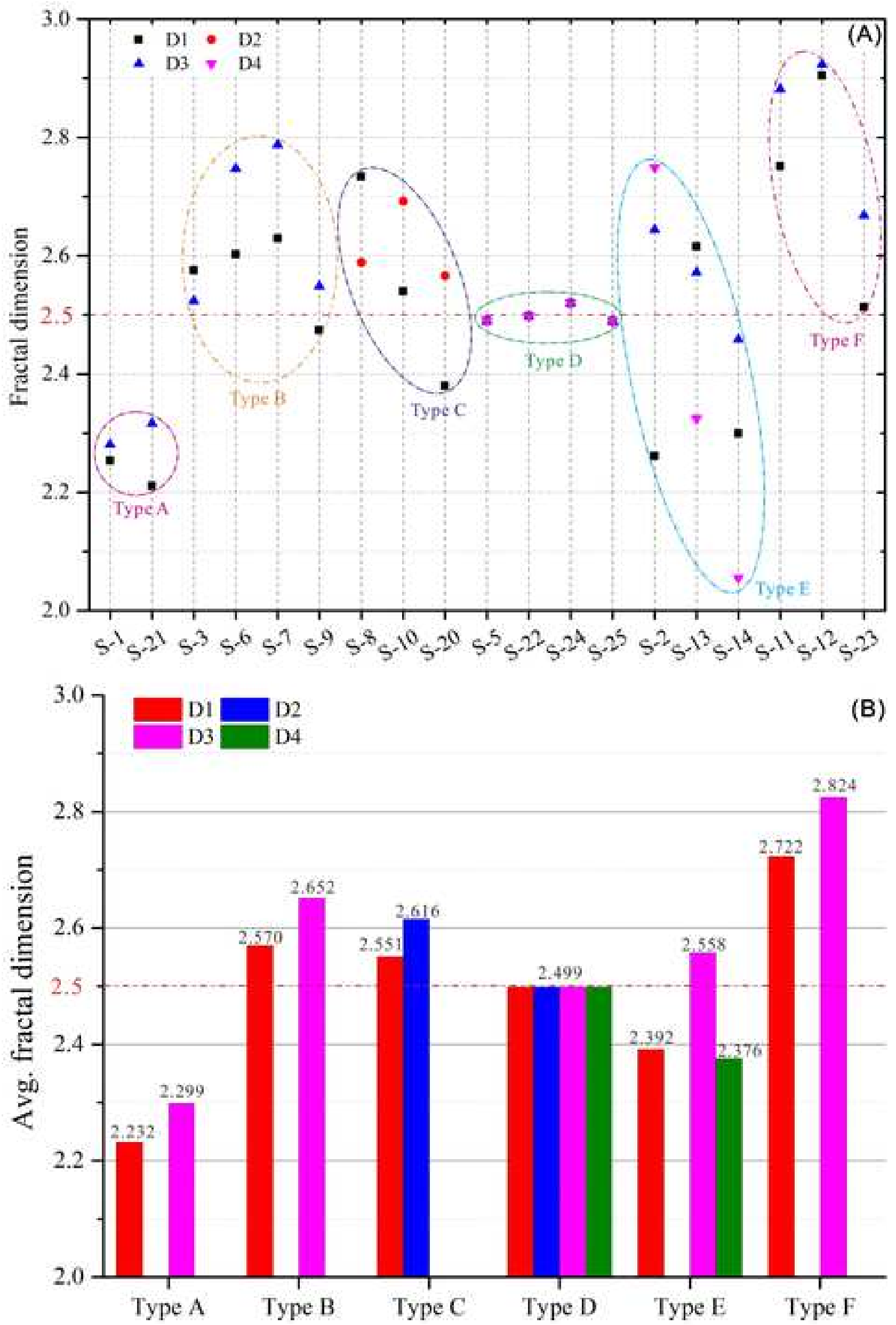

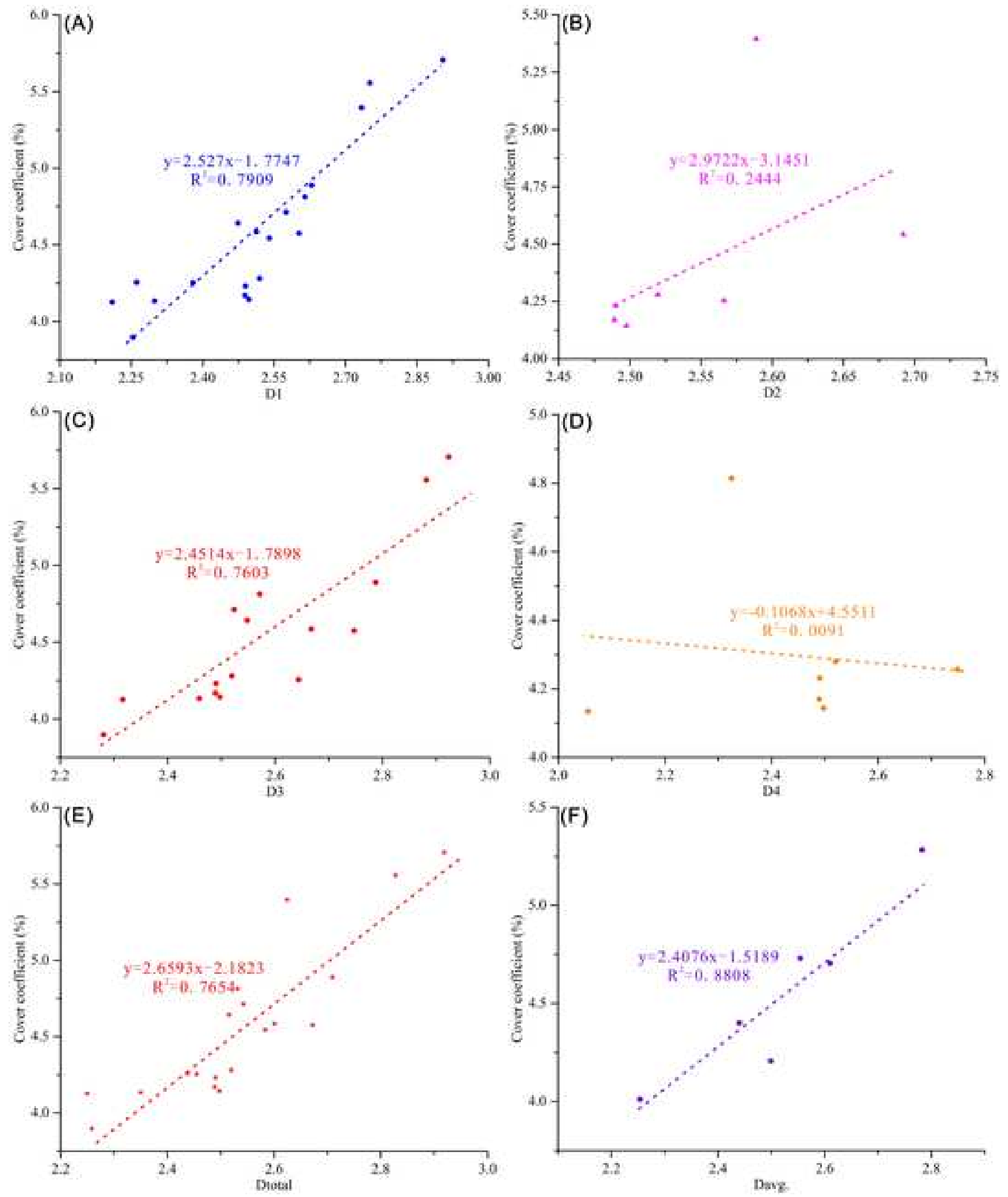
Figure 18
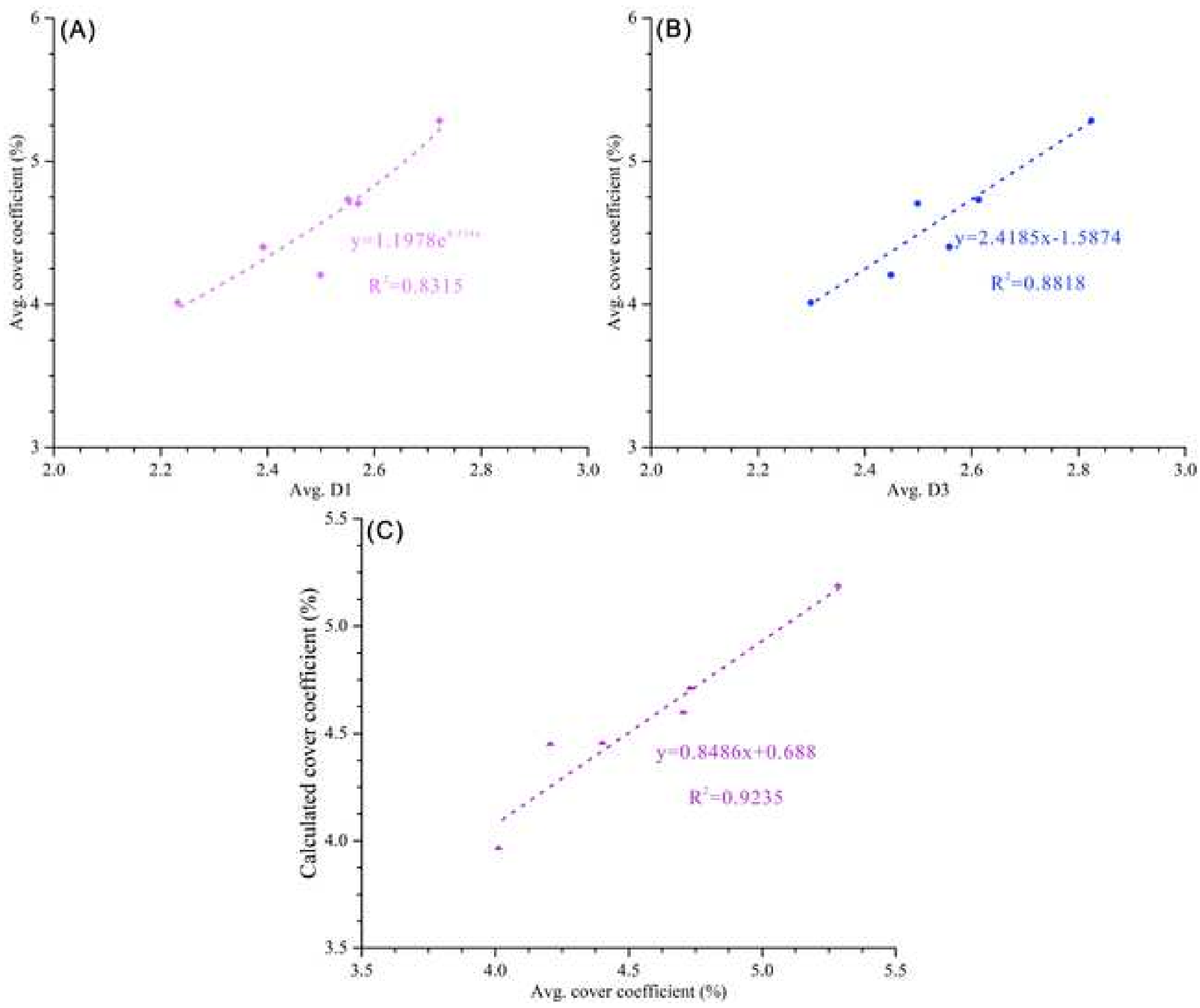


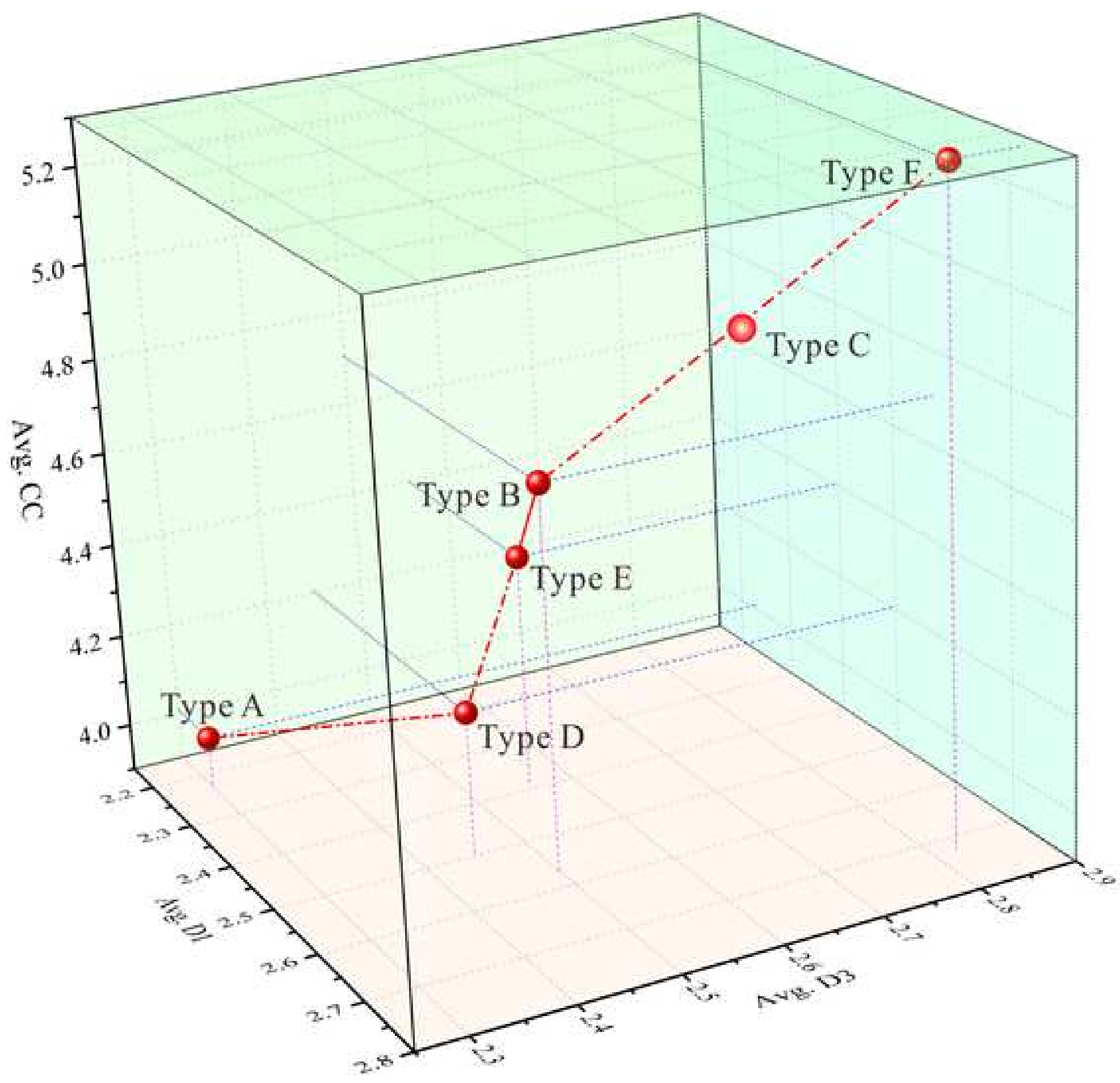




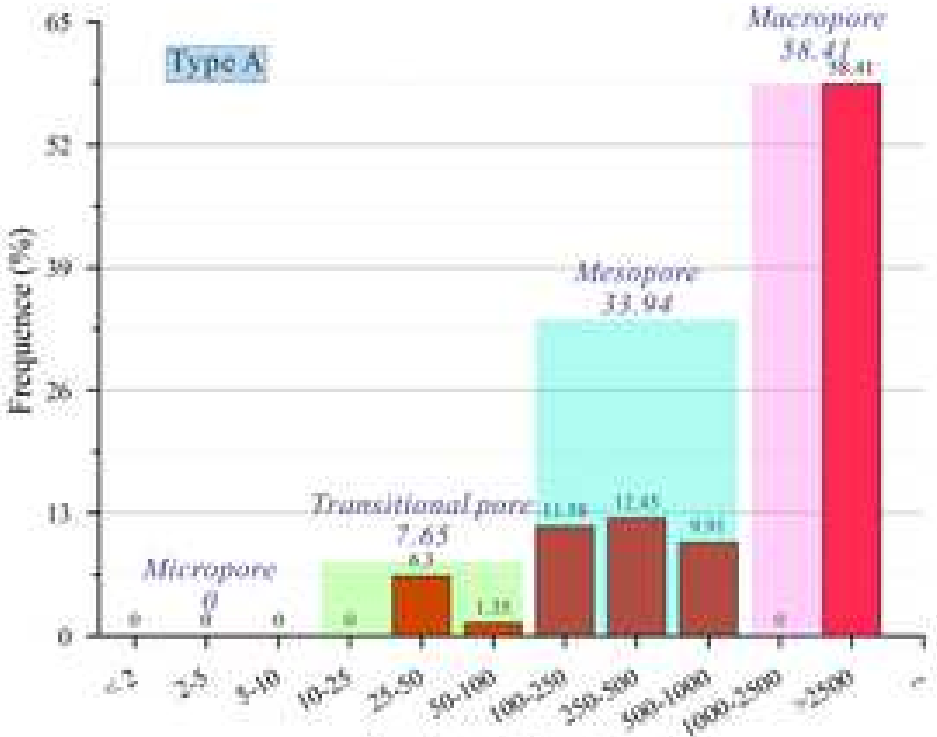

Pore throas diameter (nm)

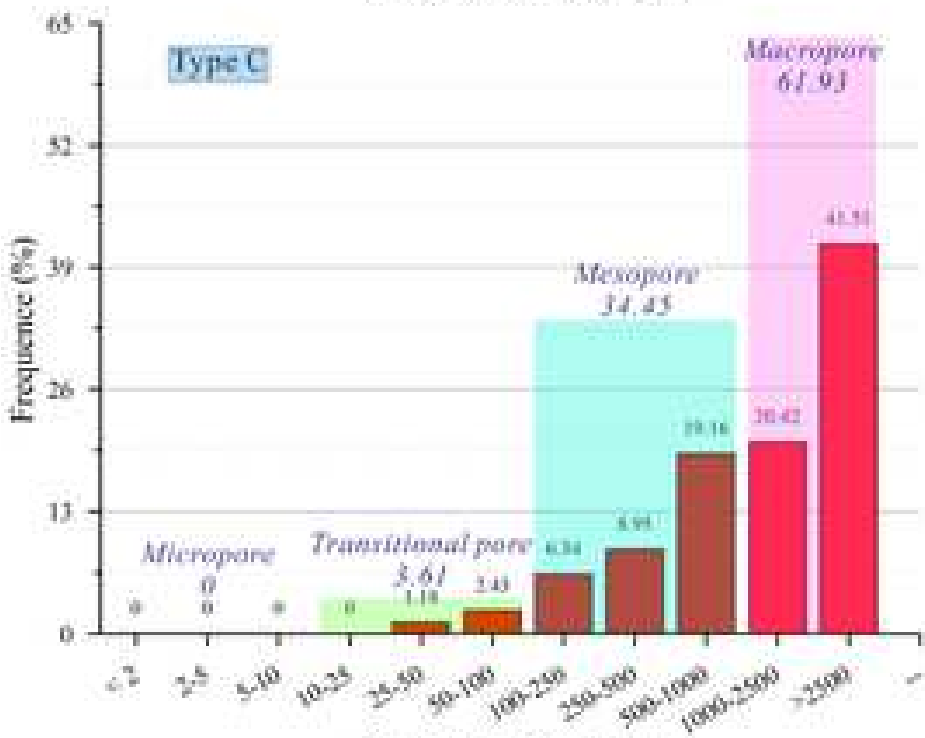

Pore throat diameter (nm)

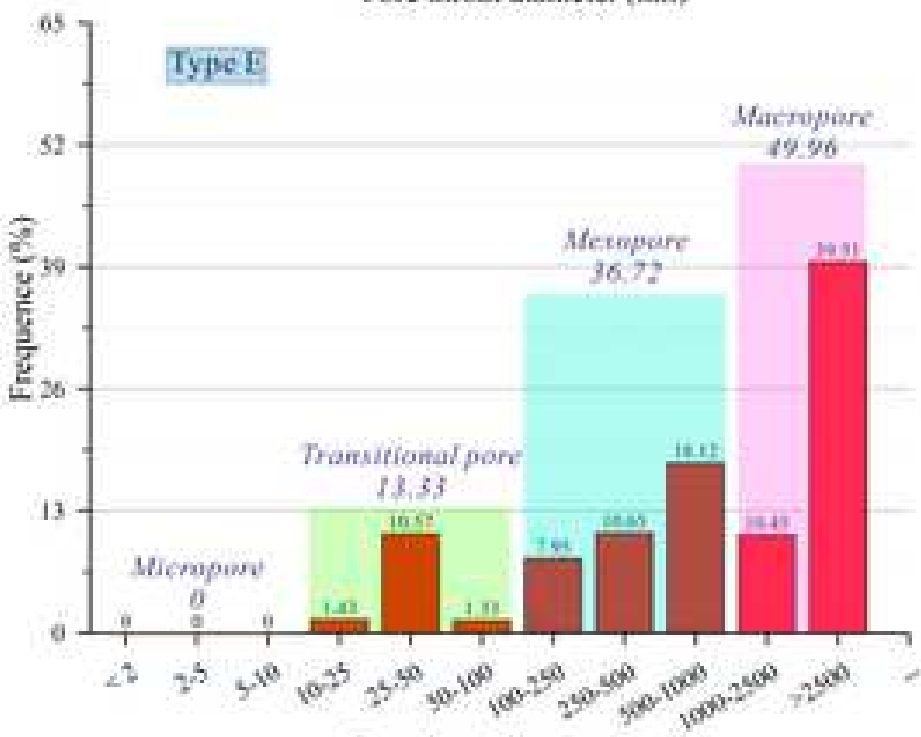

Pore throat diameter (nm)

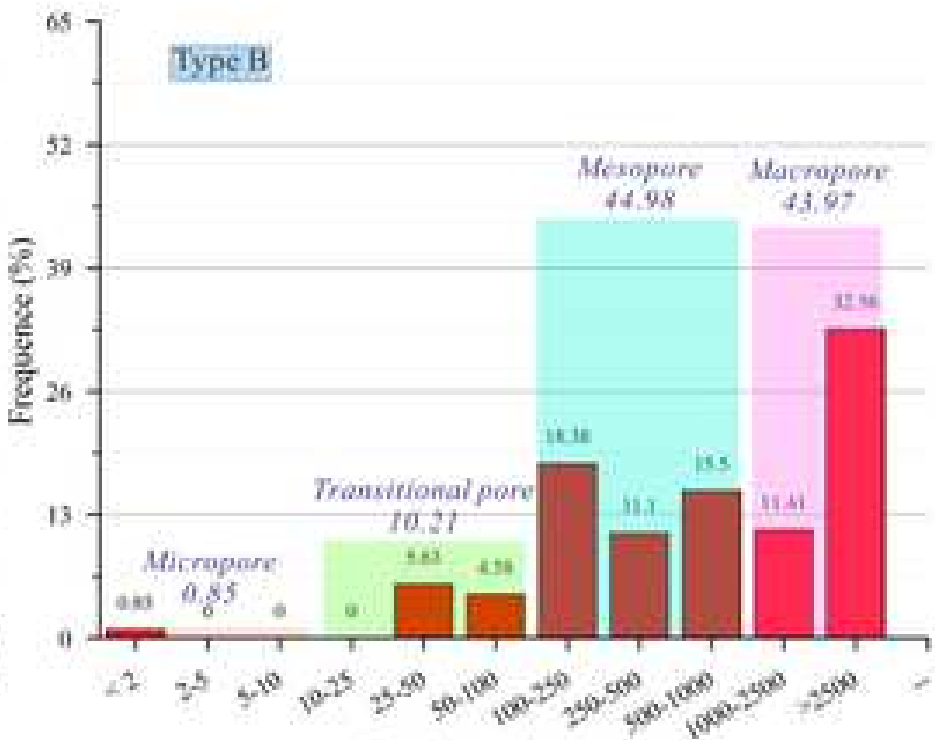

Porc throat diameter (nm)
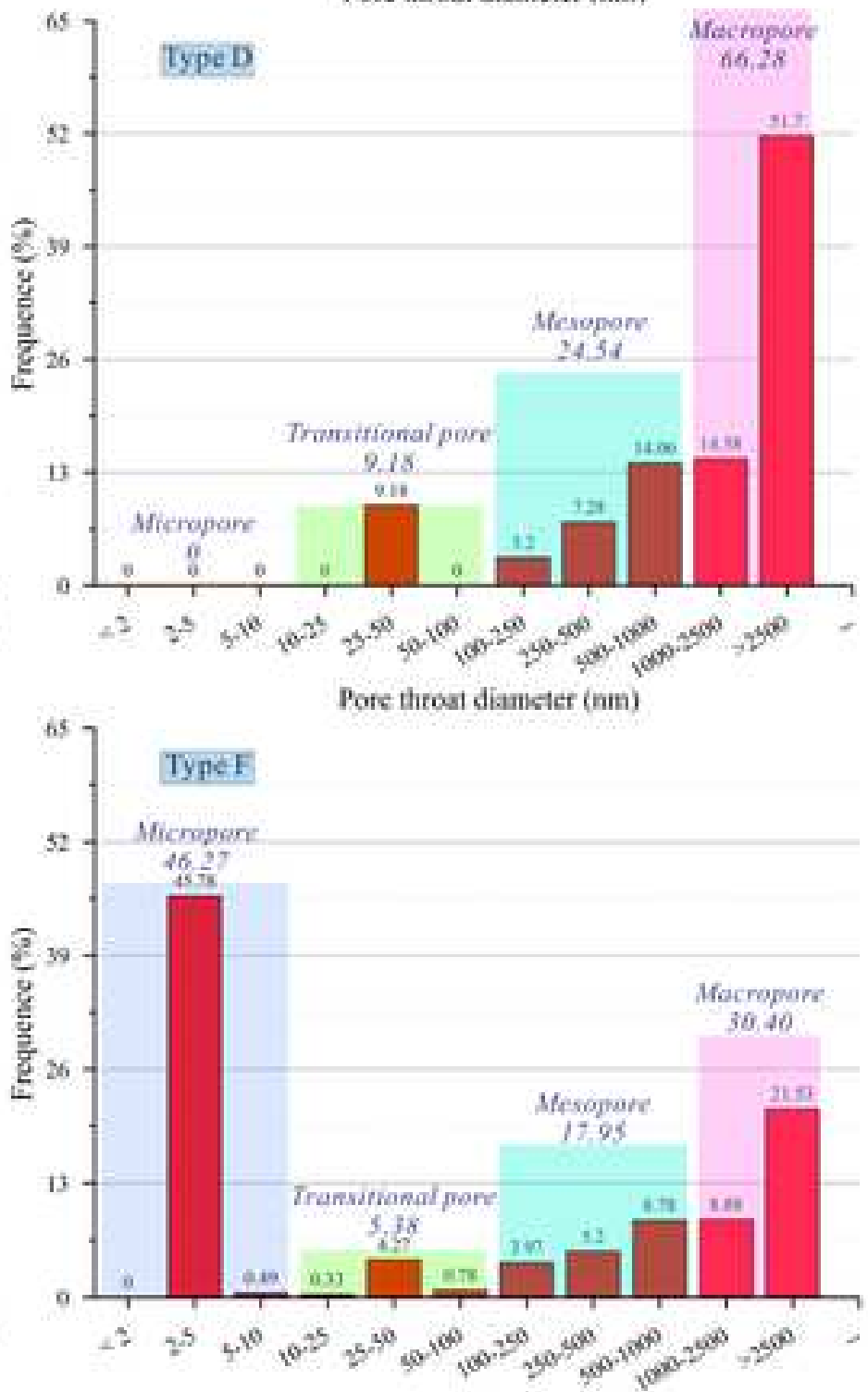

Pere throat diancter (mm) 

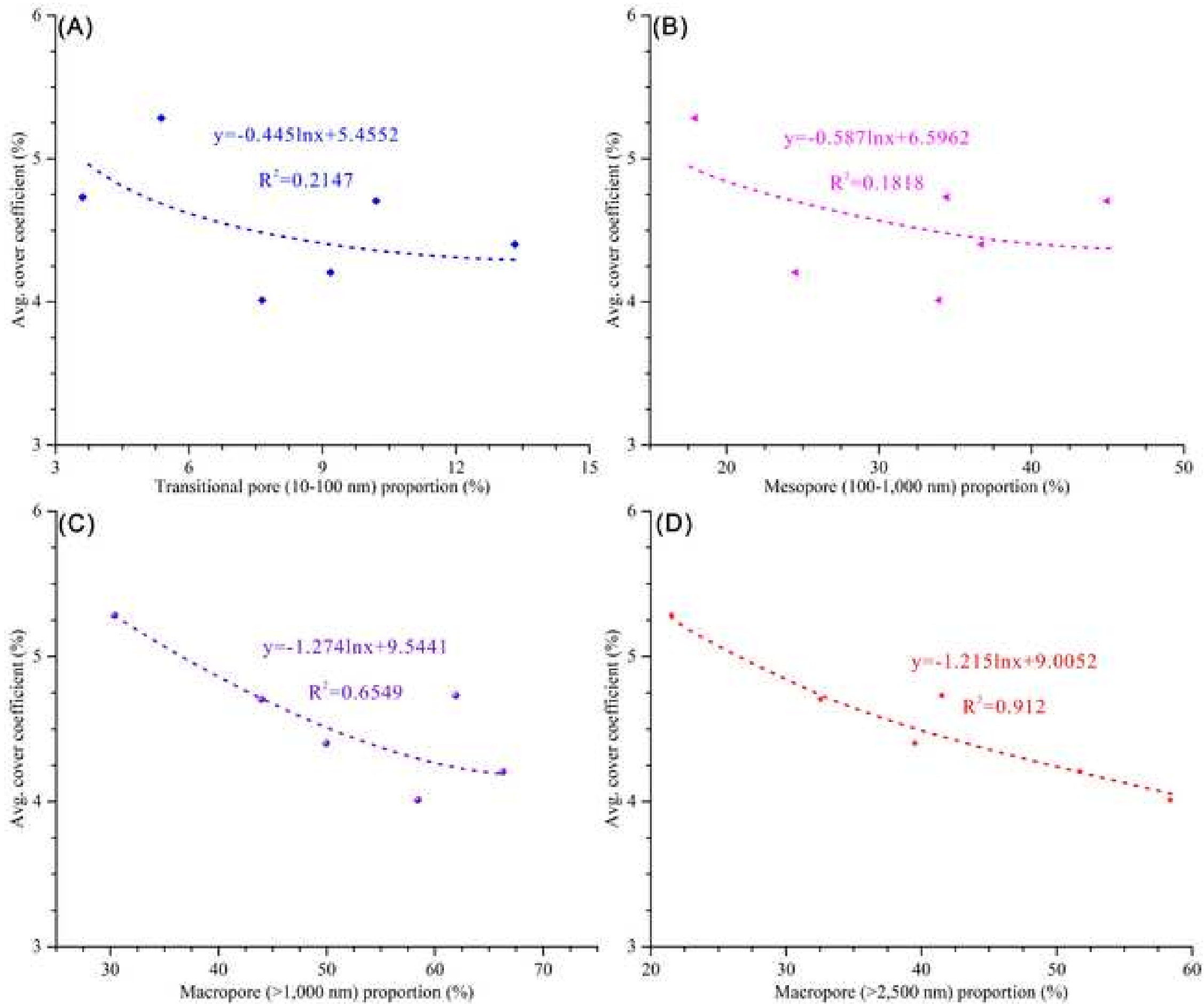


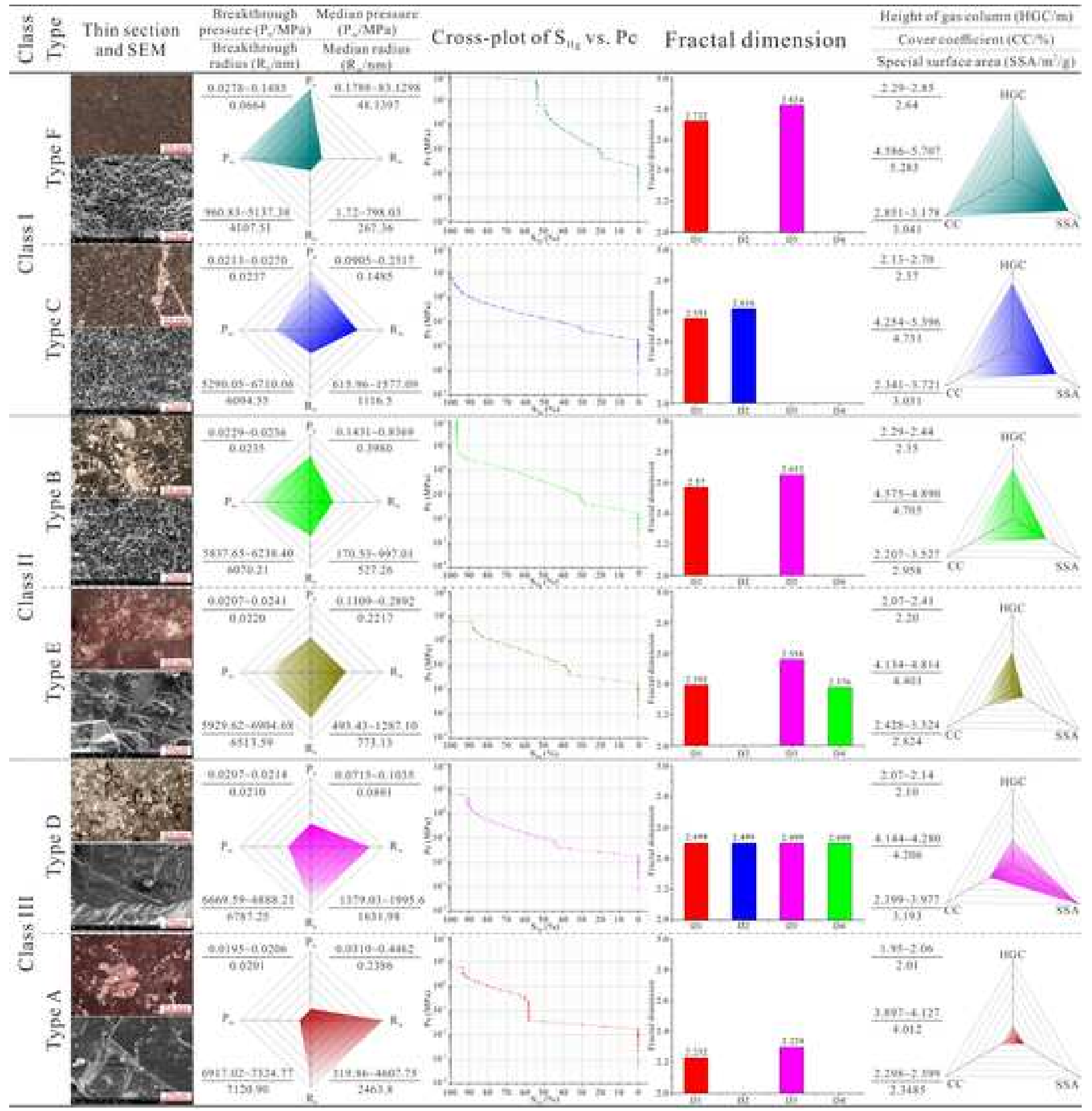


Table 1 Lithology, petrophysical parameters, pore throat structure parameters and sealing capacity obtained from the MICP and $\mathrm{N}_{2} \mathrm{GA}$ of 19 carbonate cap rock samples at four outcrops. $\Phi$ : measured porosity; $K$ : measured permeability; $P_{b}$ : breakthrough pressure; $R_{b}:$ breakthrough radius; $P_{m}$ : median pressure; $R_{m}$ : median radius; $H G C$ : height of gas column; $C C$ : cover coefficient; $S S A$ : specific surface area.

\begin{tabular}{|c|c|c|c|c|c|c|c|c|c|c|c|}
\hline Sample & Outcrop & Lithology & $\varphi(\%)$ & $K\left(\times 10^{-3} \mu \mathrm{m}^{2}\right)$ & $P_{b}(\mathrm{Mpa})$ & $R_{b}(\mathrm{~nm})$ & $P_{m}(\mathrm{Mpa})$ & $R_{m}(\mathrm{~nm})$ & $H G C(\mathrm{~m})$ & $C C(\%)$ & $S S A\left(\mathrm{~m}^{2} / \mathrm{g}\right)$ \\
\hline S-1 & Penglaiba & Mudstone & 0.33 & 0.00521 & 0.0195 & 7324.77 & 0.0310 & 4607.75 & 1.948 & 3.897 & 2.298 \\
\hline S-2 & Penglaiba & Mudstone & 0.6 & 0.0175 & 0.0213 & 6706.47 & 0.2892 & 493.43 & 2.128 & 4.256 & 3.324 \\
\hline S-3 & Penglaiba & Mudstone & 0.53 & 0.0105 & 0.0236 & 6056.62 & 0.2765 & 516.22 & 2.356 & 4.713 & 3.527 \\
\hline S-5 & Dabantage & Peloidal grainstone & 0.25 & 0.00447 & 0.0212 & 6745.74 & 0.0935 & 1526.10 & 2.116 & 4.231 & 2.399 \\
\hline S-6 & Dabantage & Dolomitic limestone & 0.72 & 0.0359 & 0.0229 & 6238.40 & 0.3356 & 425.29 & 2.288 & 4.575 & 2.704 \\
\hline S-7 & Dabantage & Dolomitic limestone & 0.67 & 0.036 & 0.0244 & 5837.65 & 0.8369 & 170.53 & 2.445 & 4.890 & 3.394 \\
\hline S-8 & Dabantage & Peloidal grainstone & 0.29 & 0.0059 & 0.0270 & 5290.05 & 0.2317 & 615.96 & 2.698 & 5.396 & 3.721 \\
\hline S-9 & Dabantage & Peloidal grainstone & 0.76 & 0.0134 & 0.0232 & 6148.15 & 0.1431 & 997.01 & 2.321 & 4.643 & 2.207 \\
\hline S-10 & Dabantage & Dolomitic limestone & 0.40 & 0.00756 & 0.0227 & 6283.53 & 0.1234 & 1156.45 & 2.271 & 4.543 & 2.341 \\
\hline$S-11$ & Yangjikan & Peloidal grainstone & 0.91 & 0.00428 & 0.0278 & 5137.38 & 83.1298 & 1.72 & 2.778 & 5.556 & 3.178 \\
\hline S-12 & Yangjikan & Mudstone & 0.87 & 0.0069 & 0.1485 & 960.83 & 61.1106 & 2.34 & 2.854 & 5.707 & 2.851 \\
\hline S-13 & Yangjikan & Mudstone & 0.52 & 0.0083 & 0.0241 & 5929.62 & 0.2648 & 538.87 & 2.407 & 4.814 & 2.721 \\
\hline S-14 & Yangjikan & Mudstone & 1.27 & 0.00858 & 0.0207 & 6904.68 & 0.1109 & 1287.10 & 2.067 & 4.134 & 2.428 \\
\hline
\end{tabular}




\begin{tabular}{|c|c|c|c|c|c|c|c|c|c|c|c|}
\hline S-20 & Kepingshuinichang & Peloidal grainstone & 0.32 & 0.00947 & 0.0213 & 6710.06 & 0.0905 & 1577.09 & 2.127 & 4.254 & 3.032 \\
\hline S-21 & Kepingshuinichang & Peloidal grainstone & 0.48 & 0.0109 & 0.0206 & 6917.02 & 0.44619 & 319.86 & 2.063 & 4.127 & 2.399 \\
\hline S-22 & Kepingshuinichang & Peloidal grainstone & 0.39 & 0.00783 & 0.0207 & 6888.21 & 0.0877 & 1627.20 & 2.072 & 4.144 & 3.304 \\
\hline$S-23$ & Kepingshuinichang & Peloidal grainstone & 0.33 & 0.00639 & 0.0229 & 6224.31 & 0.1788 & 798.03 & 2.293 & 4.586 & 3.094 \\
\hline S-24 & Kepingshuinichang & Peloidal grainstone & 0.54 & 0.00613 & 0.0214 & 6669.59 & 0.1035 & 1379.03 & 2.140 & 4.280 & 3.977 \\
\hline S-25 & Kepingshuinichang & Mudstone & 0.22 & 0.00571 & 0.0208 & 6845.47 & 0.0715 & 1995.60 & 2.085 & 4.170 & 3.091 \\
\hline
\end{tabular}


Table 2 Characteristics of six pore structures of the Ordovician Yingshan Fm. carbonate cap rock in the Tarim Basin.

\begin{tabular}{|c|c|c|c|c|}
\hline \multirow[t]{2}{*}{ Type } & \multirow{2}{*}{$\begin{array}{l}\text { Morphology of cross-plot of capillary vs. mercury } \\
\text { saturation }\end{array}$} & \multicolumn{2}{|c|}{ Median pressure (MPa) } & \multirow[t]{2}{*}{ Dominant pore throat diameter } \\
\hline & & Variation range & Sequence & \\
\hline Type A & $\begin{array}{l}\text { A relatively horizontal step firstly, then a vertical } \\
\text { step and a gentle slope, and finally a horizontal step }\end{array}$ & $0.031-0.446$ & 1 & $\begin{array}{l}\text { A considerably bimodal shape: a large model }(7,200-12,800 \mathrm{~nm} \text {, } \\
\text { avg. } 8,090.5 \mathrm{~nm}) \text {, and a small model }(250-500 \mathrm{~nm} \text {, avg. } 416.8 \mathrm{~nm})\end{array}$ \\
\hline Type B & $\begin{array}{l}\text { First a relatively gentle trend, followed by a nearly } \\
\text { vertical steep and a gentle slope, and finally a } \\
\text { marked horizontal trend }\end{array}$ & $0.143-0.837$ & 4 & Unimodal shape: $100-8,000 \mathrm{~nm}$ \\
\hline Type C & A gentle step and a nearly vertical step & $0.090-0.232$ & 2 & $\begin{array}{l}\text { Trimodal shape: a large model }(7,200-10,000 \mathrm{~nm} \text {, avg. } 8,089.8 \mathrm{~nm}) \text {, } \\
\text { a medium mode }(3,000-4,000 \mathrm{~nm} \text {, avg. } 3,415.3 \mathrm{~nm}) \text {, and a small } \\
\text { model }(2,000-3,000 \mathrm{~nm} \text {, avg. } 2,087.0 \mathrm{~nm})\end{array}$ \\
\hline Type D & $\begin{array}{l}\text { First a relatively gentle increasing trend, following } \\
\text { by a nearly vertical step and a steeper trend, and } \\
\text { finally a short horizontal trend. }\end{array}$ & $0.072-0.103$ & 3 & $\begin{array}{l}\text { Bimodal shape: large pore diameters }(7,200-12,000 \mathrm{~nm} \text {, avg. } \\
8,088.7 \mathrm{~nm}) \text {, and small pore diameters }(25-50 \mathrm{~nm} \text {, avg. } 48.9 \mathrm{~nm})\end{array}$ \\
\hline Type E & $\begin{array}{l}\text { First a relatively gentle increasing trend, followed } \\
\text { by a steeper slope with different variable angles, } \\
\text { and finally a horizontal trend. }\end{array}$ & $0.111-0.289$ & 5 & $\begin{array}{l}\text { Bimodal shape: large pore throat diameters }(7,200-10,000 \mathrm{~nm} \text {, avg. } \\
8,089.9 \mathrm{~nm}) \text {, and small one }(600-1,000 \mathrm{~nm} \text {, avg. } 993.3 \mathrm{~nm})\end{array}$ \\
\hline Type F & $\begin{array}{l}\text { First shows a steep increasing trend, then a vertical } \\
\text { step, and finally a horizontal trend. }\end{array}$ & $0.179-83.130$ & 6 & $\begin{array}{l}\text { Bimodal shape: large pore throat diameter greater than } 2,500 \mathrm{~nm} \\
\text { and small pore throat diameters lower than } 2-5 \mathrm{~nm} \text {. }\end{array}$ \\
\hline
\end{tabular}


Table 3 Six pore structures from A to F of carbonate cap rocks and their fractal dimensions from the Ordovician Yingshan Fm. at four outcrops in the Tarim Basin. D1 and PSR1: Fractal dimension of first group and their corresponding pore size range in the double-logarithm coordination $\lg \left(1-S_{H g}\right)-\lg P_{c}$. D2 and PSR2, D3 and PSR3, D4 and PSR4 present the fractal dimension and pore size range of second, third and fourth groups. $\mathrm{D}_{\text {total }}$ : total fractal dimension.

\begin{tabular}{|c|c|c|c|c|c|c|c|c|c|c|c|c|c|c|}
\hline Types & Sample & D1 & $\mathrm{R}_{1}^{2}$ & PSR1 (nm) & $\mathrm{D} 2$ & $\mathrm{R}_{2}{ }^{2}$ & PSR2 (nm) & D3 & $\mathrm{R}_{3}{ }^{2}$ & PSR3 (nm) & D4 & $\mathrm{R}_{4}^{2}$ & PSR4 (nm) & $D_{\text {total }}$ \\
\hline \multirow[t]{2}{*}{ Type A } & S-1 & 2.2534 & 0.9922 & $12717-5460$ & - & - & $5460-3040$ & 2.2807 & 0.9817 & $3040-180$ & - & - & $180-50$ & 2.2584 \\
\hline & $\mathrm{S}-21$ & 2.2104 & 0.9986 & $12720-5464$ & - & - & 5464-3007 & 2.3164 & 0.9904 & $3007-271$ & - & - & $271-50$ & 2.2498 \\
\hline \multirow[t]{4}{*}{ Type B } & $\mathrm{S}-3$ & 2.5754 & 0.9932 & $12716-5422$ & - & & $5422-3005$ & 2.5238 & 0.964 & $3005-325$ & - & - & $325-50$ & 2.5427 \\
\hline & S-6 & 2.6023 & 0.9955 & $12718-4322$ & - & & $4322-2770$ & 2.7473 & 0.9985 & $2770-324$ & - & & $324-50$ & 2.6723 \\
\hline & S-7 & 2.629 & 0.996 & $12719-5525$ & - & & $5525-3026$ & 2.7874 & 0.9691 & $3026-325$ & - & & $325-2$ & 2.7091 \\
\hline & S-9 & 2.4743 & 0.997 & $12717-5445$ & - & & $5445-3012$ & 2.5481 & 0.9938 & $3012-325$ & - & & $325-50$ & 2.5158 \\
\hline \multirow[t]{3}{*}{ Type C } & S-8 & 2.7337 & 0.9992 & $12719-5532$ & 2.5885 & 0.9716 & $5532-3028$ & - & & $3028-325$ & - & & $325-81$ & 2.6246 \\
\hline & S-10 & 2.5398 & 0.9958 & $12717-5492$ & 2.692 & 0.9641 & $5492-3027$ & - & & $3027-180$ & - & & $180-50$ & 2.5832 \\
\hline & S-20 & 2.3797 & 0.9954 & $12717-5455$ & 2.566 & 0.9906 & 5455-3009 & - & & $3009-180$ & - & & $180-81$ & 2.4549 \\
\hline \multirow[t]{4}{*}{ Type D } & S-5 & 2.4901 & 0.9869 & $12718-4422$ & 2.4901 & & $4422-3145$ & 2.4901 & & $3145-324$ & 2.4901 & & $324-50$ & 2.4901 \\
\hline & $\mathrm{S}-22$ & 2.4975 & 0.9809 & $12720-5467$ & 2.4975 & & $5467-3007$ & 2.4975 & & $3007-325$ & 2.4975 & & $325-81$ & 2.4975 \\
\hline & S-24 & 2.5196 & 0.9771 & $12714-5244$ & 2.5196 & & $5244-3112$ & 2.5196 & & $3112-325$ & 2.5196 & & $325-50$ & 2.5196 \\
\hline & S-25 & 2.4891 & 0.9901 & $12716-5503$ & 2.4891 & & $5503-3014$ & 2.4891 & & $3014-325$ & 2.4891 & & $325-50$ & 2.4891 \\
\hline \multirow[t]{3}{*}{ Type E } & $\mathrm{S}-2$ & 2.2612 & 0.998 & $12717-5461$ & - & & $5461-3041$ & 2.6439 & 0.9862 & $3041-325$ & 2.749 & 0.9693 & $325-46$ & 2.4379 \\
\hline & S-13 & 2.615 & 0.996 & $12716-5407$ & - & & $5407-3056$ & 2.5714 & 0.9703 & $3056-324$ & 2.3244 & 0.9354 & $324-49$ & 2.5322 \\
\hline & S-14 & 2.2993 & 0.9953 & $12716-5417$ & - & & 5417-3059 & 2.4586 & 0.9818 & $3059-270$ & 2.055 & 0.9897 & $270-50$ & 2.3501 \\
\hline \multirow[t]{3}{*}{ Type F } & S-11 & 2.7512 & 0.9976 & $12713-4766$ & - & & $4766-3025$ & 2.8817 & 0.991 & $3025-270$ & 2.8817 & & $270-3$ & 2.8278 \\
\hline & $\mathrm{S}-12$ & 2.9047 & 0.9961 & $12713-4969$ & - & & 4969-2999 & 2.9233 & 0.9917 & $2999-270$ & 2.9233 & & $270-5$ & 2.9188 \\
\hline & S-23 & 2.5128 & 0.9926 & $12714-4769$ & - & & 4769-2994 & 2.6678 & 0.995 & 2994-325 & 2.6678 & & $325-4$ & 2.6008 \\
\hline
\end{tabular}

